\title{
Bioscience Laboratory: Online and Face-to-Face Laboratory Experiences in Requisite Biosciences for Nursing At a Community College
}

Deborah K. Folger

West Virginia University

Follow this and additional works at: https://researchrepository.wvu.edu/etd

\section{Recommended Citation}

Folger, Deborah K., "Bioscience Laboratory: Online and Face-to-Face Laboratory Experiences in Requisite Biosciences for Nursing At a Community College" (2011). Graduate Theses, Dissertations, and Problem Reports. 4713.

https://researchrepository.wvu.edu/etd/4713

This Dissertation is protected by copyright and/or related rights. It has been brought to you by the The Research Repository @ WVU with permission from the rights-holder(s). You are free to use this Dissertation in any way that is permitted by the copyright and related rights legislation that applies to your use. For other uses you must obtain permission from the rights-holder(s) directly, unless additional rights are indicated by a Creative Commons license in the record and/ or on the work itself. This Dissertation has been accepted for inclusion in WVU Graduate Theses, Dissertations, and Problem Reports collection by an authorized administrator of The Research Repository @ WVU.

For more information, please contact researchrepository@mail.wvu.edu. 
Bioscience Laboratory:

Online and Face-to-Face Laboratory Experiences in

Requisite Biosciences for Nursing

At a Community College

Deborah K Folger

\begin{abstract}
A Dissertation submitted to the College of Human Resources and Education

at West Virginia University in partial fulfillment of the requirements

for the degree of
\end{abstract}

Doctor of Education

in

Curriculum and Instruction

Approved by

Patricia Obenauf, Ed.D., Chair

David Callejo-Perez', Ed.D.

Jeffrey Carver, Ed.D.

Vicki Riley, Ed.D.

Sarah Selmer, Ed D.

Department of Curriculum \& Instruction / Literacy Studies

Morgantown, West Virginia

2011

Keywords: bioscience, face-to-face laboratory, knowledge transfer, nursing education, online laboratory, student perceptions

Copyright 2011 Deborah Folger 


\begin{abstract}
Bioscience Laboratory: Online and face-to-Face laboratory experiences in requisite biosciences for nursing at a community college

\section{Deborah K Folger}

The purpose of this study was to analyze student perceptions of the online and face-to-face bioscience laboratory experiences in Anatomy and Physiology and Microbiology. The study took place at a community college in a rural geographic area and data were collected from associate degree seeking first and second year nursing students via a survey questionnaire and student focus groups in addition to archival enrollment and graduate data. The research study was guided by the following questions: What are nursing student perceptions concerning the impact of Anatomy and Physiology and Microbiology bioscience laboratory experiences on the transfer of knowledge to nursing education? What are nursing student perceptions of the impact of the Anatomy and Physiology and Microbiology laboratory on the transfer of knowledge to future nursing courses? What are nursing student perceptions of the impact of the Anatomy and Physiology and Microbiology laboratory on the transfer of knowledge to future nursing practicum experiences? Archival data was used to determine if there was any correlation between Anatomy and Physiology and/or Microbiology laboratory experiences and nursing student graduation success from the nursing program. Analysis of the data supported the conclusion that nursing students perceive that they transfer knowledge to their nursing education, courses and practice when in face-to-face bioscience laboratory sections. Although the numbers were low, findings suggested these students have a higher graduation rate.
\end{abstract}

Keywords: bioscience, face-to-face laboratory, knowledge transfer, nursing education, online laboratory, student perceptions 


\section{Table of Contents}

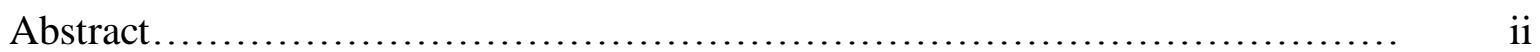

Table of Contents.................................................. iii

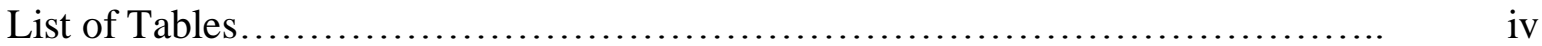

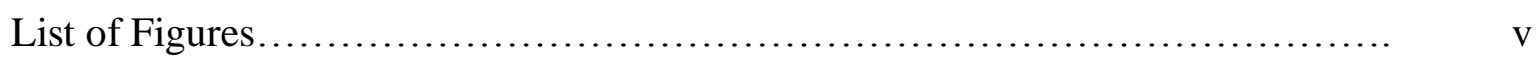

Chapter 1: Introduction................................................ 1

Conceptual Framework................................................................... $\quad 5$

Statement of the Problem.......................................... 8

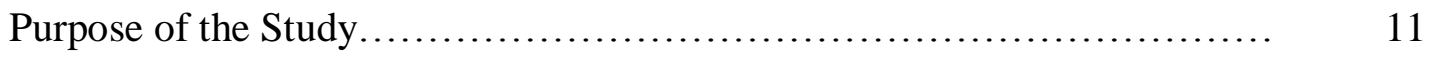

Research questions...................................... 11

Significance of the Study...................................... 12

Limitations of the Study....................................... 14

Perspective of researcher.................................. 16

Operationalization of Terms..................................... 17

Chapter 2: Review of Related Literature............................. 18

Bioscience Education Foundational to Nursing........................ 19

Student Perceptions............................................ 22

Transfer of Knowledge.......................................... $\quad 27$

Nature of Online Bioscience Laboratories........................... 31

History of Online Education................................ 31

Characteristics of Online Science Laboratories.................. 32

Nature of Face-to-face Bioscience Laboratories...................... 34

Demographics.............................................. 37 


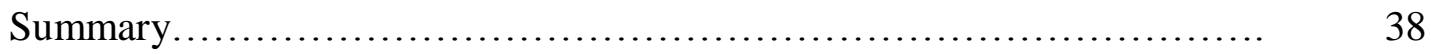

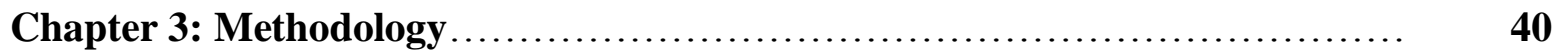

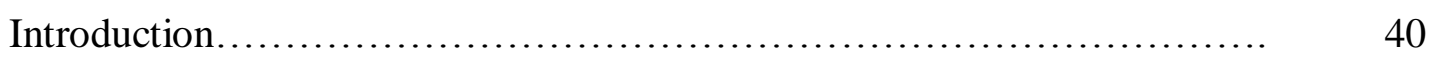

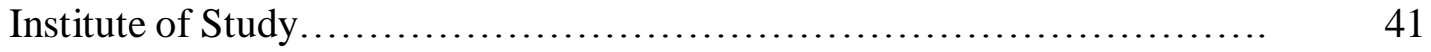

Course Description............................................ $\quad 42$

Participants.................................................. 43

Instruments........................................................... 49

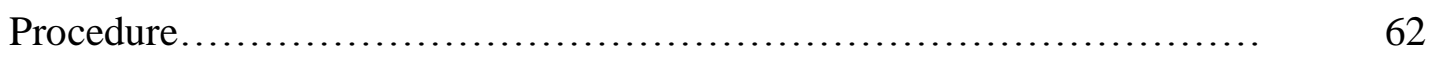

Design of the Study........................................... 65

Chapter 4: Results................................................................ 66

Research Question One.......................................... $\quad 67$

Questionnaire data........................................ 67

Focus group data...................................... 70

The purpose of the bioscience laboratory............ 71

Learning specific to subject.................... 71

Reasons for scheduling, advantages and

disadvantages of each.................... $\quad 72$

Research Question 1a.......................................... 74

Questionnaire data................................................. $\quad 74$

Focus group data...................................... 75

How laboratory prepared students for nursing

courses and program......................

Ways students reminded of bioscience 


\section{Connecting information from bioscience}

to nursing

Research Question 1b.

Questionnaire data.

Focus group data.

Laboratory skills relevant to nursing practice.

Laboratory activity and patient's conditions

and education

Student reminded of bioscience laboratory

Research Question Two.

Questionnaire data.

Focus group data.

Archival Data

Summary.

Introduction

Discussion / conclusions.

Research Question One.

Research Question 1a.

Research Question 1b....

Research Question 1c 
Research Question Two.................................... 104

Implications................................................... 106

Future Research............................................. 111

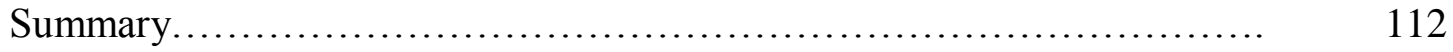

References........................................................ 116

Appendix A - Online Microbiology Syllabus Sample....................... 128

Appendix B - Face-to-face Microbiology Syllabus Sample..................... 130

Appendix C - Online Anatomy and Physiology Syllabus Sample............... 132

Appendix D - Face-to-face Anatomy and Physiology Syllabus Sample............ 133

Appendix E - Survey Questionnaire ........................................................ 134

Appendix F - Corrected Survey Questionnaire with Eliminations.......................... 136

Appendix G - Focus Questions........................................ 137

Appendix H - Permission to Conduct Study.............................. 138

Appendix I - IRB Protocol-exemption................................... 139

Appendix J - Cover Letter...................................................................... 141 


\section{List of Tables}

Table 1 - Survey Participant Age, Gender, and Bioscience Laboratory Experience..... $\quad 45$

Table 2 - Focus Group Participant Age, Gender, and Bioscience Laboratory Experience 48

Table 3 - Keiser-Meyer-Olkin Measure of Sampling Adequacy................ 52

Table 4 - Principal Component When Selecting Eigenvalues $>0.5 \ldots \ldots \ldots \ldots \ldots \ldots . \quad 55$

Table 5 - Pattern Matrix After Factor Rotation............................. 57

Table 6 - Alignment of Measurement Items and Research Questions............... 60

Table 7 - Mean Scores and Standard Deviations from Student Surveys of

Online and Face-to-Face Bioscience Laboratories........................ 68

Table 8 - Focus Questions Relative to Research Question One.................... 73

Table 9 - Focus Questions Relative to Research Question 1a..................... 78

Table 10 - Focus Questions Relative to Research Question 1b.................... 83

Table 11 - Effect Size................................................. 86

Table 12 - Archival Data of Bioscience Laboratory Enrollment and Nursing Graduation 90 


\section{List of Figures}

Figure 1 - Scree plot for principal component analysis....................... 54 


\section{Chapter 1: Introduction}

Educational laboratories in both Anatomy and Physiology and Microbiology Bioscience and the delivery methods of these laboratories may have an impact on the transfer of knowledge (application) and student success in nursing. The concentration of the study was on face-to-face and online and/or computer based laboratory sections of requisite bioscience courses in Anatomy and Physiology and Microbiology at a community college. Participating students were in a nursing program at a two-year community college in a rural area of the Middle Atlantic region. Students shared their perceptions as to whether the bioscience laboratory experiences did or did not have an impact on their transfer of knowledge to their nursing education and practice. Data were collected through the use of a student questionnaire, focus groups, archival bioscience enrollment, and nursing graduation records.

Bioscience content knowledge is foundational to understanding human physiologic processes, disease, and patient care (Gresty \& Cotton, 2003). Nursing students must be able to integrate the basic knowledge of Anatomy \& Physiology and Microbiology into their nursing courses and professional practice. If they do not understand what is physically and emotionally happening with their patient, they will not be able to sufficiently educate or reassure them. In addition, nurses must know the science of the body and the science behind the disease to be able to recognize problems as they assess their patients and to understand the mechanisms of treatment for each patient (Clancy, McVicar \& Bird, 2000).

Nursing educators are concerned that there is a gap between the theory and practice of nursing. This is consistent with the emphasis of the current research concerning the possible gap between the pre-requisite bioscience laboratory and nursing education and practice that may be 
impacted by teaching methodology. Friedel and Treagust (2005) surveyed nursing students and educators and reported that both groups emphasized the need for a strong bioscience background in nursing. Participants expressed the need for more bioscience knowledge that would better prepare them for nursing. Educators were particularly concerned with the students' lack of bioscience understanding and the ability to apply their bioscience knowledge to nursing. They noted that nursing students often lack the confidence necessary to explain and teach their patients about their medical condition, treatment and care.

The importance of Anatomy and Physiology and Microbiology biosciences to nursing is evident and the existence of the gap between theory and practice has been established. Education must respond to the issue. All communities need nurses and the community college is an increasingly important educational avenue for potential students, particularly considering the ongoing economic challenges. Similar to other two year colleges, the study institution must compete for new students and increase enrollment to grow and prosper. Budget constraints impact curricular decisions when the results cut costs and increase revenue. Increasing online offerings is one viable answer to benefit stakeholders involved. However, an across the board increase in online courses may be a concern specifically for the biosciences as they pertain to the nursing program. Research is important to assess the impact an all online bioscience laboratory course may have on the nursing student in addition to the benefit of increasing student numbers and college growth, particularly since nursing practice depends on personal interaction, human contact, and physical manipulative skills which may be a challenge with a fully online format (Jairath \& Mills, 2006).

Likewise, the fully face-to-face bioscience laboratory teaching methodology may negatively impact the nursing student. Face-to-face laboratories can be restrictive in learning 
opportunities as the dissection tissues are unresponsive compared to the electronic medium (McLachlan, Blich, Bradley \& Searly, 2004) or do not allow for the extension and enhancement in design afforded by the online methodology (Bhargava, Antonakakis, Cunningham \& Zehnder, 2005; Hamza-Lup \& Stanescu, 2010). The dynamics of student interaction in the learning environment of the face-to-face classroom may also exclude the more reticent student (Harrington \& Loffredo, 2010).

Advancements in technology have provided education with the tools to reach untold numbers of students beyond the boundaries of the physical classroom. Most institutions offer online courses and many online programs (Hopper \& Hendricks, 2008). More and more students are taking courses online than ever before. The Sloan Consortium (Allen \& Seaman, 2008) reported a $12 \%$ growth in the number of students taking at least one course online from 2006 to 2007 with almost $20 \%$ of all college students taking at least one online course (Allen \& Seaman, 2007). There is a continued push to increase numbers to increase the profit margin, especially considering today's economic uncertainty. The more recent pressures for increased online courses begin at the top with President Barack Obama's American Graduation Initiative which he introduced when he spoke at a community college in Michigan in July of 2009 (Oosting, 2009). His goal for our country is to have the "highest proportion of college graduates in the world" by 2020 (Oosting, 2009, para. 14). As the President outlined his plan for community colleges, he specifically emphasized the math and science disciplines in our efforts to be competitive. The third point of the initiative calls for a new virtual infrastructure, a new online, and "a clearinghouse of courses so that community colleges across the country can offer more classes without building more classrooms" (Oosting, 2009, para. 24). 
Administrative decisions are being made to utilize a standardized online teaching format for all disciplines (Stuckey-Mickell \& Stuckey-Danner, 2007). Instructors are assigned or strongly encouraged to teach online even though not all faculty members have the same abilities or interests. Unique efforts are required for online teaching and the development of a meaningful educational experience for the students (Kearsley, 2008). The issue presented here is that instructors and institutions alike are being urged to increase the number of online courses, and many times this may result in less than optimum educational practice. At the very least it is open to variation in standards. Educators are aware that course design varies with instructors and institutions for both online and face-to-face courses. Education must progress with the times and take advantage of all that today's technology presents.

There is a push national to local levels to increase technology and online learning opportunities. The nursing shortage and economic concerns in society increase the significance of community college education since most nurses are products of the more cost efficient community college system. Biosciences are foundational to nursing programs. Financial constraints and budgeting demands can impact educational administrative decisions relative to programming and curricula. The emerging reality is that decisions are being made to offer more courses and programs online to save money, generate funds, and reach more students. Before a full efficiency model is implemented, research is indicated to investigate the consequences of such decisions on student education and ultimately the nursing profession.

At the study institution, the number of online Anatomy and Physiology and Microbiology bioscience laboratory course sections offered increased to the current level of the past five years, and more health care students are increasing the number of these courses they choose to schedule. Although the online enrollment numbers are increasing, a large majority of the 
population continues to register for face-to-face sections of the bioscience laboratory. The faceto-face environment can limit the students' laboratory experience (Bhargava et al., 2005; HamzaLup \& Stanescu, 2010). There are also certain advantages to the physical sensual bioscience laboratory investigations as students learn and transfer their knowledge (Granger \& Calleson, 2007; Hsu \& Roth, 2008). The online laboratory delivery has its own concerns such as the question of replicating face-to-face experiences and evaluation ("Science \& Engineering Indicators," 2004), along with the educational benefits of online delivery and the added personal benefits of time, flexibility, reduced travel, and convenience (Angulo \& Bruce, 1999; Bell, 1999; Bhargava et al., 2005). With clear benefits and challenges of both teaching methodologies, investigation into the impact of laboratory delivery specific to the nursing student should continue as there are questions surrounding both delivery formats and the consequences the delivery may have on the students preparing for their future within the health care program.

\section{Conceptual Framework}

Theoretical foundations guided the current study from the point of inception through planning, design and implementation, to the culmination of the process. Areas of concentration and the relevance to the this work include the nuances of teaching with respect to specific content (biosciences for nursing) reflecting the inference of the research of Ball, Thames and Phelps (2008) and the methodology of teaching and the learning environment (the online and face-to-face) emphasized by Dewey (1900) and Schwab (1969a). A discussion of student consciousness during learning experiences (Greene, 2001) is pertinent to the research with respect to the online and face-to-face formats and the transfer of knowledge. The theories of Eisner (1979), Freire (1993), and Giroux (1988) are germane to this work as they are consistent 
with the importance of student involvement in his or her own education reflecting the qualitative nature of the study and the significance of curricular choices by educators and students alike.

Ball, Thames and Phelps (2008) emphasize the importance of knowing that transcends the content to processing within the content. Although the participants of their study were education students, the teaching and learning strategies they defend were the underpinning for this study of bioscience laboratory course methodology. The pedagogy of teaching content specific to a discipline is crucial to student learning and application of the content. Thinking and reasoning are key tools to the student's application of science basics to nursing performance and patient care. The methodology of how students think and reason as they learn may impact how they think and reason as they apply the knowledge in their program studies and profession. The content, processing, and teaching of the biosciences are different (Ball et al., 2008) than the nursing courses, yet the students must be able to transfer and apply knowledge from the sciences to nursing.

Building on the work of John Dewey (1900), I posit that the benefit of a student's education is determined by the student. Students must be involved in their own understanding of the knowledge; therefore, their perceptions of knowledge and the processes involved are pertinent to this study. Dewey was particularly concerned with the students' ability to function in society for the betterment of society. This research specifically addressed the impact of laboratory delivery methods on the students' ability to function in the nursing program and ultimately their profession, which is certainly for the good of society although, not always considered politically significant as Dewey's concerns were. Dewey (1897) stated that methodology of instruction itself should be determined by the student; therefore, students' perceptions of the relevance of course delivery methods were vital to my study. 
Maxine Greene (2001) writes about consciousness, feeling and understanding beyond the obvious as students engage in knowledge seeking experiences. The development of this consciousness may be compared to the development of feelings of empathy and a sense of urgency and seriousness that translates to the nursing students' work when they look into the faces of their patients during student-patient interactions. Parker Palmer (1993) implores the reader to immerse themselves in the knowing and understanding. He calls us to internalize, analyze, interpret, reflect, and connect. The students' consciousness and involvement in learning directly correlate to the premise of this study that elicited their perceptions of their knowledge acquisition and transfer to other courses and programs.

Joseph Schwab's (1969a) four commonplaces for teaching and learning involve the teacher, learner, subject matter, and the interaction of these within the educational environment or milieu. The subject matter of the current study was specific to Anatomy and Physiology and Microbiology, and the environment and setting analyzed was the online and face-to-face laboratory. Whether courses are taught online or face-to-face the students need to be conscious of their experience in the learning process and that process encompasses Schwab's four commonplaces. All of these aspects were considered in the study as the students shared their perceptions of their learning experiences in the face-to-face or an online computer based learning environment.

The inclusion of student perceptions in research is consistent with the philosophies of both Eliot Eisner (1979) and Paulo Freire (1993). Eisner's work on the significance of communication, artistic expression, and connoisseurship in curriculum evaluation and Freire's emphasis on the value of the students' own involvement in the process of the evaluation of their own learning is reflected in the precepts of this study. Students' perceptions were utilized to 
gauge the extent to which they gained knowledge and personally connected with that knowledge, as well as connected that knowledge to the nursing discipline and practice. The study investigated whether the students thought the laboratory itself or the method of laboratory delivery had any impact on that transition.

Henry Giroux (1988) calls for us to be reflective and thoughtful, to know the theory behind our actions rather than jump through the hoops as directed by others. This was foundational to the study as students were asked to consider the consequences of their educational choices. Additionally, educators should respond to the dynamics of technology and the possible impact on science and nursing education. I attempted to consider and analyze the impact of technological changes in education and laboratory delivery specific to the bioscience laboratory as they pertain to the nursing students and their progression through the nursing program.

\section{Statement of the Problem}

Continuing advancements in technology necessitate responses by the educational system specific to nursing education and practice. Making changes without considering the consequences and the impact on the nursing students in regard to curricular choices and success in the program can create problems. The National Center for Educational Statistics (Parsad \& Lewis, 2008) reported that two thirds of institutions in higher education offer online courses. The 1999 report stated that $33 \%$ of the institutions offered biological sciences online. However, according to the National Science Board's report, Science and Engineering Indicators (2004) fewer than $10 \%$ of students in science and engineering took their science courses online, preferring the face-to-face laboratory experience. There is a need and demand for education and science to progress in educational technology and provide for the student, but there is clearly a 
reticence in providing the sciences online and for science students in taking sciences online. This may have a particular impact on nursing students as their profession is based on biological sciences.

More than $80 \%$ of two-year community colleges offer online courses (Allen \& Seaman, 2010) and provide us with $65 \%$ of our registered nurses (Lords, 1999). Therefore, it is important to investigate the nursing students' perception of the impact of their laboratory bioscience course on their education. Lords (1999) reported that of the 2.5 million registered nurses in the United States in 1999, 65\% were Associate Degree Nurses and 35\% were Baccalaureate of Science Degree Nurses. Results of the 1998 National Council Licensure Examination for Registered Nurses showed similar pass rates with an $85 \%$ Associate Degree Nursing pass rate to an $84 \%$ Baccalaureate of Science Degree Nursing pass rate. Considering the demand for nurses and the existing nursing shortage, the community college nursing program in more important than ever.

The associate degree nursing programs of the community colleges are significant in the education of quality nurses for the profession. Many of these two-year programs include both online computer based and face-to-face basic sciences as crucial components of the curricula. The requisite Anatomy \& Physiology and Microbiology courses foundational to the program should build a solid content base for the students' transition into the health care program (Friedel \& Treagust, 2005). Students may have a more difficult time in transition without the feel, smell, sound, direct visual observation, and general sensation of physical laboratory experiences (McLachlan et al., 2004). However, other students may benefit from the autonomy and nature of the online structure and design as they transition from the basic sciences to the nursing courses (Haavind, Rose, Galvis \& Tinker, 2002; Hamzu-Lup \& Stanescu, 2010) and may be more likely to enter a program with the freedom and flexibility of online courses rather than the rigid 
structure of the face-to-face course (Doherty, 2006). As education attempts to meet the needs of our current nursing shortage, these are issues that potentially impact the nursing students' choices and completion of the nursing program.

Students seeking a two-year nursing degree do not have choices concerning the content of courses required for their specific program (Queensborough Community College, 2010; Riverside Community College, 2009; Saint Louis Community College, 2010), but they do have choices about how they get that content. Many educational institutions such as Sacramento State (n.d) and The University of Alabama (n.d.) offer a nursing degree through online programs with stipulations for face-to-face science laboratories as well as clinical practice. These two institutions are representative of others in that they offer most courses via the online format but require face-to-face core science laboratories before completing the majority of required courses for the nursing program online. Anatomy and Physiology and Microbiology as well as Chemistry are typically listed as the core face-to-face science laboratory courses required. Ultimately, students are making initial scheduling decisions about laboratory course methodology that may have an impact on meeting their educational and professional goals. Through the current study, I attempted to provide evidence of the impact of the bioscience laboratory on student success in nursing.

Student scheduling choices are made for many reasons, with convenience heading the list for an online preference (Doherty, 2006; Harrington \& Loffredo, 2010). The evidence from both investigations supports that emotional interaction and class structure are factors that students cite for preferring face-to-face courses. The current study attempted to address how students perceived their initial scheduling choices had an impact on them in subsequent courses and programs where they had to apply the knowledge of their previous Anatomy and Physiology and 
Microbiology bioscience laboratory courses. I not only asked how the students' decisions affected their learning and performance in their nursing program, but provided data that could be utilized to analyze their perceptions in order to determine how educators may gain knowledge that would guide instruction and curriculum planning and lead to better counseling for future students as they pursue careers in the health profession.

Research exists that speaks to the benefits and success of both online (Hamza-Lup \& Stanescu, 2010; Mickle \& Aune, 2008) and face-to-face courses (Granger \& Calleson, 2007; Hsu \& Roth, 2008), method comparisons between disciplines (Smith, Heindel \& Torres, 2008), studies of the transfer of knowledge (Granger \& Calleson, 2007, Sadler \& Fowler, 2006), and the value of student perceptions to learning (Kariya, 2003; O’Neil \& Fisher, 2008). This study touched on each of these and attempted to investigate the nursing students' perceived impact of these combined elements on student learning and the transfer of knowledge from bioscience laboratory courses to the nursing program courses and practice.

\section{Purpose of the Study}

The purpose and research questions were developed through my personal lens based on the conceptual perspective and encompass the issue discussed. The purpose of this study was to analyze nursing student perceptions of teaching methodology of the requisite bioscience laboratory to determine if methodology had an impact on the students' nursing education and practice. Student choices are not just a matter of completing the one course but may have an impact on progressing through and succeeding in the nursing courses, practice, and program. The effects of scheduling decisions pertaining to laboratory delivery may not be evident until semesters later when the student is already in the nursing program. 
This study investigated and attempted to present evidence of nursing students' perceptions related to the role of the bioscience laboratory in Anatomy and Physiology and Microbiology on their transfer of knowledge and their transition to nursing curricula and practice with specific emphasis on the impact of the bioscience laboratory teaching format. I attempted to determine if nursing students perceive the bioscience laboratory delivery format as an area of concern for two year nursing degree seeking students as they transition from foundational bioscience courses into their nursing program.

Research questions. Questions support the purpose of the study and guide the research throughout the process (Gay, Mills, \& Airasian, chap. 2, 2009). This study was guided by two major and several subsidiary research questions.

Research question one: What are nursing student perceptions concerning the impact of Anatomy \& Physiology and Microbiology bioscience laboratory experiences on the transfer of knowledge to nursing education?

Research question 1a: What are nursing student perceptions of the impact of Anatomy \& Physiology and Microbiology laboratory experiences on the transfer of knowledge to future nursing courses?

Research question $1 \mathrm{~b}$ : What are nursing student perceptions of the impact of the Anatomy \& Physiology and Microbiology laboratory on the transfer of knowledge to future nursing practicum experiences?

Research question 1c: Does face-to-face versus online laboratory delivery format have an impact on nursing student perceptions of the transfer of knowledge to a) nursing courses or b) nursing practicum experiences? 
Research question two: How do demographic factors, such as age, gender, and educational and technological experience impact nursing student perceptions of the online and face-to-face bioscience laboratory and the transfer of knowledge and transition to and success in nursing?

\section{Significance of the Study}

Regardless of the findings, asking questions and conducting the study enabled me to collect data and information that could guide laboratory studies in the biosciences for nursing education. The results from this investigation could provide administration and curriculum development professionals in higher education with more data to consider in their decision making beyond accessibility, convenience, and profit. The research also emphasized the importance of appropriate methodology for learning and preparation within the biological sciences and requisite laboratory science courses to the nursing program at the community college.

Investigative data may provide evidence to support the current increase in online offerings and the continued use of the face-to-face laboratory for the requisite bioscience laboratory for the nursing program at the community college level. The current trends to increase online offerings are altering the face of laboratory science education and the conclusions drawn from this study may affect the path of those trends, whether to meet the marketing demands of the institution to increase student numbers through online science education or to regulate the requisite bioscience courses offered online and face-to-face for the nursing program. This may also lead to more deliberate regulation of student scheduling and course selection which would ensure that each graduate complete a minimum face-to-face and online laboratory experience and demonstrate bioscience competencies via both formats. Conclusions may also suggest the need 
to increase the online and computer based laboratory offerings in the biosciences in addition to maintaining a face-to-face laboratory component. Equally important are the insights the study brings to the curricular impact on the student transitioning from the biosciences to the health programs. Most nursing requisite science courses are currently taught through the science department rather than nursing personnel. This study may or may not suggest new perspectives in teaching specific to nursing concerns and application for the requisite biosciences for the nursing students.

Decisions of scope and sequence must reflect an understanding of the variability of course delivery and the impact the delivery format may have on providing the experiences necessary to offer a sound and functional biological curriculum (Tyler, 1949). The impact of student scheduling choices is magnified at the community college level when course choices are already narrowed and each one is significant to the program. Curricula from community colleges across the country, such as California (Riverside Community College, 2009), New York (Queensborough Community College, 2010) and Missouri (Saint Louis Community College, 2010) are representative of Associate in Applied Science programs in nursing, all having strict requirements leaving little flexibility in student scheduling choices. Each institution offers one or two choices of courses meeting general education requirements with no delineation in scheduling. Representative college catalogs list required courses by semester with no electives to complete the 60 to 66 credit requirements for graduation. In addition, the face-to-face bioscience laboratory is required for the programs. The impact of their decisions about format choice may also be significant as students seek to continue their education with a lack of a physical laboratory or online computer experience, and they may find that transitions are difficult. The long-term implications to Science, Technology, Engineering and Math curricula should be 
considered as students in these areas must also be proficient in both online and face-to-face learning environments.

\section{Limitations of the Study}

Limitations of the study can be divided into three parts: 1) subject related, 2) participant related and 3) researcher related. Each area of discussion considers aspects of the study that were outside of my control, therefore, appropriate for inclusion within this context (Gay et al., chapt. $4,2009)$. The subject related limitation is that regardless of the findings in the literature the students may not have perceived that the bioscience laboratory, whether online or face-to-face, was significant to their educational success in nursing. Any perceived relevance may not have been related to the delivery method. Participants entered the bioscience Anatomy and Physiology and Microbiology courses with a wide variety of experiences. Some had considerable biologic foundations including physical hands on laboratory studies while others had never been in a laboratory or were not proficient (University of Maryland, 2006). Some students had used computers since they were in early elementary years, but others did not know how to turn on the computer. Non-traditional students make up a larger percentage of the community college population (U.S. Department of Education, 2002). The findings of the current study may not be widely generalizable except to other community colleges considering the expected range of demographic data and the nature of the depressed rural site of the study.

Because many participants in the study were currently enrolled in courses taught by me or had previously completed courses taught by me, questionnaire and focus group responses could be skewed. Students self selected into face-to-face and online bioscience laboratory sections as they scheduled for classes; therefore, random grouping was not possible. Students could have chosen to take their bioscience as pre-requisite or co-requisite to their nursing 
courses. This might not have had an impact on their responses to survey or focus questioning but could have had an effect on the direct comparison of responses with archival data. The use of data is discussed in chapter three. Without specific student tracking and immigration and emigration of pre-nursing students in the biosciences, archival data should be interpreted loosely as the totals could include students who did not take their bioscience at the research location and those who did not continue in the program. In addition, there was no triangulation of demographic data without that information reported with archival data.

Paper and pencil questionnaires were completed by students during face-to-face meetings which could have skewed data as students evaluate face-to-face and online instructional methodologies differently (Arbaugh, Bangert \& Cleveland-Innes, 2010). Focus groups also met face-to-face. To reach groups in their chosen format, the creation of an online discussion or chat tool may have better served the online student. It should be noted that sessions were scheduled when all nursing students, regardless of whether their bioscience laboratory was online or faceto-face, were on campus for other classes. Students have varied comfort levels with technology and this could have also clouded their perceptions (Young \& Norgard, 2006). Because of student self selection, the online students were significantly outnumbered in the focus groups which may have discouraged their responses. Due to the small and disproportionate sample size the ability to make generalizations from the study is reduced.

Perspective of the researcher. The researcher related limitations are due to my current position and course assignments and based on personal experiences teaching both face-to-face and online sections of bioscience laboratories. Personal biases were considered in the research of literature and previous studies so as not to skew the narrative and report of the findings with a slant toward personal thoughts, experiences, and beliefs. We generally teach as we were taught 
(Eisner, 1979; Rudolph, 2002). My belief in the importance of student involvement in a physical laboratory is predicated on foundational face-to-face science laboratory educational experiences. I do not however, attempt to negate the positive aspects of the use of fully online and computer technology or face-to-face laboratory experiences in education (Bhargava et al., 2005; Hamza-Lup \& Stanescu, 2010; Hsu \& Roth, 2008; Stuckey-Mickell \& Stuckey-Danner, 2007). From personal experience alone, I can attest to the benefits and possibilities of online and computer technology in the bioscience laboratory that are far superior to purely cook book type experiences that allow for little or no student inquiry and discovery, or other poorly planned face-to-face laboratory experiences (Eisner, 1979). However, it is my belief that the bioscience laboratory should primarily include well designed, hands on, face-to-face experiences. Increased online offerings were emphasized by the administration of the research institution and may have played a role in my perspective. At the study institution, which is similar to many others, nursing student scheduling of bioscience laboratory courses was personal, individual, and may have been made with or without thought as to the educational impact on future nursing courses and nursing practice within the program. How confident were students with their scheduling decisions concerning the bioscience laboratory once they were in their nursing program? Would they still make the same choices? Nursing students eventually work with living patients and human tissue and have experiences that may not be pretty or easy to handle. Working with dissection, models, real bones, and the mundane measuring are beneficial experiences that will help prepare students for the everyday events, smells, and practice with which they will be bombarded on the job (Hsu \& Roth, 2008). As I consider what is best for the students as they prepare for professions in health care, it is my opinion that the face-to-face laboratory offers them a more solid preparation 
for the sensual nature of their work (Hamzu-Lup \& Stanescu, 2010) than would fully online laboratory studies and therefore should be a required component for their curricular program.

\section{Operationalization of Terms}

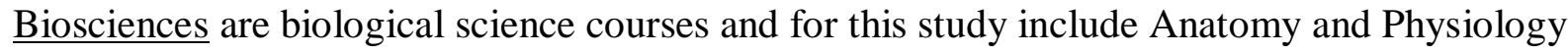
and Microbiology. The use of the term bioscience throughout the writing refers to the Anatomy and Physiology and Microbiology courses.

Face-to-face course means the educator and student or students are interacting in the same physical classroom setting. Students are physically participating in investigations and performing physical skills and practice.

Online laboratory experiences refer to course work completed where educator and student are not present and interacting in the same physical room and/or fully computer based lab experiences and/or refer to labs where students access interactive information, simulations and online sites to gain lab knowledge.

Kitchen laboratories require the student to complete laboratory activities in their own home utilizing typical supplies and equipment found in their own kitchen.

Simulated laboratories are electronic scenarios where students enter information and get predetermined results; this generally takes the form of click and drag on the computer and/or adjusting conditions of an event and the computer program determines the outcome.

$\underline{\text { Streaming data is real time information and data received by the student who generally has }}$ remote access to laboratory equipment.

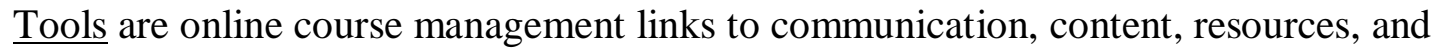
assessment. 
Virtual laboratories are interactive computer system environments for conducting simulated experiments.

\section{Chapter 2: Literature Review}

The review literature addresses the relevance of biosciences to health care education, the educational aspects of how students transfer knowledge from one course to another, student perceptions of online and face-to-face course delivery, the general characteristics of online and face-to-face instruction, and, more specifically, bioscience laboratory instruction and demographic factors that may be relative to bioscience laboratory course delivery. The topics relate to the research focus areas and questions. Literature specific to research question one, What are nursing student perceptions concerning the impact of Anatomy and Physiology and Microbiology bioscience laboratory experiences on the transfer of knowledge to nursing education?, is organized around five themes that elaborate on bioscience education foundational to nursing, student perceptions concerning laboratory and course delivery, the transfer of knowledge in education and nursing education and practice, the nature of face-to-face laboratories, and the nature of online laboratories. A sixth section examining demographics correlates with research question two: How do demographic factors, such as age, gender, and educational and technological experience impact nursing student perceptions of the online and face-to-face bioscience laboratory and the transfer of knowledge and transition to and success in nursing? The seventh and final section summarizes the review of literature.

\section{Bioscience Education Foundational to Nursing}

John Rudolph (2002) emphasized that science education should reflect real science research. To remove either the physical laboratory experience or technology from science education may have an impact on not only how students learn, but how they practice what they 
learn. This notion is relevant to nursing education in that it also should reflect the nursing profession and therefore, pre-nursing courses should parallel subsequent nursing courses. Studies corroborate the importance of sound bioscience teaching to nursing education (Clancy et al., 2000; Davis, 2010; Friedel \& Treagust, 2005). Clancy et al., (2000) asked students and staff nurses their perceptions of the importance of biological science knowledge as it pertained to specific patient cases. Questions addressed content knowledge as well as probed the student's and staff's comfort level in talking with and teaching patients about their medical condition and care. Both students and staff noted the vital importance of a strong biological science foundation for nursing practice with neither group feeling confident with their knowledge base in bioscience. Physiology was one area of concern particularly relating to making rationales for intervention, drug actions, and needing to better understand the clinical condition of the patient. Nurse educators and nursing students completed the Bioscience in Nursing questionnaire and participated in focus groups in Friedel and Treagust's (2005) study of bioscience nursing education. The results support the necessity of bioscience foundation for nursing education with both groups reporting their background was not enough. Both groups also expressed difficulty talking about and explaining bioscience concepts, and students said they needed more knowledge to understand what was happening with their patients.

Similarly, Davis (2010) reports that $40 \%$ of nurses participating in her investigation felt they needed more bioscience in preparing them for nursing practice and $57 \%$ stated their bioscience education was limited. Survey results showed $77 \%$ of participants indicated that Anatomy and Physiology and Microbiology were relevant to the nursing program. Although Davis' sample population was small, surveying 42 registered nurses engaged in further professional studies, her findings were corroborated by the literature identifying a trend toward a 
gap between bioscience knowledge and nursing practice. Participants generally indicated that their biosciences did not link to their nursing practice with stronger negative responses from the younger, more recent nursing graduates.

The importance of a holistic approach to nursing education is the topic of the article by Wynne, Brand, and Smith (1997). Their comments are in line with the above studies concerning the nursing students' lack of bioscience knowledge and their lack of ability to apply that knowledge to their nursing practice. Wynne et al. (1997) acknowledge the gap between theory and practice. They are concerned that physiology is not tied closely to clinical situations and conditions of the patient. They call for the collaboration between content specialists and nursing faculty to integrate nursing and biological sciences.

Elkan and Robinson (1993) provided survey data leading them to more specific conclusions about the nature of and emphasis in teaching by nurse educators. Nurse educators were surveyed about their perceptions of the importance of each area and their priorities in teaching. They found that some nurse educators teach more to the psychology and interpersonal skills and hold those skills at a higher degree of importance over the manual, physical skills related to the bioscience laboratory.

While the above studies address the importance of bioscience in nursing education with some relevance to nursing practice, the literature thus far does not specifically consider delivery methods of the bioscience laboratory in nursing education. There are numerous investigations of delivery methods of nursing education pertaining to post practice degrees; however, the curriculum beyond the initial $\mathrm{RN}$ degree does not typically include bioscience courses and therefore, is not included in this review of literature. There is also documented research 
pertaining to delivery methods of biosciences, but few specific to the delivery methods of the biosciences or bioscience laboratories in nursing education.

Gresty and Cotton's (2003) action research evaluated online resources for supporting biosciences in a nursing curriculum. The biologic course in the study was a supplemental course to the program, embedded in the nursing curriculum and not taught by specialists in a science department. Students said the resource helped them master course components and solidify content material. Researchers concluded the online format met their needs and the needs of their students with few concerns. Those that were expressed were related to computer experience and access as well as the availability of existing online curriculum packages. The need for such a course taught by nurses within the nursing program was the same as cited by the previous studies concluding that nursing students do not have enough bioscience background and are not able to apply their knowledge to nursing practice.

Jairath and Mills (2006) write about the different teaching approaches and models for different content in their book, Online health science education: Development \& implementation. They address the benefits of online communication, variability and meeting diverse student learning styles as well as infrastructure and cost analysis. The authors also address specific issues of health science, such as clinical skill building and the need for continued development of tools and online sites to aid the students' learning experiences as the current technological packages and use are not sufficient. Although they share some sites, they note a lack of an online environment to aid the development of motor skills necessary for clinical practice. The authors even say virtual environments, holographic and robotic laboratories need future developments and that most of those currently developed are not available or too costly.

\section{Student Perceptions}


Investigating the impact the delivery format of the bioscience laboratory may have on knowledge transfer for nursing students is one avenue of study relevant to finding answers of how to bridge the gap that exists between theory and practice in nursing education. Students' perceptions concerning the online and face-to-face course delivery as well as their perceptions of these instructional methodologies specific to the science laboratory are foundational to the current research.

Online designs may foster student negotiation, interaction and overall communication (Haavind et al., 2002). The online environment encourages students to make their own meaning from group conversations. Although online discussions involve all students and may be realtime, they allow the students time to process and edit their comments and responses. Reflection and processing time strengthens and expands learning. Student success can be attributed to the degree of interaction they have with their peers and with the instructor (Hirumi \& Bermudez, 1996; Roblyer \& Ekhaml, 2000). Following a student's thought process through discovery is paramount to the fundamentals of inquiry methodology (National Research Council, 2004), thus the benefit of additional time for processing afforded by the online format is an advantage for the student.

Bhargava et al. (2005) revealed benefits of the online laboratory format. They concluded from their study of a virtual torsion laboratory that the online format aided students' understanding and provided them with an open approach to experimentation. Two hundred sophomore students in an engineering course at Cornell completed an online laboratory addressing torsion. Of the 200 participants, 193 surveys were completed. Students also submitted a ten page laboratory report similar to that submitted by students in the face-to-face physical laboratory. Students stated the traditional laboratory was more interesting and fun but the 
computer based online laboratory gave them the freedom to alter the experimental design as they investigated particular concepts. These procedural changes allowed learners the freedom to follow the process where it took them.

Bell (1999) stated that the study of science is enhanced via simulated (online) laboratories through the inquiry approach, the application of scientific processes and student formulation of experimental designs. Student responses to the developed Biology Labs On-line project were positive and demonstrate the project's correlation to the National Research Council's (2004) standards for teaching science. Students said the online laboratory experiences were valuable, enjoyable, and helped them solve problems in a systematic way and understand the material better. Bell concluded that the online laboratory simulations were another tool to facilitate the inquiry approach to teaching science, but added that they should not replace the hands-on laboratory, that the science curriculum should be balanced.

Student perceptions noted by Angulo and Bruce (1999) reflect the benefits of web-based (online) instruction, but most students said they would not want to go without some regular class meetings. This is also reflected in Stuckey-Mickell and Stuckey-Danner's (2007) investigation of virtual laboratories in an online Biology course where most students felt that the face-to-face laboratory was more effective. The researchers go on to conclude that the online experience is a good supplement in course instruction, but a fully online course would be more appropriate for a non-major Biology student. The study was in response to a department decision for the online offering.

In addition to considering disciplinary differences in making decisions about laboratory delivery, student differences concerning teaching methods should also be investigated. Each one of us has our own unique strengths and preferred modes of teaching and learning (Gardner, 
2006). All students are not the same in their intellectual abilities, their approach to learning, their attitude toward education, or their familiarity with technology (Bhargave et al, 2005). It takes a certain type of learner to excel in online studies say Kariya (2003) and O’Neil and Fisher (2008). Based on interviews with students in undergraduate courses and those in graduate programs, Kariya (2003) concluded that the online student must possess a good work ethic including responsibility, self motivation, time management, and perseverance. O’Neil and Fisher (2008) compared student success and perceptions in the same course taught both online and face-to-face and also concluded that the successful online student must be self motivated and involved in the process of personal learning. In addition they say the successful online student must be computer savvy.

Johnson (2002) conducted a comparative study of 116 students enrolled in online and campus based Biology at Mesa Community College. Pretests and posttests determined that there was no significant difference in content student achievement; however, results showed that online learners had higher reasoning pretest skills. Online students also had significant differences in positive attitudes toward working with computers and negative attitudes toward working in groups. This is consistent with Kariya's (2003) contention that there is a difference in the type of learner who is successful in online courses. Participants were not randomly selected as format choices were made by the individual student. Johnson (2002) concluded that students lacking time management skills, discipline, reasoning, or have a weak background in biology may not be served well by the online format where virtual experiences and visuals replaced physical laboratories. "If a student elects later on to become a biology major, then the microscope is a tool with which they must become skilled" (Johnson, 2002, p. 313). Johnson 
(2002) went on to say that if needed, students would have opportunities to learn this skill in subsequent courses.

Research shows that motivation is better at predicting student success than intelligence (Cote' \& Levine, 2000). Sixty first year Canadian University students completed two batteries of test measures, one initial, and one two years later. Numerous intelligence and attitude measures were administered and correlations revealed that motivation is more closely related to good student roles than intelligence. Student perceptions and attitudes toward online and Internet course work will affect their success (Roblyer \& Ekhaml, 2000; Rodriguez, Ortiz \& Dvorsky 2006).

Individuals have different perceptions toward animate and inanimate objects and tools, says Gardner (2006). If students interact differently with inanimate objects than animate objects then their learning will be impacted by the course delivery format. Seeing, hearing, touching, and moving is fundamental to aesthetic education and motivates us to feel and know (Greene, 2001). Implications of student involvement in the learning process was also emphasized by Mullen \& Tallent-Runnels (2006) as students interviewed stated that in-class discussion and application made learning easier. In a case study comparing student perceptions of both online discussions and face-to-face discussions, Meyer (2007) noted that students consistently preferred face-toface discussions (Haavind et al., 2002; Hirumi \& Bermudez, 1996; Roblyer \& Ekhaml, 2000). Mullen \& Tallent-Runnels (2006) also revealed that one difference in student perceptions of online and face-to-face instruction was their impression of affective support, the degree to which the instructor listens, encourages, shares, and demonstrates a caring attitude. They found that students in face-to-face courses reported higher levels of affective support. 
As reflected in the research included here, the most mentioned reason for taking an online class over the face-to-face setting was convenience. Doherty (2006) surveyed community college students in an effort to investigate the reasons for the high rate of retention in online courses. His findings were consistent with those stated above. Data was collected independently for each of the four research questions. Participants ranged from 52 responses to over 10,000 (demographic data from the institutions information system). Of 52 respondents, $37 \%$ said there were time constraints that prevented them from attending a class with others responding that they had a scheduling conflict with another course or it wasn't convenient to travel to campus. Of 100 students surveyed about the perceived advantages of online courses, most cited reasons that were also related to convenience; they did not have to come to campus, could work at their own pace, could work faster, and didn't have to deal with other students or class lectures. Their perceived disadvantages to the Web-based course were procrastination, communication issues, the need for help, the amount of reading, and boredom. Harrington and Loffredo (2010) also cited convenience, travel, and interest as reasons students prefer online instruction. They concluded, from surveying 166 college students, that students also preferred face-to-face instruction because of the auditory modality and emotional interaction.

\section{Transfer of Knowledge}

The ability to transfer knowledge from one course experience to another is a subject of emphasis for some educational research and is pertinent to bridging the gap between theory and practice. Representative studies specific to nursing education, face-to-face and online teaching methodologies, and the biosciences are applicable to the current study.

Both the surveys and the interviews by Davis (2010) revealed concerns of the students' ability to link bioscience knowledge to practice. Jordan and Reid (1997) examined the problem 
of the gap between theory and practice and the importance of bioscience knowledge to knowledge transfer and application within nursing practice. Their surveys of nurses in continuing education bioscience courses revealed the positive impact the biosciences had on their nursing practice: enhancing their patient care.

Literature speaks to the strategies and methods to enhance knowledge transfer. Sadler and Fowler (2006) suggest argumentation as a viable strategy for transition of knowledge from one context to another. Three sample groups were composed of high school and college level students with the college students subdivided into science and non-science major groups. Researchers stated that participants must have a solid grasp of the basic knowledge in order to convince others to view the issue from their perspective. Most participants defended their stance with solid content knowledge and referenced their understanding throughout the scenarios.

Conclusions of both Ballon and Silver (2004) and Barab et al. (2009) support the utilization of games to enhance knowledge transfer. Ballon and Silver (2004) use the "Context is Key" game as a tool to help psychology students to diagnose disorders. Other examples have been developed for the investigation of various heart conditions, fever, and respiratory symptoms. Of the 173 participants in the study, almost $1 / 3$ commented that the game helped them apply the content to practice. The game also required participants to share knowledge and expand their understanding as they gained new knowledge from one another. Researchers said the games are a good complement to the didactic teaching.

Barab et al. (2009) utilize a 3-D game to teach environmental concepts of water quality. Levels of contextualization require students to immerse themselves in situations where they must understand content in order to effectively transform their environment for the betterment of the community. The methods of cause and effect and consequences helped the students to associate 
content and practice. Fifty-one undergraduates were involved in the study. Successive conversations and reports showed an increase in situational understanding and use of terminology in proper context. Student interview comments addressed some frustrations with material, environment, and interaction but participants in all groups noted similarities between their experience and the real world. The games of both studies directly correlate with online strategies described by Jairath and Mills (2006).

Granger \& Calleson (2007) conclude that in-class experience aids retention, problem solving and knowledge integration. Research participants, students in a medical anatomy laboratory, were divided into two groups completing both face-to-face dissections and computer enhanced online dissections. Student groups alternated their laboratory experience and performed better on written exams during their rotation of face-to-face dissection laboratory experience. Researchers also concluded that dissection laboratories allowed for more facultystudent interaction and opportunities for enhanced construction of knowledge.

McLachlan et al. (2004) specifically address the advantages of face-to-face dissections of real material for transferring knowledge to clinical practice for medical students. They concluded that direct cadaver dissections and laboratory experiences aid students in applying the scientific method in diagnosis or clinical problem solving, and that dissection experiences help students develop manual skills. They noted other important aspects of face-to-face laboratory experiences that would aid students in their clinical practice: personal development, identifying personal values, and addressing the issue of death and dying. They concluded that these resulted from the experience and the byplay of interaction between students and the instructor during the course of dissections. 
Students of science study the natural world and gather information that enables them to arrive at an understanding about situational tendencies and interactions (Kuhn, 1996). Consistent with the findings of Hsu and Roth (2008), taking samples, running tests, and repeating trial after trial with others allows for an exchange of information and are opportunities to assist one another with the physical work while interacting. Their research investigating the impact of the interactions between scientists and students revealed increased opportunities for educational growth and knowledge transference when facilitated through dialectic experiences within the physical laboratory. The look and feel of the laboratory enhances the experience as well as the consequences of the students' actions and decisions throughout the learning process (Hsu \& Roth, 2008). This type of process provides the experience and skill development that can be transferred to new situations and is reflective of Dewey's (1900) pragmatic educational approach.

McLachlan et al. (2004) also address the advantages of virtual-reality, simulations, and interactive models that engage the medical student in processing situations that more closely reflect clinical situations and therefore enhance transfer and application. They say the problem with depending only on cadaver dissection experience is that the tissue is not responsive or interactive. Dissection is not necessary as not every student will become a surgeon (McLachlan et al. 2004).

The online learning environment was the focus of the research of Kelly, Lyng, McGrath and Cannon (2009). They concluded that their online instructional videos contribute to the nursing students' skill set, were received well by the students, and enabled the instructor to more effectively teach to a large number of students. In addition to the reviewable nature of the video instruction and demonstrations, the researchers said the video decreased inconsistencies that are 
inherent when teaching manual skills to large numbers of students in the traditional face-to-face setting. Overall, student responses supported the use of skill videos in teaching as a supplement to, not a replacement of, lecture demonstrations.

Jette, Tribble, Gagnon and Mathieu (2010) analyzed nursing student perceptions of the sources utilized in learning to access health information. Surveys emphasized the importance of computer skills and information technology in nursing education. Researchers concluded that online experiences give the students access to database information and tools that will help prepare them for nursing practice. Their survey results showed that very few of the students had prior knowledge or understanding of information systems. Based on their evidence, Jette et al. (2010) recommend student experiences in searching databases and accessing Web sites that will directly transfer to their nursing practice as important learning strategies in nursing education.

The use of online videos in preparing nursing students to deal with difficult patient situations was the focus of McConville and Lane's (2006) study. Participants completed surveys of self efficacy before and after study modules specifically depicting contextual scenarios they would be expected to confront in their nursing practice. Their responses suggested that their confidence in being able to engage in positive patient interaction in related situations increased after viewing the online videos. The flexible online format gave the students the opportunity to review the scenarios repeatedly and independently. Although the researchers suggest the online videos compliment rather than replace lecture, the value of the online learning in nursing was supported by the evidence of increased student confidence in responding in difficult situations.

\section{Nature of Online Bioscience Laboratories}

History of online education. Dissemination of information in a manner other than the traditional classroom is not new to education. Distance education has been utilized since early 
correspondence between students and their teacher through letter writing. Early mail order courses of the 1920's were primarily established for employee training purposes (Bright, 2009). Monko's (n.d.) look at online history notes the significance of the communication system known as PLATO (Programmed Logic for Automated Teaching Operations) developed by the University of Illinois in 1960. According to the Hobbes' Internet Timeline (Zakon, n.d.) educational research at MIT in the 1960's addressed online communication systems. In addition to the advances of computer technologies and university networking the Internet was founded in 1969. Ivan Illich (1972), author of "Deschooling" wrote of the changing nature and needs of students and his envision of learning webs. Other notable events of the decade include e-mail, Ethernet, shockwave, and increased numbers of computer networks (Zakon, n.d.). The World Wide Web was born in the 1980's and the University of Phoenix offered the first bachelor program in 1989 (Monko, n.d.). Zakon also notes that during the 1990's the first fully web based university (Jones International University) and virtual schools were established, WebCT was released, and Blackboard was founded. Harasim (2000) refers to this time of change in the fundamental way of learning and understanding in education as a new paradigm for learning. In addition to increasing numbers of online universities and programs, servers and domains, schools are currently utilizing online course delivery at all levels. Regulation has been an issue with the rapid growth of online institutions and offerings over the years even though there are currently more accredited schools in existence (Bright, 2009).

Characteristics of online science laboratories. Biological online laboratory strategies include a wide range of student interaction and diversity of forms. Formats include student tutorials, simulations, virtual environments, remote access, kitchen laboratories, and packaged home laboratories. At the college level, professors require photographs and/or videos to verify 
completion of the home laboratory (Mickle \& Aune, 2008). Virtual or simulated laboratories are also utilized to fulfill the online laboratory requirement. Sam Dillon (2006) of the New York Times reports that professors say the Internet is a great supplement to their science courses; however, some say they would be "concerned about giving credit to students who never had any experience in a hands-on lab.” He also quotes Dr. Earl Fleck, creator of a virtual pig dissection, as saying the virtual dissection is useful but "markedly inferior" to the real thing. Harry Keller, Ph.D. (2008), the operator and president of the online science laboratory site www.SmartScience.net admits there are limitations to online laboratory; they don't get to "feel and smell" as with the hands-on experiences and he states that virtual science laboratories would benefit from hands-on experience. Online capabilities have vastly improved since the first virtual dissections, and the technology is currently breaking the sensual barrier.

Hamza-Lup and Stanescu (2010) write about the advances in multimodal (visual, auditory and kinesthetic) virtual environments, also referred to as haptic (sense of touch) environments; where vibrations and motions are sensed through the communication channel. They refer to this haptic paradigm in their case studies surrounding force and friction principles in a physics course. Downing and Holtz (2008) summarize a variety of possibilities in designing an online science laboratory course. Most virtual and simulated laboratories currently available utilize canned data sets and scenarios with predetermined results. They refer to laboratories easily available through an Internet search where there is typically a wealth of data for student manipulation and problem solving practice. If students have access to streaming data, there are other possibilities described that would give them the opportunity to work with data and technical instrumentation not normally available to them in the face-to-face laboratory. The authors note the lack of availability to all and the lack of manipulation and physical skill building 
practice which they say presents a challenge for the methodology. Their best practices include the more recent haptic, three dimensional, and remote technologies that are currently being researched and refined. Regardless of the level of technology available to each educational institution, laboratory experiences can be designed to promote learning (Downing \& Holtz, 2008). They go on to conclude that a blend of online and face-to-face laboratory experiences for authentic science investigation will better serve the student.

Smith et al. (2008) analyzed the differential use of online tools by instructors of different sciences. Researchers counted the use of online tools in over 500 courses. They found that messages and e-mails were used in courses needing more communication. There was a decrease in document use in bioscience type courses and an increase for nursing courses. The use of the document tool suggests “instructor-customized content postings.” Researches concluded that distance learning education is changing in a way that some disciplines, with the sciences in this category, are leaning toward commoditization while others are diversifying.

Kearsley (2008) discusses the difficulty of student skill development that can not be done in an online format. He refers to the incorporation of remote laboratories as a possible solution. Keller (2008) also reports the development and use of remote laboratory experiences with "electronic equipment with no moving parts," but states the study of biology utilizing this format is not currently available. Even, most of the advertised fully online courses require on-campus laboratory time (Kearsley, 2008).

The commonalities apparent in the characteristics of the successful online students revealed by Kerr, Rynearson and Kerr (2006), Mullen and Tallent-Runnels (2006) and O’Neil and Fisher (2008) show that the successful online student is self motivated, self directed, dedicated, and determined. Academic skills such as reading and writing are the best indicators 
for success (Kerr et al., 2006). Researchers utilized the Test of Online Learning Success (TOOLS) to investigate characteristics of successful online students from a population of 188 four-year university students. Data was gathered via multiple questionnaires and an index of learning styles. Graduate students from the College of Education and the College of Human Sciences, interviewed by Mullen and Tallent-Runnels' (2006) noted that online strategies are reading intensive. Their research also generated survey data instrumental in providing evidence of the differences in the online and traditional learning environments resulting from instructional design and the impact on student affective outcomes. Nursing students in online and traditional sections of the same health course responded through surveys and focus groups (O’Neil \& Fisher, 2008). Their findings yielded data corroborating distinctions between successful students in online and traditional (face-to-face) learning environments, concluding that successful online students are more likely self directed and involved in the learning process.

\section{Nature of Face-to-face Bioscience Laboratories}

According to the National Research Council (2004), students will develop scientific skills and a scientific attitude for problem solving applicable to life and the natural world if the way they learn reflects the way scientists learn. Although computers and advanced technology are invaluable in research today, science and scientists must still engage in the work of science. Scientists engage in normal science (Kuhn, 1996), meaning they are doing the research of science based on past achievements and knowledge which is used as the foundation for further work. Science professionals function within the rules of the current model. As they research to refine their understanding, they utilize instrumentation, observe, collect evidence, and draw conclusions about the meaning of their findings within the rules of the model. Anomalies that occur may lead to the necessity of new rules for understanding or an eventual paradigm shift. 
Without the direct involvement in scientific research and the work of normal science, anomalies may not be evident and progress will be inhibited (Rudolph, 2002).

Rudolph (2002) writes that "science skills are lacking in America." Scientific processing and reasoning skills are vital to knowing science but the full sensual nature of discovery continues to be an integral component to research. Hamza-Lup and Stanescu (2010) examined the continual sensual challenges of the online haptic environment and concluded that these strategies should "augment" and not replace the current science laboratory methods of learning. The National Research Council (2004) supports an inclusive educational approach that is balanced in format and procedures.

Granger and Calleson (2007) explored the impact of dissection in a medical anatomy course on student performance in both written and practical assessments. Two groups alternated anatomical instruction between dissection and web-based programming as compared to the previous year when all groups dissected in every laboratory. Results showed no difference in practical performance, but dissecting had a significant impact on student performance on the written examination. Researchers concluded that dissecting may help in retaining knowledge. The alternating program was well received by students who shared comments of support and concern. Some students were concerned they were missing learning opportunities without dissecting while others appreciated the break, giving them time to concentrate on reading and preferred to have the time on the web-based program.

In addition to the physical nature of content learning within the face-to-face laboratory setting, there is evidence of distinctive aspects of social interaction as compared to the online format. Body language allows students to gauge emotional reactions, to show support among participants, and to communicate the need for clarification without verbalizing a question 
(Harrington \& Loffredo, 2010; Hsu \& Roth 2008). Hsu and Roth (2008) investigated the practice of normal science in their ethnographic study following the learning processes of students interning with laboratory technicians and science researchers. Throughout the experience hesitant students moved forward through activities when encouraged by their peers and the technicians. At times the encouragement came in the form of a nudge, verbal comments, or a look or smile. Laboratory experiences surrounded enzyme function and bacterial growth and transfer, both of which are pertinent concepts in nursing and health care.

Hsu and Roth (2008) affirm that as a result of the direct participation in physical laboratory activities and the interaction with technicians while they work in science, students have many opportunities for "clarifying presuppositions, reformulating retrospective instructions, further explanations, connecting previous and upcoming practices and reflecting science practices" (p.10). The dialog between students and scientists while engaged in science often opened avenues for the students to more directly control what they learned. The questions asked during the activity guided the experts toward further explanations that expanded the learning beyond the original intent of the experience. Both participants then became learner and instructor through the transactional process say Hsu and Roth (2008).

Harrington and Loffredo (2010) had participants take the Myers Briggs Type Indicator as a measure in their study and results showed that more extroverts prefer face-to-face experiences than introverts and more introverts than extroverts prefer the online format over the face-to-face delivery. Participants also completed surveys revealing that over $90 \%$ of students who preferred the face-to-face environment noted the importance of auditory learning and being able to read the emotions of those around them.

\section{Demographics}


Beyond the biological content and teaching methodology, there are equity issues to consider. Age, socioeconomic status, gender, technological and laboratory experience, and cultural socialization may impact educational experiences. Based on survey results and open question responses from 276 community college students, Muse (2003) found age to be one indicator of success in online retention, and concluded that older students are more likely to continue in a Web-based course. Doherty (2006) surveyed over 10,000 successful and/or unsuccessful students in Web-based courses at two different community colleges. Gender and age were found to be significant factors impacting student success in Web-based courses, and they concluded that females and older students are more likely to be successful in their Webbased courses.

Kelly et al. (2009) surveyed 134 nursing students and evaluated 10 of those students to determine the effectiveness of video instruction in teaching nursing skills. Students were randomly assigned to one of two research groups; the control group received face-to-face skill instruction, and the experimental group viewed instructional videos. Researchers concluded that older students were more favorable to the video instruction than younger students, and compared to male students, female participants were two thirds more favorable to online materials.

Young and Norgard's (2006) findings support the idea that strong interaction is important for online success, noting that interaction was significantly more important for females. Survey responses from 233 online students supplied the data contributing to their conclusions that the amount of online experience was a significant factor of online satisfaction. Students with more online experience felt they learned more from online than face-to-face courses, preferred the online format, and felt more comfortable in online courses; however, the opposite was true for students with less online and technical experience. 
Morris and $\mathrm{Wu}(2005)$ concluded that access to financial assistance was an indication of online success with 76\% accuracy. Questionnaires were completed by 211 humanities, science and social science students in higher education. Participants were divided into two groups based on their completion or non-completion of web-based courses. Parker (1999) administered the Rotter Locus of Control Scale instrument and interviewed 94 college students and found that financial access along with external (outside of self) or internal (self efficacy) identification of locus of control were dependable predictors of student success and college completion of online courses. The financial access variable was divided into three groups, self pay, family, and other. Self paying, external locus of control students, were least likely to complete online courses, and yielded an $80 \%$ indication rate. The findings showed that many students have to work while in school which contributes to their non-completion, a point also corroborated by Doherty (2006) and Muse (2003).

\section{Summary}

Research questions and sub-questions guiding the study and literature review were in reference to nursing student perceptions concerning the impact of Anatomy and Physiology and Microbiology bioscience laboratory experiences on the transfer of knowledge to nursing education and practice. The impact of the face-to-face and online instructional formats, and demographic factors on student perceptions were significant aspects of the inquiry.

Ramage (2002) expounds on the work of Thomas Russell ("No Significant Difference Phenomenon"). He states that the success of any educational media depends on the content and methods of instruction and not just the modality of the media. The literature review addressed the gap that exists between nursing theory and practice and the biosciences that specifically pertain to nursing education. Other areas of the review that relate to the research questions concern the 
transfer of knowledge as well as student perceptions, characteristics of both online and face-toface instruction and demographic factors that may impact nursing student perceptions of learning online versus learning in a face-to-face laboratory and the transfer of knowledge.

The literature included research examining how students transfer information (Davis, 2010; Granger \& Calleson, 2006; Jordan \& Reid, 1997; McConville \& Lane, 2006; Sadler \& Fowler, 2006) supporting the development of online and/or computer based content and face-toface instruction. Investigations debating online and face-to-face courses (Angulo \& Bruce, 1999; Harrington \& Loffredo, 2010; Kerr et al., 2006) were discussed. Some studies considered online and face-to-face methodologies specific to science laboratories (Bhargava et al., 2005; HamzaLup \& Stanescu, 2010; Hsu \& Roth, 2008; Stuckey-Mickell \& Stuckey-Danner, 2007) and others addressed nursing methodologies (Kelly et al., 2009; McConville \& Lane, 2006; O’Neill \& Fisher, 2008). Gresty and Cotton (2003) evaluated the use of online supplements to biosciences for nursing; however, the study was not specific to the science laboratory.

Although each component pertinent to this study was addressed, there is an apparent missing link specific to relating the impact of the online and the face-to-face bioscience laboratory delivery to the transfer of knowledge to nursing and nursing practice. The literature does not speak to student perceptions of the learning laboratory environment and subsequent nursing courses and practice. Research is needed that integrates all the elements as they impact nursing education and should continue with respect to delivery methods of bioscience laboratories and the impact on students as they progress through a community college nursing program.

\section{Chapter 3: Methodology}

\section{Introduction}


The purpose of this study was to determine the nursing students' perceived impact of online and face-to-face biological laboratories on student learning in community college bioscience courses as they prepare for the nursing program. The qualitative study investigated student perceptions of knowledge transfer into health care, and the perceived role of the bioscience laboratory method of instruction on student success and performance in nursing.

The institute of the study, participants, instruments, the procedure, and the study design are described. Data were collected from a student questionnaire, focus groups, and archival records and were utilized to answer the following research questions: What are nursing student perceptions concerning the impact of Anatomy and Physiology and Microbiology bioscience laboratory experiences on the transfer of knowledge to nursing education? What are nursing student perceptions of the impact of the Anatomy and Physiology and Microbiology laboratory on the transfer of knowledge to future nursing courses? What are nursing student perceptions of the impact of the Anatomy and Physiology and Microbiology laboratory on the transfer of knowledge to future nursing practicum experiences? Does face to face versus online laboratory delivery format have an impact on nursing student perceptions of the transfer of knowledge to a) nursing courses or b) nursing practicum experiences? How do demographic factors, such as age, gender, and educational and technological experience impact nursing student perceptions of the online and face-to-face bioscience laboratory and the transfer of knowledge transition to and success in nursing?

\section{Institute of Study}

The research took place at a community college in a rural Middle Atlantic region. It is a comprehensive community college offering an Associate of Arts degree, an Associate of Science degree, an Associate of Applied Science degree, and specialized program certificates. The 
college serves six counties in the state in addition to six bordering counties in other states. Three campuses have a total enrollment of approximately 3,000 students. A large number of these students are enrolled in applied science and health programs. The Center of Economic and Workforce Development serves the region through continuing education, technical programming, business partnerships, training and consultation. The area is economically depressed, as are many rural regions across our country. The keystone steel industries of the area have reduced employees from 23,000 fifty years ago to 7,000 in 2006; with approximately 1,300 employees reported in July of 2009 (Brown, 2009). The two-year community college is a refuge for displaced workers, those reentering the work field, and recent high school graduates getting a less expensive start on their education closer to home. This specific community college was selected based on convenience sampling.

At the institution of this study, laboratory sections of the bioscience courses are offered through both the face-to-face and online computer based formats. Depending on their choices students may or may not complete their programs having never been in a physical, hands on science laboratory or having never been exposed to laboratory technologies in Anatomy and Physiology and Microbiology. Both laboratory sections are taught by multiple instructors with varying teaching strategies and methodologies.

\section{Course Description}

Students in online and/or fully computer based laboratory sections apply content through interactive online sites and simulation activities. The following are examples of online Microbiological experiences in which these students were involved: view, compare and contrast photomicrographs of microbes, access sites utilizing a virtual microscope, investigate bacterial cell physiology, differentiate colonial morphology, participate in interactive tutorials, and 
investigate (literature review, design and present) a microbial concept through a group project assignment. A sample course syllabus is found in Appendix A. Microbiology laboratory students in the face-to-face sections were asked to transfer microbes, culture, and test a variety of bacteria, and as a group they had to design, test and present the investigation of a microbiological concept (Appendix B). Note that each sample syllabus has only a few outcomes included that are specific to the laboratory teaching methodology; common outcomes have been excluded for this writing.

Anatomy and Physiology online laboratory experiences included comparing and contrasting photomicrographs of cell and tissue samples, comparing values of varied blood tests, identifying anatomical structures, relating physiologic processes, and performing simulated exercises (Appendix C). Face-to-face Anatomy and Physiology laboratory students were asked to prepare cell and tissue slides as well as compare and contrast prepared slides of cell and tissue samples, perform blood tests and urinalysis, check pulse and blood pressures, perform selected dissections, and investigate physiologic processes (Appendix D). Learning outcomes and student learning performance objectives are not included with the Anatomy and Physiology sample syllabi as they are written specific to lecture content and intended to be used for both the online and face-to-face laboratories. Specific assignments are included for distinction of teaching methodology.

\section{Participants}

Participants for this study were first and second-year nursing students who entered the program with varying degrees of laboratory experiences. Students from all three campuses selfselected into two groups: those who scheduled in an online and/or fully computer based 
laboratory section of Anatomy and Physiology and/or Microbiology and those who scheduled in a face-to-face laboratory.

Student questionnaires were completed by 108 of the 134 first and second-year nursing students for an $80 \%$ participation rate. The study yielded a sample of $n=107$, as one survey was submitted with incomplete data. Most students were female (88\%), with males making up $11 \%$ of the sample; one participant did not report gender. Among participants $37 \%$ were 26 to 35 years of age, $34 \%$ were younger than 26 , and $28 \%$ were older than 35 . A large majority of students (85\%) reported having the face-to-face Anatomy and Physiology laboratory, 14\% had the online laboratory, and three did not report. The Microbiology laboratory was also comprised of the majority of students $(91 \%)$ who had the face-to-face laboratory, $8 \%$ reported having the online laboratory, and four did not report. Of the $17 \%$ of students who had at least one bioscience laboratory online, most were female (18 of 19) and over the age of 25 (12 of 19). Approximately $33 \%$ of students reported having no previous online experience, with the same percentage of students saying they had at least one online science course. Most students reported having had experience in science courses with $25 \%$ having had three or more science laboratory courses (Table 1). 
Table 1

Survey Participant Age, Gender, and Bioscience Laboratory Experience

\begin{tabular}{lllll}
\hline & \multicolumn{2}{l}{ Age 18 -25} & \multicolumn{2}{l}{ Age over 25 } \\
& Female & Male & Female & Male \\
\hline Total gender/age & 33 & 4 & 61 & 8 \\
\# both AP/Micro & 4 & & 1 & \\
online & & & & \\
\# AP online & 2 & 1 & 7 & \\
\# Micro online & & & 4 & \\
$\begin{array}{l}\text { Total \# at least 1 } \\
\text { online Biosci }\end{array}$ & 6 & 1 & 12 & \\
\# with < 3 sci lab & 9 & 1 & 15 & 2 \\
$\begin{array}{l}\text { \# with at least 1 } \\
\text { online sci } \\
\text { experience }\end{array}$ & 12 & 18 & 3 & \\
$\begin{array}{l}\text { \# without online } \\
\text { experience }\end{array}$ & 12 & 17 & 4 & \\
\hline
\end{tabular}


A total of three focus groups were conducted with student representation from each of the three campus locations. A total of 44 students who completed surveys volunteered to participate in these discussions. Students completed the demographic page of the survey questionnaire to provide data concerning age, gender, and educational and technological experience. Notations were also made during the discussions and/or during data transcription with regard to the approximate age and gender of the speaker. Educational and technological experience was expressed by the student or asked for during the conversation. A majority of participating students were female with only 6 males in attendance, and all but one male was over the age of 25. Of female subjects, 15 were under 25 and 23 were over 25 years of age. Six of the females identified as having had the bioscience laboratory online with two in Microbiology and four in Anatomy and Physiology. One male had the online Anatomy and Physiology laboratory. No students expressed having had both bioscience laboratories through the online experience. All students in online laboratories had previous online courses, and all but two had multiple types of laboratory experiences. Most students in the online sections had previous online science experience with two exceptions, one in Microbiology and one in Anatomy and Physiology.

There were 32 female and five male students in the face-to-face bioscience laboratory who participated in focus groups. Representative female age groups were approximately even with 15 younger than age 25 and 17 older than 25 . All males were older than 25 years of age. Most all students had multiple laboratory experience with only nine reporting fewer than three experiences. Eleven students who had face-to-face bioscience laboratories had some online science experience. Additionally, most students in this representation had online course experience with 11 reporting no experience (Table 2). Oral responses and subsequent discussions provided another perspective of student perceptions of the impact of bioscience laboratory 
methodology on nursing education. 
Table 2

Focus Group Participant Age, Gender, and Bioscience Laboratory Experiences

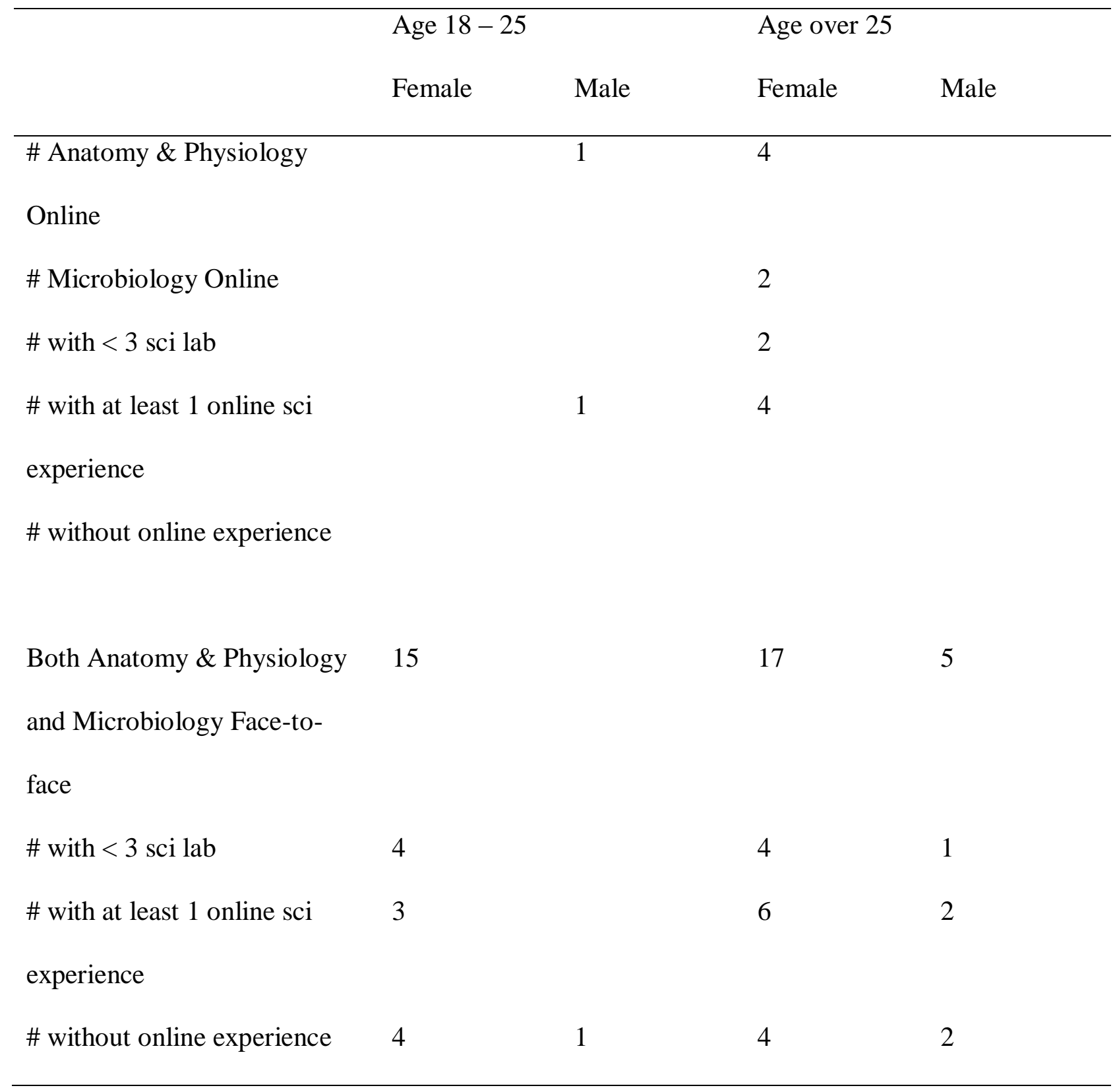




\section{Instruments}

The use of surveys in research is abundant (Gay et al., chap. 6, 7, 2009) and a prominent component of this study. Paper based student surveys (Appendix E) were completed and used to determine if research study variables, such as age, gender, and experience levels were related, as well as to reveal student perceptions toward online and face-to-face laboratory experiences. Literature supports the importance of the bioscience laboratory to learning and nursing education and the relevance of student perceptions to learning and research analysis. Data collected via the questionnaire survey reflect the literature as questions related to bioscience knowledge, student transfer of bioscience knowledge to nursing courses, and student success and performance in nursing practice. The questionnaire items were developed by adapting some items from previous studies to build validity. Modifications were made to items from the Community of Inquiry survey (Diaz, Swan, Ice \& Kupczynski, 2010), the Motivated Strategies of Learning Questionnaire utilized by Mullen and Tallent-Runnels (2006), and the Bioscience in Nursing questionnaire utilized by Friedel and Treagust (2005). Other items were personally developed based on my own teaching experiences.

Survey questionnaires contained 20 statements with two forms for each, one specific to the Anatomy and Physiology laboratory (items 1-20) and one form of the statement specific to the Microbiology laboratory (items 21-40). Items 1-6 specific to Anatomy and Physiology and items 21-26 specific to Microbiology, were developed consistent with research question one (What are nursing student perceptions concerning the impact of Anatomy \& Physiology and Microbiology bioscience laboratory experiences on the transfer of knowledge to nursing education?). Items 7-13 for Anatomy and Physiology and 27-33 for Microbiology were specific 
to research question 1a (What are nursing student perceptions of the impact of Anatomy \& Physiology and Microbiology laboratory experiences on the transfer of knowledge to future nursing courses?), and items 14-20 (Anatomy and Physiology) and 34-40 were relevant to research question $1 \mathrm{~b}$ (What are nursing student perceptions of the impact of the Anatomy \& Physiology and Microbiology laboratory on the transfer of knowledge to future nursing practicum experiences?). The demographic section of the questionnaire supplied data pertinent to research question 1c (Does face-to-face versus online laboratory delivery format have an impact on nursing student perceptions of the transfer of knowledge to a) nursing courses or b) nursing practicum experiences?) and research question two (How do demographic factors, such as age, gender, and educational and technological experience impact nursing student perceptions of the online and face-to-face bioscience laboratory and the transfer of knowledge and transition to and success in nursing?).

Each item was positively stated with participants responding to a typical Likert type scale and the following assigned values: strongly disagree $=1$; disagree $=2$; agree $=3$; and strongly agree $=4$; the higher the number, the more positive the response. In addition, survey data included whether participants had taken their Anatomy and Physiology and Microbiology laboratory online or in a face-to-face setting, the number of online courses, science laboratory courses, and online science laboratory courses the student had taken. Data also included the participant's age, gender, and semester at the institution.

Measures of sampling adequacy revealed two survey items that correlated with no others, suggesting elimination: Item \#13 (My A\&P lab helped me understand the disease processes studied in my nursing courses.) and Item \#30 (My Micro lab experiences relate well with my nursing courses). In addition, Item \#1, Item \#26, and Item \#29 were eliminated with Eigenvalues 
below 0.7. Hereafter, all findings and discussion exclude eliminated items (Appendix F). After item elimination the Kaiser-Meyer-Olkin (KMO) measure of sampling adequacy (Table 3) was .918 with anti-imaging correlation at .848 or above. 
Table 3

Kaiser-Meyer-Olkin Measure of Sampling Adequacy

Keiser-Meyer-Olkin Measure of Sampling Adequacy.

.918

Bartlett's Test of Sphericity Approx. Chi-Square

4052.979

df

Sig.

.000 
Survey items refer to research question one and sub-questions $1 \mathrm{a}$ and $1 \mathrm{~b}$ specific to both Anatomy and Physiology and Microbiology laboratory sections. The scree plot (Fig. 1) suggests a five factor solution and, although there were only two components with Eigenvalues $>1.0$, there were five factors with Eigenvalues $>.5$ (Table 4) reflective of item groupings: Anatomy and Physiology, Microbiology, research question one, research question1a, and research question $1 \mathrm{~b}$ (Field, chap. 15, 2005). 


\section{Scree Plot}

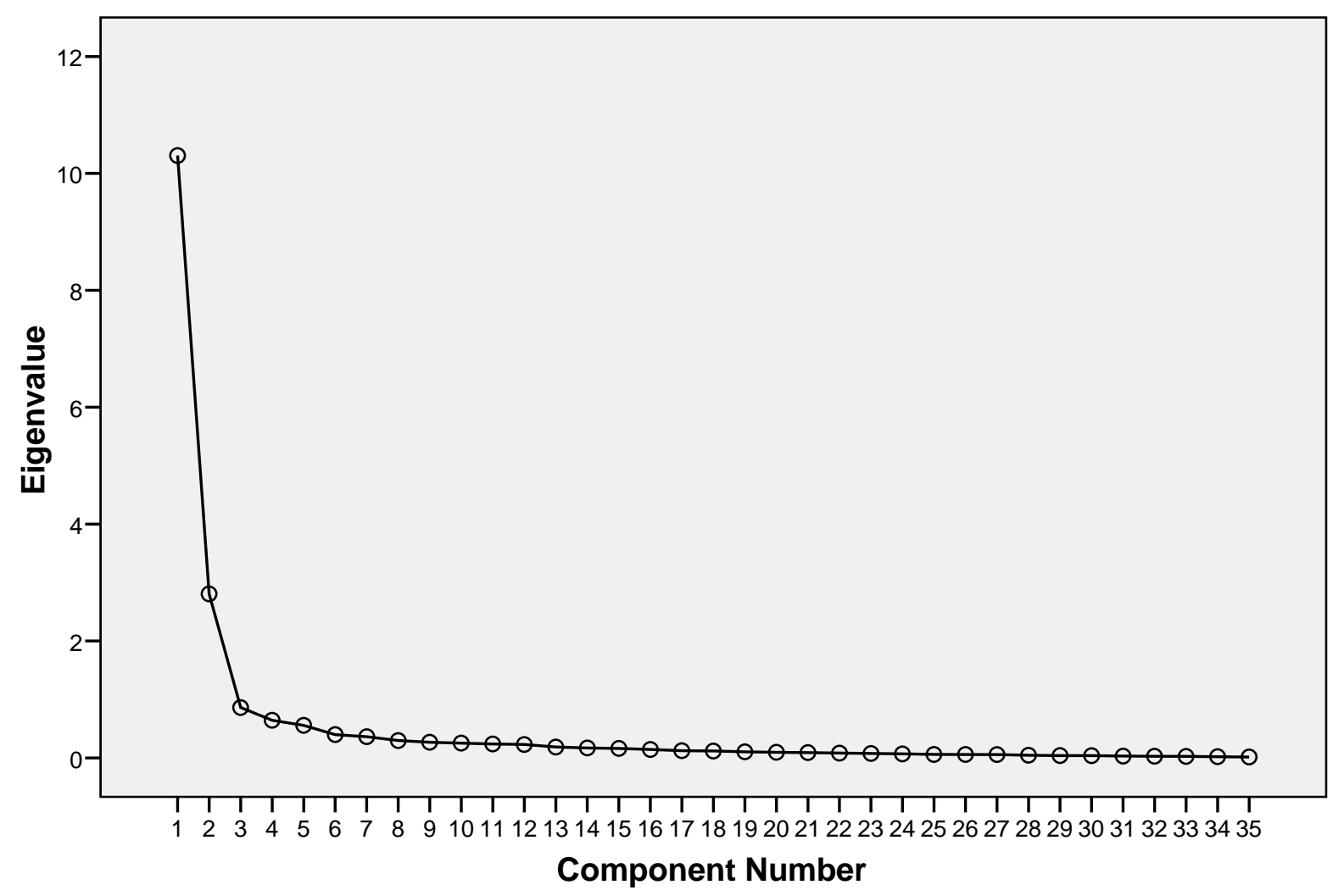

Figure 1. Scree plot for principal component analysis. 
Table 4

Principal Component When Selecting Eigenvalues $>0.5$

\begin{tabular}{|c|c|c|c|}
\hline Component & Initial eigenvalues & & \\
\hline & Total & $\%$ of variance & Cumulative $\%$ \\
\hline 1 & 10.305 & 54.078 & 54.078 \\
\hline 2 & 2.804 & 14.716 & 68.794 \\
\hline 3 & .862 & 4.522 & 73.315 \\
\hline 4 & .643 & 3.375 & 76.690 \\
\hline 5 & .556 & 2.919 & 79.610 \\
\hline
\end{tabular}


After factor rotation (see Table 5) the pattern matrix as described by Field (2005) supports the interpretation of data grouping Anatomy and Physiology items 2-20 and the Microbiology items 21-40. Items 7-13 and 27-33 refer to research question 1a and items 14-20 and 34-40 refer to research question $1 \mathrm{~b}$. The only other clear pattern suggested by the matrix, groups items 2-5 and 21-25, correlate with research question one. Sample sizes vary among groups with the Anatomy and Physiology online group sample of $n=15$, the face-to-face group sample of $n=90$, the Microbiology online group sample of $n=9$, and the face-to-face group sample of $n=95$. Missing data from blank responses per item resulted in the apparent discrepancies of sample sizes. Internal consistency among all items was determined with a Cronbach's Alpha of $0.974,0.967$ for Anatomy and Physiology, 0.968 for Microbiology, 0.723 for research question one, 0.930 for research question $1 \mathrm{a}$, and 0.939 for research question $1 \mathrm{~b}$. 
Table 5

Pattern Matrix After Factor Rotation

\begin{tabular}{|c|c|c|c|c|c|}
\hline \multirow[t]{2}{*}{ Item } & \multicolumn{5}{|c|}{$\begin{array}{l}\text { Rescaled } \\
\text { Component }\end{array}$} \\
\hline & 1 & 2 & 3 & 4 & 5 \\
\hline 2 & .154 & ${ }^{*} .632$ & ${ }^{*} .576$ & .088 & .127 \\
\hline 3 & .144 & ${ }^{*} .600$ & *.693 & .060 & .009 \\
\hline 4 & .120 & ${ }^{\star} .566$ & *.729 & .012 & .091 \\
\hline 5 & .222 & *.623 & ${ }^{*} .622$ & .058 & .071 \\
\hline 6 & .288 & ${ }^{\star} .467$ & .088 & ${ }^{\star} .589$ & .093 \\
\hline 7 & .099 & ${ }^{\star} .794$ & .314 & .353 & .010 \\
\hline 8 & .167 & ${ }^{\star} .740$ & .117 & ${ }^{*} .520$ & -.024 \\
\hline 9 & .176 & *.778 & .295 & *.419 & .013 \\
\hline 10 & .257 & *.766 & .263 & .287 & .059 \\
\hline 11 & .248 & ${ }^{*} .672$ & .184 & .345 & .270 \\
\hline 12 & .251 & ${ }^{\star} .774$ & .237 & .021 & -.002 \\
\hline 14 & .358 & ^.738 & .177 & -.018 & .241 \\
\hline 15 & .283 & * .820 & .206 & .074 & .036 \\
\hline 16 & .295 & ${ }^{\star} .847$ & .029 & -.022 & .233 \\
\hline 17 & .292 & ${ }^{\star} .869$ & .023 & -.066 & -.015 \\
\hline 18 & .306 & ${ }^{\star} .825$ & .033 & -.027 & .230 \\
\hline 19 & .178 & ${ }^{\star} .532$ & .214 & .049 & ${ }^{\star} .740$ \\
\hline 20 & .265 & ${ }^{\star} .618$ & .084 & .111 & ${ }^{\star} .520$ \\
\hline 21 & *.672 & .175 & ${ }^{*} .444$ & .214 & .118 \\
\hline 22 & ${ }^{*} .664$ & .090 & ${ }^{*} .476$ & .134 & .270 \\
\hline 23 & ${ }^{\star} .705$ & .086 & .392 & .326 & .244 \\
\hline 24 & ${ }^{*} .796$ & .197 & .284 & .170 & .204 \\
\hline 25 & ${ }^{*} .729$ & .162 & ${ }^{*} .405$ & .124 & .109 \\
\hline 27 & ${ }^{\star} .780$ & .266 & .093 & .350 & .084 \\
\hline 28 & ${ }^{\star} .777$ & .310 & .021 & .294 & .079 \\
\hline 31 & ${ }^{\star} .784$ & .321 & .028 & .212 & .023 \\
\hline 32 & ${ }^{*} .826$ & .229 & .039 & -.041 & .092 \\
\hline 33 & ${ }^{*} .794$ & .146 & .175 & -.079 & .105 \\
\hline 34 & *.879 & .169 & .003 & -.081 & .037 \\
\hline 35 & ${ }^{\star} .797$ & .290 & .046 & .230 & -.031 \\
\hline 36 & ${ }^{\star} .857$ & .281 & -.018 & .086 & -.014 \\
\hline 37 & ${ }^{*} .821$ & .164 & .111 & -.199 & -.166 \\
\hline 38 & ${ }^{*} .892$ & .207 & .065 & -.010 & -.032 \\
\hline 39 & ${ }^{\star} .720$ & .178 & .110 & .027 & .201 \\
\hline 40 & ${ }^{*} .802$ & .243 & -.006 & .121 & .092 \\
\hline
\end{tabular}

Note. Extraction Method: Principal Component Analysis.

Rotation Method: Varimax with Kaiser Normalization.

a Rotation converged in 9 iterations. 
Correlations of demographic data relevant to the second research question compare relationships between each factor (age, gender, educational and technological experience, and laboratory delivery method): age vs. laboratory delivery, gender vs. laboratory delivery, Anatomy and Physiology laboratory experience vs. laboratory delivery, Microbiology laboratory experience vs. laboratory delivery, and technological experience vs. laboratory delivery.

Nursing students voluntarily participated in focus groups and shared their perceptions of the impact of their bioscience laboratory experiences on their science knowledge, transfer and success in their nursing program. Focus questions (Appendix G) were reflective of the research questions and were developed by me or modified from other studies (Davis, 2010; O’Neil \& Fisher, 2008) adding to the validity of the study. Focus questions were open ended in design to encourage discussion.

Focus questions one through three guided the discussions to reveal insights dealing with research question one in reference to the transfer of knowledge to nursing education. Question one concerning the purpose of the bioscience laboratory was intended to guide the discussion toward the content of the laboratory course and explore any perceived relevance between the two. Question two asked the students to consider how their learning in the bioscience laboratory was the same or different than in other courses. This was pertinent to the research concerning the impact of teaching format specific to the bioscience laboratory and nursing. Question three opened the dialog to include the reasons students chose to take the online or face-to-face bioscience and the positives and negatives of each, leading them toward voicing their perceptions of the impact of both methods of delivery on their nursing.

The next set of focus questions were more specifically designed to relate to the relevance of the bioscience laboratory to the students' nursing courses, research question 1a. Question four 
directly asked how laboratory experiences prepared students for the nursing courses, and number six again addressed relevance as they were asked to connect the bioscience laboratory to the nursing courses. Students needed to reflect as they considered question five which asked when they thought about laboratory experiences while in their nursing courses. This also guided them to recall times when they connected information from the laboratory experience to nursing content.

Practical nursing experiences were the emphasis of questions seven through nine which correlated with research question $1 \mathrm{~b}$. Questions prompted the students to discuss laboratory skills and activities they connected to nursing and direct patient education and care. Number seven was specific to bioscience laboratory skills relevant to nursing, number eight directed their thoughts toward their patients, and number nine asked them to reflect and consider connections between their laboratory experience and work with their patients. Data analysis enabled me to make assumptions about the impact of student scheduling choices concerning bioscience laboratory delivery methods, consistent with research question 1c, and evaluate the impact of demographic factors on student perceptions, research question two. Discussions during focus groups were recorded and transcribed. Responses were analyzed to verify themes and patterns relative to each research question. An alignment of focus questions with research questions and survey items is shown in Table 6. 
Table 6

Alignment of Measurement Items and Research Questions

\begin{tabular}{|c|c|c|}
\hline $\begin{array}{l}\text { Research } \\
\text { Question }\end{array}$ & $\begin{array}{l}\text { Survey Items - Statements } 2-20 \\
\text { specific to Anatomy \& } \\
\text { Physiology and same statements } \\
21-40 \text { specific to Microbiology }\end{array}$ & $\begin{array}{l}\text { Focus } \\
\text { Questions }\end{array}$ \\
\hline $\begin{array}{l}\text { RQ 1 What are } \\
\text { nursing student } \\
\text { perceptions concerning } \\
\text { the impact of Anatomy } \\
\& \text { Physiology and } \\
\text { Microbiology } \\
\text { bioscience laboratory } \\
\text { experiences on the } \\
\text { transfer of knowledge } \\
\text { to nursing education? }\end{array}$ & $\begin{array}{l}\text { 21 The assignments in my A\&P/Micro } \\
\text { lab helped me master the course } \\
\text { content. } \\
\text { 2/22 The interpersonal interaction in } \\
\text { my A\&P/Micro lab was beneficial to } \\
\text { my success in the course. } \\
\text { 3/23 My A\&P/Micro lab experiences } \\
\text { were as beneficial to my learning as my } \\
\text { A\&P/Micro lecture. } \\
\text { 4/24 Learning activities in my } \\
\text { A\&P/Micro lab helped me construct } \\
\text { explanations and/or solutions. } \\
\mathbf{5 / 2 5} \text { The A\&P/Micro lab experience } \\
\text { helped me understand the concepts of } \\
\text { A\&P/Micro } \\
6 \text { The A\&P/Micro lab should be } \\
\text { required for nursing students taking an } \\
\text { A\&P/Micro lecture course. }\end{array}$ & $\begin{array}{l}1 \text { What do you think is the purpose of } \\
\text { the Anatomy \& Physiology and } \\
\text { Microbiology bioscience lab? } \\
2 \text { How do you think learning is the } \\
\text { same for all subjects and how do you } \\
\text { think learning should be different for } \\
\text { different subjects? } \\
\mathbf{3} \text { What factors were important to as } \\
\text { you scheduled for online or face-to- } \\
\text { face Anatomy \& Physiology and } \\
\text { Microbiology labs? What are } \\
\text { advantages and disadvantages of } \\
\text { each? }\end{array}$ \\
\hline $\begin{array}{l}\text { RQ 1a What are } \\
\text { nursing student } \\
\text { perceptions of the } \\
\text { impact of the Anatomy } \\
\& \text { Physiology and } \\
\text { Microbiology } \\
\text { laboratory on the } \\
\text { transfer of knowledge } \\
\text { to future nursing } \\
\text { courses? }\end{array}$ & $\begin{array}{l}\text { 7/27 I use the knowledge from my } \\
\text { A\&P/Micro lab experiences to nursing } \\
\text { courses. } \\
\mathbf{8 / 2 8} \text { My A\&P/Micro lab experience } \\
\text { helped me understand nursing } \\
\text { concepts. } \\
\mathbf{9} \text { I am more comfortable in my nursing } \\
\text { courses after having my A\&P/Micro } \\
\text { lab experience. } \\
\mathbf{1 0} \text { My A\&P/Micro lab experiences } \\
\text { relate well with my nursing courses. } \\
\mathbf{1 1 / 3 1} \text { Some nursing knowledge builds } \\
\text { on knowledge from my A\&P/Micro lab } \\
\text { experience. } \\
\mathbf{1 2 / 3 2} \text { There were times in my nursing } \\
\text { course when I recalled an experience } \\
\text { from my A\&P/Micro lab. } \\
\mathbf{3 3} \text { My A\&P/Micro lab helped me } \\
\text { understand the disease processes } \\
\text { studied in my nursing courses. }\end{array}$ & $\begin{array}{l}\text { 4. How do you perceive your AP and } \\
\text { Microbiology bioscience laboratory } \\
\text { prepared you for your nursing } \\
\text { courses and program? } \\
\text { 5. In what ways have you ever been } \\
\text { reminded of Anatomy \& Physiology } \\
\text { or Microbiology bioscience lab while } \\
\text { in your current courses? When? How } \\
\text { so? } \\
\text { 6. How do you connect information } \\
\text { from bioscience courses to nursing? }\end{array}$ \\
\hline
\end{tabular}




\begin{tabular}{|c|c|c|}
\hline $\begin{array}{l}\text { Research } \\
\text { Question }\end{array}$ & $\begin{array}{l}\text { Survey Items - Statements } 2-20 \\
\text { specific to Anatomy \& Physiology and } \\
\text { same statements } 21-40 \text { specific to } \\
\text { Microbiology }\end{array}$ & $\begin{array}{l}\text { Focus } \\
\text { Questions }\end{array}$ \\
\hline $\begin{array}{l}\text { RQ 1b What are } \\
\text { nursing student } \\
\text { perceptions of the } \\
\text { impact of the Anatomy } \\
\& \text { Physiology and } \\
\text { Microbiology } \\
\text { laboratory on the } \\
\text { transfer of knowledge } \\
\text { to future nursing } \\
\text { practicum } \\
\text { experiences? }\end{array}$ & $\begin{array}{l}\text { 14/34 My A\&P/Micro lab helped me } \\
\text { transition easily into the nursing } \\
\text { program. } \\
\text { 15/35 The A\&P/Micro activities were } \\
\text { practical to my nursing practice. } \\
\text { 16/36 I use the skills gained from my } \\
\text { A\&P/Micro lab experiences in my } \\
\text { nursing practice. } \\
\text { 17/37 My A\&P/Micro lab experiences } \\
\text { accurately represent reality. } \\
\mathbf{1 8 / 3 8} \text { My A\&P/Micro lab experience } \\
\text { has helped me become more proficient } \\
\text { in my nursing practice. } \\
\text { 19/39 My A\&P/Micro experience has } \\
\text { helped me reduce contamination in my } \\
\text { nursing care practice } \\
\mathbf{2 0 / 4 0} \text { My A\&P/Micro lab helped me } \\
\text { explain the disease process to my } \\
\text { patients. }\end{array}$ & $\begin{array}{l}\text { 7. What Anatomy \& Physiology or } \\
\text { Microbiology bioscience lab skills } \\
\text { have been most relevant to you in } \\
\text { your nursing practice? } \\
\mathbf{8} \text { What Anatomy \& Physiology or } \\
\text { Microbiology lab activity has helped } \\
\text { you understand your patient's } \\
\text { medical condition? With patient } \\
\text { education? } \\
\text { 9. In what situations have you ever } \\
\text { worked with patients when you were } \\
\text { reminded of your Anatomy \& } \\
\text { Physiology or Microbiology } \\
\text { bioscience lab? }\end{array}$ \\
\hline
\end{tabular}

RQ 1c Does face to face versus online laboratory delivery format have an impact on nursing student perceptions of the transfer of knowledge to a) nursing courses or b) nursing practicum experiences?

RQ 2 How do demographic factors, such as age, gender, and educational and technological experience impact nursing student perceptions of the online and face-to-face bioscience laboratory and the transfer of knowledge transition to and success in nursing?
Data from survey questions 1-40. Survey will identify participants as having had online or face-to-face lab experiences in Anatomy \& Physiology and/or Microbiology.

Data from demographic information 
Historically, greater than $90 \%$ of nursing students graduating from the program at the research institution pass the nursing board licensure examination, supporting the use of nursing graduate records in this study to represent nursing success. Enrollment records are an established source of data in qualitative studies (Gay et al., chap. 14, 2009) and for this study, were obtained through the institutional information system. Data from archival enrollment and nursing graduation records from 2007 - 2009 were analyzed to determine if there were any differences in the percentage of students who took online and/or fully computer based and face-to-face bioscience laboratory courses and those who successfully completed the program. Data did not include demographic information; therefore, conclusions are limited to a comparison of total enrollment numbers for Anatomy and Physiology and Microbiology in each laboratory teaching format and the number of students graduating.

Group data was analyzed rather than individual tracking. Most students take the biosciences as pre-requisite courses instead of requisite with their nursing courses resulting in a delay in records from enrollment to graduation. The 2007-2009 archival data were not representative of the specific students participating in the survey and focus group components of this study but served to establish a historic trend of students in the program. Anonymity was maintained as no names were associated with the data collected. Confidentiality was assured by myself but could not be guaranteed if participants discussed focus group conversations. Data was secured in locked storage with the researcher having the only access.

\section{Procedure}

A research of science education literature revealed inquiries into technology in science teaching and the debate concerning online and face-to-face instruction. Once the focus of the study to concentrate in the area of bioscience laboratories and nursing education was established, 
the location of the research was chosen. This was done with respect to my geographic location, financial concerns, teaching load, and convenience. The permission to conduct the study

(Appendix H) was sought earlier than considered typical as a professional courtesy and the intent of full disclosure since I was under contract with the institution of the study. As the research was in partial fulfillment of the requirements for a doctoral degree, consultation with my committee chairperson was ongoing.

In preparing the research proposal, a more in depth comprehensive review of the literature added to the body of knowledge. Research questions were refined through the search and the search of literature was refined by the research questions. These questions continued to contribute to the literature review and guide the rest of the study. Participants were identified as representative stakeholders in this research, who would provide an adequate and accessible sample population.

Measure instruments and data sources were considered with an emphasis on triangulation. Survey questionnaires were developed by myself and modified from other studies. Information requested addressed general demographics of the sample as well as questions aimed at student perceptions about learning in online and face-to-face laboratories and perceptions of how the laboratory experiences had an impact on student success in the nursing program courses and performance in the field. A pilot study was implemented in one nursing class to test the survey. Adjustments were made for ease of completion, clarification, and direction. Measures of sampling adequacy revealed the need to eliminate items with no correlation to others. A scree plot and eigenvalues were examined and suggested a five factor solution with the pattern matrix supporting those findings, establishing validity of the instrument (Gay et al., chap. 6, 2009). Internal consistency was determined with Cronbach's Alpha. The development of the survey 
items and statistical analysis of items served as evidence of validity and reliability of the measure and lead to the corrected questionnaire form.

In addition to the student survey, focus questions were developed to specifically align with survey and guiding research questions. Questions were modified from other referred studies with a concerted effort toward the alignment with the questionnaire which strengthened the validity and reliability of the instrument. A pilot focus group was conducted to determine the most appropriate question and wording to direct the conversation without using leading questions and to maintain objectivity. The pilot group also increased my level of comfort in the process. Course enrollment and nursing graduate data was included as a data source to complete the triangulation of data as the design of the study was established.

Multiple adjustments to narrow the focus and direction of the study took place before a prospectus meeting could be scheduled. The study was refined and resulted in clarification of the research questions, reorganization, focus, and direction to guide the work. The process of attaining IRB approval began after committee approval of the proposal. With IRB exemption (Appendix I) and survey instruments finalized, data collection commenced. Archival data specific to the study was requested from the institution with follow-up e-mail communications and reminders. Addressing the logistics of timing and scheduling to meet participants for survey completion took place for each campus location. Three meetings were planned and held for participants to complete survey questionnaires. Cover letters (Appendix J) were distributed and a brief introduction was done at each meeting and included the initial announcement of times and locations of scheduled focus groups. Reminders were also posted at each location.

Preliminary writing and statistical analysis of survey data began during the time surrounding focus group meetings. Quantitative analysis of survey data included mean scores, $t$ - 
tests, and Analysis of Variance (ANOVA). Focus group conversations were taped and written notes were taken at each of three scheduled focus sessions. Conversations were transcribed following each meeting. Focus group data was analyzed to determine if any themes or patterns emerged. Archival data was also analyzed to determine if there was a relationship between bioscience laboratory enrollment and nursing graduation data. At the completion of all data analysis conclusions were drawn with respect to each research question, and the process of dissertation writing was continued to completion of the reporting of the study.

\section{Design of the Study}

I established the focus of the study based on personal experience and practice, literature significance, and current educational research pertaining to the nature of teaching methodology in the sciences. The foundational approach to research design was followed (Gay et al., chap. 4, 2009). The current research design included first and second-year students in the nursing program as participants because they were the main stakeholders in this inquiry. The crosssectional survey study measure was utilized to reveal demographic variables that may impact student success in the laboratory setting in addition to understanding the student's perspectives concerning the laboratory teaching format and its relevance to the learning and success in the program. A second source of data came from focus groups that were conducted to gain an understanding of the issue of the study as students voiced their perspectives.

Triangulation of data sources was further accomplished utilizing archival institutional data and strengthened the validity of the study (Patton, 2002). Enrollment and graduation records from 2007-2009 were analyzed to determine if there was any impact of the instructional laboratory delivery on nursing student success in the program. Specific data included the number of students enrolled in each of the laboratory sections, both online (and/or computer-based) and 
face-to-face. The percentage of nursing students in each was compared to graduation data specific to what laboratory methodology each nursing graduate had taken. This particular data served as evidence of past performance and established a trend of expected performance relative to the method of teaching in the bioscience laboratory and the impact of that method on nursing graduation or success in nursing.

\section{Chapter 4: Results}

The purpose of this study was to analyze nursing student perceptions of teaching methodology of the requisite bioscience laboratory to determine if methodology had an impact on nursing education and practice. After a brief introduction, the study data is presented in sections specific to each research question and includes an analysis of the data obtained from student questionnaires, focus groups, and archival records, with an ending summary segment.

Research question one referenced nursing students' perception of the impact of their bioscience laboratory on the transfer of knowledge to nursing education. Sub-questions 1a and $1 \mathrm{~b}$ were specific to student perceptions of the impact of the bioscience laboratory on the transfer of knowledge to future nursing courses and to future nursing practicum experiences respectively. Data pertinent to sub-question 1c specific to the delivery format were integrated in all survey items as data was reported by respondents who self identified as having been in online or face-toface bioscience laboratory learning environments. The data comparison of the online and face-toface groups is reported with the results of each of the other research questions. Demographic data is presented with respect to research question two that addressed other variables of age, gender, educational, and technical experience and the impact on student perceptions of bioscience laboratories and nursing. 
Analysis of the survey items was accomplished via comparative online and face-to-face group mean scores. A discussion of survey items with the high and low mean scores and standard deviations is followed by comparisons of the online and face-to-face groups through $t$ tests organized by research question. Demographic data was totaled and percents were calculated with analysis via t-tests and ANOVA statistics and significant differences were determined (Gay et al. chap. 13). The focus group data is presented by question and the discussion includes student responses as evidence of research conclusions. The report of archival data supplied by the study institution included student enrollment and graduation data.

\section{Research Question One}

Questionnaire data. Research question one (What are nursing student perceptions concerning the impact of Anatomy \& Physiology and Microbiology bioscience laboratory experiences on the transfer of knowledge to nursing education?) pertained to the impact of the bioscience laboratory on the transfer of knowledge to nursing education. Survey items 1-20 addressed the Anatomy and Physiology laboratory experience and items 21-40 addressed the Microbiology laboratory experience. A comparison of the mean scores of student responses to each item of the student survey was done to compare the student perceived impact of the bioscience laboratory on the transfer of knowledge to nursing education. Table 7 lists mean scores of survey item responses for both laboratory courses and standard deviations grouped by research question, course, and delivery format. 
Table 7

Mean Scores and Standard Deviations from Student Surveys of Online and Face-to-face

Bioscience Laboratories

\begin{tabular}{|c|c|c|c|c|c|c|}
\hline Research Question & Course & $\begin{array}{l}\text { Survey } \\
\text { Item \# }\end{array}$ & $\begin{array}{l}\text { Online } \\
\text { Mean }\end{array}$ & $\begin{array}{l}\text { Online } \\
\text { s.d. }\end{array}$ & $\begin{array}{l}\text { Face-to- } \\
\text { face Mean }\end{array}$ & $\begin{array}{l}\text { Face-to- } \\
\text { face s.d. }\end{array}$ \\
\hline $\begin{array}{l}\text { RQ } 1 \text { What are nursing } \\
\text { student perceptions } \\
\text { concerning the impact of } \\
\text { Anatomy \& Physiology and } \\
\text { Microbiology bioscience } \\
\text { laboratory experiences on the } \\
\text { transfer of knowledge to } \\
\text { nursing education? }\end{array}$ & $\begin{array}{l}\text { Anatomy \& Phys } \\
\text { Micro }\end{array}$ & $21-25$ & 2.74 & .776 & 3.23 & 1.248 \\
\hline $\begin{array}{l}\text { RQ 1a What are nursing } \\
\text { student perceptions of the } \\
\text { impact of the Anatomy \& } \\
\text { Physiology and Microbiology } \\
\text { laboratory on the transfer of } \\
\text { knowledge to future nursing } \\
\text { courses? }\end{array}$ & $\begin{array}{l}\text { Anatomy \& Phys } \\
\text { Micro }\end{array}$ & $27-33$ & 3.00 & .800 & 3.20 & .771 \\
\hline $\begin{array}{l}\text { RQ 1b What are nursing } \\
\text { student perceptions of the } \\
\text { impact of the Anatomy \& } \\
\text { Physiology and Microbiology } \\
\text { laboratory on the transfer of } \\
\text { knowledge to future nursing } \\
\text { practicum experiences? }\end{array}$ & Anatomy \& Phys & $14-20$ & 3.03 & .606 & 3.10 & .748 \\
\hline
\end{tabular}


The mean scores of survey items referring to research question one were higher than the means of items pertaining to the other research questions with two exceptions. Responses from the students having had their Microbiology laboratory online yielded a lower mean score for research question one and the responses of students who had their Anatomy and Physiology laboratory online yielded mean scores that were nearly the same for research question one and research question 1a (transfer to nursing courses). Closer inspection of the item analysis of questionnaire statements revealed that data contributing to each of the survey items with the lowest mean scores were from responses of students who had their laboratory via the online format. Four of the survey items with the lowest mean score of 2.67 align with research question one: Item \#3 (My A\&P lab experiences were as beneficial to my learning as my A\&P lecture), Item \#4 (Learning activities in my A\&P lab helped me construct explanations and/or solutions), Item \#22 (The interpersonal interaction in my Micro lab was beneficial to my success in the course), and Item \#25 (The Micro lab experience helped me understand the concepts of Micro). Students who had their laboratory in a face-to-face setting did not contribute to a mean score below 3.01 for any of the survey items. Item \#6 (The A\&P lab should be required for nursing students taking an A\&P lecture course) of the questionnaire yielded the highest mean score of 3.68 and was also recorded by the students having had the face-to-face laboratory experience. In addition, one of the two highest standard deviations was determined for Item \#6 $(\mathrm{sd}=3.22)$. The analysis of items 2-6 specific to Anatomy and Physiology yielded a mean score of 2.94 for the online student group and 3.31 for the face-to-face student group. Questionnaire items 21-25 that addressed the same research question but were specific to Microbiology yielded a mean score of 2.74 for the online group and 3.23 for the face-to-face group. 
Further data analysis was done to determine if there was a significant difference in the responses of students whether they were in an online or face-to-face bioscience laboratory. The difference in the means between the groups (online and face-to-face) was determined via $t$-tests for pair wise comparisons between the means of student responses to survey items. Significant differences were noted for four of the questionnaire items relative to Anatomy and Physiology with three of those specific to research question one: \#2 (The interpersonal interaction in my A\&P lab was beneficial to my success in the course), \#3 (My A\&P lab experiences were as beneficial to my learning as my A\&P lecture), and \#4 (Learning activities in my A\&P lab helped me construct explanations and/or solutions). The significance of $t$-test analysis of survey items specific to research question one suggests that nursing students perceive the instructional format of the bioscience laboratory experience impacts knowledge capture.

Focus group data. Focus groups were held within a campus classroom with 10 to 20 students present in each of three group meetings. Participants were students who completed questionnaires and chose to continue in the next phase of the study by discussing their educational experiences and sharing personal opinions as they responded to each of the focus questions. Within the familiar setting, most students appeared to feel at ease and freely conversed about their thoughts concerning the biosciences and nursing program. The presentation of data from focus groups is organized by focus questions relative to research question one.

Students were in consensus that the best bioscience laboratory would be a combination of online and face-to-face experiences. Once voiced in the discussions, all participants agreed with the statement and implied that either methodology exclusive of the other was a narrow approach that limited learning possibilities relevant to nursing. Focus group data includes specific student 
responses that reflect the essence of student discussions as prompted by focus questions relative to research question one.

The purpose of the bioscience laboratory. Ultimately, nursing students agreed that the reason for the bioscience laboratory was to reinforce content learning. Even when not all agreed how that was best accomplished there was a consensus that while the "course is only as good as the instructor," "the learning is up to the student." Additional samples of student comments include: "... must do it to reinforce lecture," "nursing starts with these experiences," and "education is what you make of it." A number of responses were specific to the face-to-face laboratory as students expressed their assumptions that "lab is hands on" and "you have to physically do it to understand labs."

Learning specific to subject. Based on responses, students overwhelmingly felt that science and nursing courses were different from other courses. Students said, "Nursing is different" and "You have to have some real lab experience." Many connected the face-to-face experience with concrete learning of science and agreed that "Face-to-face is good for learning structures." What was somewhat surprising to the researcher was that despite whether students had online experiences or not, the group consensus was that "Human experience [imperative to nursing] must be face-to-face." Several students having had both online and face-to-face courses stated that "doing online assignments were a job to get done; then reality is a different focus" and "Micro online lab results didn't make as much sense to me - need to physically see it develop." One student supporting the online laboratory said that "Micro was good online and helped me with the book." The conversation centered on how students thought that learning should be different for different subjects and participants had to be guided to respond to the portion of the focus question that addressed how they thought learning was the same for all subjects. 
Comments were similar to the previous question of the purpose of the bioscience laboratory:

"You have to work or you're not going to get through" and "It's up to you." Fewer responses were made and enthusiasm dwindled as students generally agreed the question had already been covered.

Reasons for scheduling, advantages and disadvantages of each format. Study participants reported that they scheduled for a particular bioscience laboratory section for convenience or reasons pertaining to personal learning preferences. "It was available," "it fit in my schedule," and "it was good for my time restrictions" were comments that reflected convenience as the reason they scheduled online courses. Most students cited a desire for "direct instruction" and "hands on work" as reasons they scheduled face-to-face laboratory sections. Some felt they concentrated better in the face-to-face laboratory and those comments led to further conversation concerning the nature of the face-to-face environment: "I want the instructor there for questions," "There's an entertainment factor to lab. It's not the same thing online," "it's not good to have only ADAM [Anatomy \& Physiology computer program]. It's a tool in conjunction with face-to-face lab," and "I procrastinate if I'm online." Although proponents of the online laboratory reported they initially took the online due to availability and time constraints they also felt there were benefits to the online laboratory: "I got instant results in the online AP lab," "we were able to do more expensive labs," "ADAM lets me see the human dissections," and "I could repeat the assignments." Students began touting the benefits of both learning formats and reached a consensus that "You need a little of both."

Table 8 lists focus questions for research question one. 


\section{Table 8}

Focus Questions Relative to Research Question One

\begin{tabular}{|c|c|}
\hline Research question & Focus question \\
\hline $\begin{array}{l}\text { RQ 1 What are } \\
\text { nursing student } \\
\text { perceptions concerning } \\
\text { the impact of Anatomy } \\
\text { \& Physiology and } \\
\text { Microbiology } \\
\text { bioscience laboratory } \\
\text { experiences on the } \\
\text { transfer of knowledge } \\
\text { to nursing education? }\end{array}$ & $\begin{array}{l}1 \text { What do you think is the purpose of the Anatomy } \\
\& \text { Physiology and Microbiology bioscience lab? } \\
\mathbf{2} \text { How do you think learning is the same for all } \\
\text { subjects and how do you think learning should be } \\
\text { different for different subjects? } \\
\mathbf{3} \text { What factors were important to as you scheduled } \\
\text { for online or face-to-face Anatomy \& Physiology } \\
\text { and Microbiology labs? What are advantages and } \\
\text { disadvantages of each? }\end{array}$ \\
\hline
\end{tabular}




\section{Research Question 1a}

Questionnaire data. Findings presented are relative to research question 1a: What are nursing student perceptions of the impact of Anatomy \& Physiology and Microbiology laboratory experiences on the transfer of knowledge to future nursing courses. A comparison of mean scores of survey items specific to this research question revealed a high mean score for survey Item \#11 (Some nursing knowledge builds on knowledge from my A\&P lab experience) suggesting that students felt the bioscience laboratory aided their transfer of knowledge to nursing courses. Mean scores of survey items for the face-to-face group were higher than the online group for all items that pertained to this research question except for Survey Item \#11 (Some nursing knowledge builds on knowledge from my A\&P lab experience). Responses from students who had their bioscience online and those who had the face-to-face bioscience laboratory yielded the same mean score of 3.33 for survey Item \#11. Regardless of the instructional format of the laboratory, students had the same perceptions concerning this item.

Two of the three items of the student questionnaire that reflected the lowest standard deviation were specific to research question 1a. Survey items with the lowest standard deviation $(\mathrm{sd}=.333)$ were: Items \#32 (There were times in my nursing course when I recalled an experience from my Micro lab) and \#33 (My Micro lab helped me understand the disease processes studied in my nursing courses). Both were from the online student group and indicated very little variance among student responses. The mean scores of the two survey items were considered moderate to moderately high for both students who had the online laboratory format (3.11) and those with the face-to-face teaching format (3.07 for Item \#32 and 3.19 for Item \#33). 
Tests were conducted to determine the difference in the means between the groups (online and face-to-face) for the survey items. Significant $t$-tests were noted for two items related to Microbiology: \#28 (My Micro lab experience helped me understand nursing concepts) and \#33 (My Micro lab helped me understand the disease processes studied in my nursing courses). Survey items with a significant difference in mean comparisons between responses from students who had the online and those who had the face-to-face laboratory sections reflected a greater positive response from the students who had the face-to-face bioscience laboratory.

Focus group data. Discussions concerning research question 1a revealed specific student opinions of the impact of teaching format utilized in the bioscience laboratory. Although the majority of participating students voiced that the face-to-face laboratory experiences were more relevant to their nursing courses and program, there were a few comments made describing benefits of the online laboratory. Students agreed that processing and critical thinking abilities were developed and/or strengthened because of their laboratory experience, and aided their transfer of knowledge to nursing courses.

\section{How laboratory prepared students for current courses and program. Students}

responded to this prompt by citing particular laboratory experiences they felt aided their ability to transfer knowledge specifically to their pharmacology, and medical surgical courses.

"Working with microbes helped me understand pathophysiology," "face-to-face teaches you to work together," "understanding of infection control," and "critical thinking; you need face-toface rather than online" were responses made in support of the face-to-face laboratory.

Simulation laboratory assignments were described as effective learning tools that helped students "understand increasing and decreasing pressures in blood flow and respiration." One online Microbiology student stated that the writing and literature review papers helped her develop 
critical thinking skills important to nursing. Students agreed the face-to-face laboratory experience aided them in their nursing courses, but also noted benefits of technological experiences such as the simulation activities. The suggested need for some of both experiences is a pattern also reflected in the discussions of previous questions.

Ways students reminded of bioscience laboratory while in current courses. Students mentioned several specific laboratory experiences they thought were particularly beneficial to them when they were asked how they were reminded of their bioscience laboratory while in current courses. Conversations consistently diverged from the basic question of when they were reminded of the laboratory, to why and what it meant to them in nursing. Face-to-face experiences discussed were the heart dissection, blood typing, bones, and the eye and kidney dissections in the Anatomy and Physiology face-to-face laboratory, and antibiotic discs, microbial resistance, and hand washing in the face-to-face Microbiology laboratory. Online experiences from the Anatomy and Physiology laboratory that were discussed were pressures, neural impulse transduction, ADAM muscles, and electrolytes. There was consistent and overwhelming support for the face-to-face format but students still voiced a desire to have some online laboratory experiences integrated into their bioscience laboratory course.

Connecting information from bioscience to nursing. Students felt the teaching methodology was important in connecting their bioscience to their nursing as their subsequent discussions corroborated one student's statement that "It does matter if it's face-to-face." They emphatically agreed the overall course should be "based on nursing to help with the nursing content" and again mentioned laboratory experiences that helped them develop critical thinking skills. Some comments related to instances where they connected specific bioscience laboratory experiences to their nursing, such as "pharmacology and the antimicrobial disc lab," taking a 
pulse and feeling veins," and "ADAM is excellent." Students seemed to believe that there was a positive impact of the bioscience laboratory on nursing. Table 9 shows focus questions relevant to research sub-question 1a. 


\section{Table 9}

Focus Questions Relative to Research Question 1 a

\begin{tabular}{ll}
\hline Research question & Focus question \\
\hline RQ 1a What are & 4. How do you perceive your AP and Microbiology \\
nursing student & bioscience laboratory prepared you for your nursing \\
perceptions of the & courses and program? \\
impact of the Anatomy & 5. In what ways have you ever been reminded of \\
\& Physiology and & Anatomy \& Physiology or Microbiology bioscience \\
Microbiology & lab while in your current courses? When? How so? \\
laboratory on the & $\mathbf{6 . ~ H o w ~ d o ~ y o u ~ c o n n e c t ~ i n f o r m a t i o n ~ f r o m ~ b i o s c i e n c e ~}$ \\
transfer of knowledge & courses to nursing? \\
to future nursing & \\
courses? & \\
\hline
\end{tabular}




\section{Research Question 1b}

Questionnaire data. Research question $1 \mathrm{~b}$ asked "what are nursing student perceptions of the impact of the Anatomy \& Physiology and Microbiology laboratory on the transfer of knowledge to future nursing practicum experiences." Mean scores of student responses to survey items relative to this research sub-question were determined, with high mean scores of 3.20 and 3.36 yielded from survey Item \#19 (My A\&P experience has helped me reduce contamination in my nursing care practice.) and Item \#39 (My Micro experience has helped me reduce contamination in my nursing care practice.) respectively. Analysis of student responses to survey Item \# 14 (My A\&P lab helped me transition easily into the nursing program) yielded a low mean score of 2.67. Low mean scores were also yielded by student responses to survey Item \#16 (I use the skills gained from my A\&P lab experiences in my nursing practice) and Item \#17 (My A\&P lab experiences accurately represent reality). Because survey items with two of the highest means scores and items with three of the lowest mean scores were related to research question $1 \mathrm{~b}$ the data was conflicting concerning the students' perspective of whether they thought the bioscience laboratory benefited them in their nursing practice. However, data that contributed to survey items with the high mean scores were recorded from students who had face-to-face laboratory sections and student responses to survey Items \# 14, \#16, and \#17 that yielded the three low mean scores and were all from students who had online bioscience laboratory experiences.

Tests were conducted to determine the difference in the means between the groups (online and face-to-face) for the survey items. A significant $t$-test was noted for survey Item \#14 (My A\&P lab helped me transition easily into the nursing program.). Both the comparison tests of the mean scores for survey Item \#14 and the high and low mean scores previously addressed 
support the suggestion that students who had their laboratory online had a different perception of the impact the Anatomy and Physiology laboratory had on their ease of transition into the nursing program.

Focus group data. The last three focus questions related to the transfer of knowledge to nursing practice and patient care. Students noted that laboratory experiences with microbes aided them with patient education that addressed infection control, wound care, and general contamination. Laboratory content specific to physiologic and disease processes as well as critical thinking skills were thoroughly discussed as imperative to patient education and success in nursing practice. Student responses to focus questions were similar to previous data and presented another perspective of the survey related to the research question. Both face-to-face and online experiences were mentioned as valuable to the students knowledge transfer to the nursing practicum which is consistent with and reflective of the pattern noted earlier that was suggestive of blended face-to-face and online experiences in requisite bioscience laboratories for nursing education.

Laboratory skills relevant to nursing practice. Critical thinking and sterilization were the two skills emphasized during discussions as the most important bioscience laboratory skills necessary and relevant to students in their nursing courses. The consensus was that "critical thinking is sharper in face-to-face" and "nursing is hands on and critical thinking and you need face-to-face lab to do that." One online student however, voiced that she thought the online assignments helped her develop critical thinking skills through the in depth writing that was necessary for research papers [literature review portion] in Microbiology. Most students agreed that you "have to think faster in face-to-face labs and that's important in nursing so you don't freeze up." Sterilization was another topic in the discussion as a skill relevant to nursing: 
"Sterilization; contamination with the patient," "think before you touch anything," and "the Micro lab makes you pay attention in the whole hospital environment." Some responses referred to specific laboratory activities: "the bones [face-to-face] helped in Med. Surg.," "the landmarks for physical assessment," and "feeling veins and pulse." The responses of students concerning contamination were consistent with the survey analysis (survey Items \#19 and \#39). Students were in accord that the bioscience laboratory, and specifically the face-to-face laboratory, had a positive experience for nursing students.

Laboratory activity and patient conditions and education. Responses indicated that students who had a face-to-face bioscience laboratory perceived their experience helped them understand microbes, contamination, antibiotics, and electrolytes so they could explain the medical condition to their patients. Comments were: "working with microbes helped me teach the family the steps of control," "I just had a patient with an infection ... we cultured Gram positive and negative bacteria, the experience stays with you. I could explain" and "testing $\mathrm{pH}$ helped me explain the basics of electrolytes." Other students stated that completing the computer simulated respiration laboratory activity helped them understand pressures and their patient's condition when they said, "I could recognize functions and physiology" and "the respiratory lab on computer was good." One student said the "simulated electrolyte lab helped a lot."

Students reminded of bioscience laboratory while working with patients. Comments to this question all came from students who had the face-to-face bioscience laboratory. The nature of the face-to-face laboratory experience provided many students with sensual memories they connected to working with patients. Most recalled the smell of the Microbiology laboratory and the Anatomy and Physiology dissecting experiences. "A patient had an infection and as soon as I walked in the room, I knew it was bacterial," shared one student. Another said "the 
antimicrobial disc and fungus labs helped when I had a patient with an oozing leg and I remembered the cultures in Petri dishes." Several students noted the microbial sensitivity laboratory when dealing with MRSA (methicillin resistant Staphylococcus aureus) in the hospital. One student said she had a "flash back to AP [Anatomy and Physiology] muscles and tissues when I was doing a dressing assessment" and another said "nursing is a natural extension of AP." Table 10 lists focus questions related to research sub-question $1 \mathrm{~b}$. 
Table 10

Focus Questions Relative to Research Question $1 b$

\begin{tabular}{ll}
\hline Research question & Focus question \\
\hline RQ 1b What are & 7. What Anatomy \& Physiology or Microbiology \\
nursing student & bioscience lab skills have been most relevant to you \\
perceptions of the & in your nursing practice? \\
impact of the Anatomy & $\mathbf{8}$ What Anatomy \& Physiology or Microbiology lab \\
\& Physiology and & activity has helped you understand your patient's \\
Microbiology & medical condition? With patient education? \\
laboratory on the & 9. In what situations have you ever worked with \\
transfer of knowledge & patients when you were reminded of your Anatomy \\
to future nursing & \& Physiology or Microbiology bioscience lab? \\
practicum & \\
experiences? & \\
\hline
\end{tabular}




\section{Research Question Two}

Questionnaire data. Data relative to research question two (How do demographic factors, such as age, gender, and educational and technological experience impact nursing students' perceptions of the online and face-to-face bioscience laboratory and the transfer of knowledge and transition to and success in nursing?) was obtained as surveys were completed by 107 nursing students. Collected demographic data including age, gender, the number of college science courses completed, the number of online science courses completed, the number of online courses completed, and whether the respondent completed each of the bioscience laboratory courses via the online or face-to-face delivery. The demographic data was previously reported (Table 1) under the participant section of chapter three with the online and face-to-face comparisons (research question 1c) made throughout the previous sections specific to research questions one, $1 \mathrm{a}$, and $1 \mathrm{~b}$.

General linear model multivariate tests revealed no between the subject effects that would suggest a relationship among the demographic variables. However, significant $F$ values $(\alpha<$ 0.05) were noted for the number of science laboratory courses a student had and survey items that addressed research question one (Item \#23, My Micro lab experiences were as beneficial to my learning as my Micro lecture) and research question 1a (Item \#11, Some nursing knowledge builds on knowledge from my A\&P lab experience and Item \#33, My Micro lab helped me understand the disease processes studied in my nursing courses).

Significant $F$ values were also noted for the number of online science laboratory courses a student had for two items specific to research question 1a (Items \#8, My A\&P lab experience helped me understand nursing concepts and \# 28, My Micro lab experience helped me understand nursing concepts) and five items specific to research question $1 \mathrm{~b}(\# 20$, My A\&P lab 
helped me explain the disease process to my patients, \#34, My Micro lab helped me transition easily into the nursing program, \#35, The Micro lab activities were practical to my nursing practice, \#36, I use the skills gained from my Micro lab experiences I my nursing practice, and \#40, My Micro lab helped me explain the disease process to my patients). Even though seven of the 10 survey items noted focus on Microbiology rather than Anatomy and Physiology, no pattern was evident linking subject effects of demographic variables and survey items or specific research questions. The effect size for each of the noted items on the questionnaire was quite small with $\mathrm{Eta}^{2}$ values below 0.25 (Table 11) suggesting that any variance can not be accounted for by demographic variables (Field, 2005, chap.15). 
Table 11

Effect Size

\begin{tabular}{|c|c|c|c|c|c|c|c|c|c|c|}
\hline Source & $\mathrm{RQ}$ & $\begin{array}{l}\text { Dependent } \\
\text { Variable }\end{array}$ & $\begin{array}{l}\text { Type III } \\
\text { Sum of } \\
\text { Squares }\end{array}$ & df & $\begin{array}{l}\text { Mean } \\
\text { Square }\end{array}$ & $\mathrm{F}$ & Sig. & $\begin{array}{l}\text { Partial } \\
\text { Eta } \\
\text { Squared }\end{array}$ & $\begin{array}{l}\text { Noncent. } \\
\text { Parameter }\end{array}$ & $\begin{array}{l}\text { Observed } \\
\text { Power(a) }\end{array}$ \\
\hline \multirow[t]{3}{*}{$\begin{array}{l}\text { Numb sci } \\
\text { lab }\end{array}$} & 1 & 23 & 8.747 & 6 & 1.458 & 3.318 & .005 & .175 & 19.911 & .921 \\
\hline & $1 a$ & 11 & 5.696 & 6 & .949 & 2.222 & .048 & .124 & 13.332 & .758 \\
\hline & $1 a$ & 33 & 7.732 & 6 & 1.289 & 3.114 & .008 & .166 & 18.684 & .901 \\
\hline \multirow[t]{7}{*}{$\begin{array}{l}\text { Numb } \\
\text { online sci } \\
\text { lab }\end{array}$} & $1 a$ & 8 & 7.107 & 5 & 1.421 & 2.416 & .042 & .113 & 12.078 & .744 \\
\hline & $1 a$ & 28 & 5.967 & 5 & 1.193 & 2.499 & .036 & .116 & 12.497 & .760 \\
\hline & $1 b$ & 20 & 6.641 & 5 & 1.328 & 2.505 & .035 & .116 & 12.526 & .761 \\
\hline & $1 b$ & 34 & 6.014 & 5 & 1.203 & 2.302 & .051 & .108 & 11.511 & .720 \\
\hline & $1 b$ & 35 & 6.328 & 5 & 1.266 & 2.974 & .015 & .135 & 14.871 & .840 \\
\hline & $1 b$ & 36 & 4.890 & 5 & .978 & 2.345 & .047 & .110 & 11.724 & .729 \\
\hline & $1 b$ & 40 & 5.494 & 5 & 1.099 & 2.382 & .044 & .111 & 11.912 & .737 \\
\hline
\end{tabular}


Due to unequal sample sizes resulting from participants self-selecting into the online and face-to-face groups through scheduling choices, Spearman's rank correlation coefficient was determined in the analysis (Field, 2005, p.129). Positive correlations significant at the 0.05 level were noted for the number of semesters participants had been a student and the number of online courses they had $\left(r_{s}=.21\right)$, the number of science laboratory courses they had and their online Microbiology grouping $\left(r_{s}=.20\right)$, and the number of online courses participants had and the number of online science laboratory courses they had taken $\left(r_{s}=.46\right)$. These correlations were not surprising with the assumptions that the longer a student is enrolled in school, the more courses he or she is likely to take, the more likely the student is to register for courses taught via the online and face-to-face formats, and the more likely the student is to eventually take online science courses.

Focus group data. Research question two focused on the role demographics may have on nursing students' perspectives. There was no specific focus question concerning demographics that asked how students felt their age, gender, educational, or technological experiences impacted their perceptions; therefore, the data for this question was pulled from all focus responses.

The majority of participants $(28 ; 63.6 \%)$ were over the age of 25 with 16 students (36.4\%) who were 18 to 25 years of age. Across the board responses were balanced from the two age groups of students with the possible exception of comments that regarded what they thought must be done for them to achieve success in their registered nursing program. Students over 25 were more vocal than younger students with the following responses: “... must do it to reinforce lecture," "it does matter if it's face-to-face," "Micro was good online and helped me with the 
book," and "you have to have critical thinking in online Micro with the in depth writing and lit research."

Of the 44 participants, six were male and 38 were female. Responses relative to gender and student perceptions of the laboratory on the transfer of knowledge to nursing education, future nursing courses, practicum experiences, and with regard to the bioscience laboratory delivery are presented. Most of the female responses were focused on instruction and communication. Females voiced concerns about the online format meeting their instructional needs with comments such as "I need more direct instruction," "I want the instructor there for questions," "I procrastinate if I'm online," and "Micro online lab results didn't make as much sense to me - need to physically see it develop." Both male and female students commented that "the learning is up to the student" and "education is what you make of it." The males were the students to voice personal responsibilities: "doing online assignments were a job to get done; then reality is a different focus," "I got instant results in the online AP lab," "lab is hands on," "you have to physically do it to understand labs," and "... must do it to reinforce lecture."

A majority of focus group participants (33 students, $75 \%$ ) had experience in three or more college laboratory science courses. Student comments reflected their experience as they connected information and discussed methodologies in the biosciences and other science courses. Shared responses were: "It's best if you combine online and face-to-face,” “... perfect if online and face-to-face," “...teaches you to work together," and "you have to have some real lab experience." These comments were consistent with previous responses suggesting the benefits of the blended online and face-to-face learning experience for requisite bioscience laboratories for nursing. 
Regardless of the laboratory experience students had, including those students with no online educational experience, they were in consensus that the best laboratory scenario would include both teaching methodologies. Respondents who had both format experiences said: "Human experience [imperative to nursing] must be face-to-face," "it's a tool [ADAM] in conjunction with face-to-face," "ADAM is excellent," and "have to think faster in face-to-face labs and that's important in nursing so you don't freeze up." Students with no previous online experience (11 of 44) made comments that reflected some of their concerns: "I want the instructor there for questions," "lab is hands on," "face-to-face teaches you to work together," and "nursing is hands on and critical thinking and you need face-to-face lab to do that."

\section{Archival Data}

Archival data allowed the researcher to compare and contrast bioscience laboratory enrollment and laboratory data of nursing graduates and was pertinent to research questions one, 1a and $1 \mathrm{~b}$, as each question sought the nursing students' perception of the impact of their bioscience laboratory on the transfer of knowledge to nursing education, future nursing courses, and future nursing practicum experiences. Research question 1c was specific to the face-to-face and online laboratory delivery formats, therefore pertinent data to this question has been threaded through the results of previous research questions. Archival data (Table 12) was provided by the Institutional Research Director at the research location. Data was reported for the academic years $2007-2009$. 
Table 12

Archival Data of Bioscience Laboratory Enrollment and Nursing Graduates

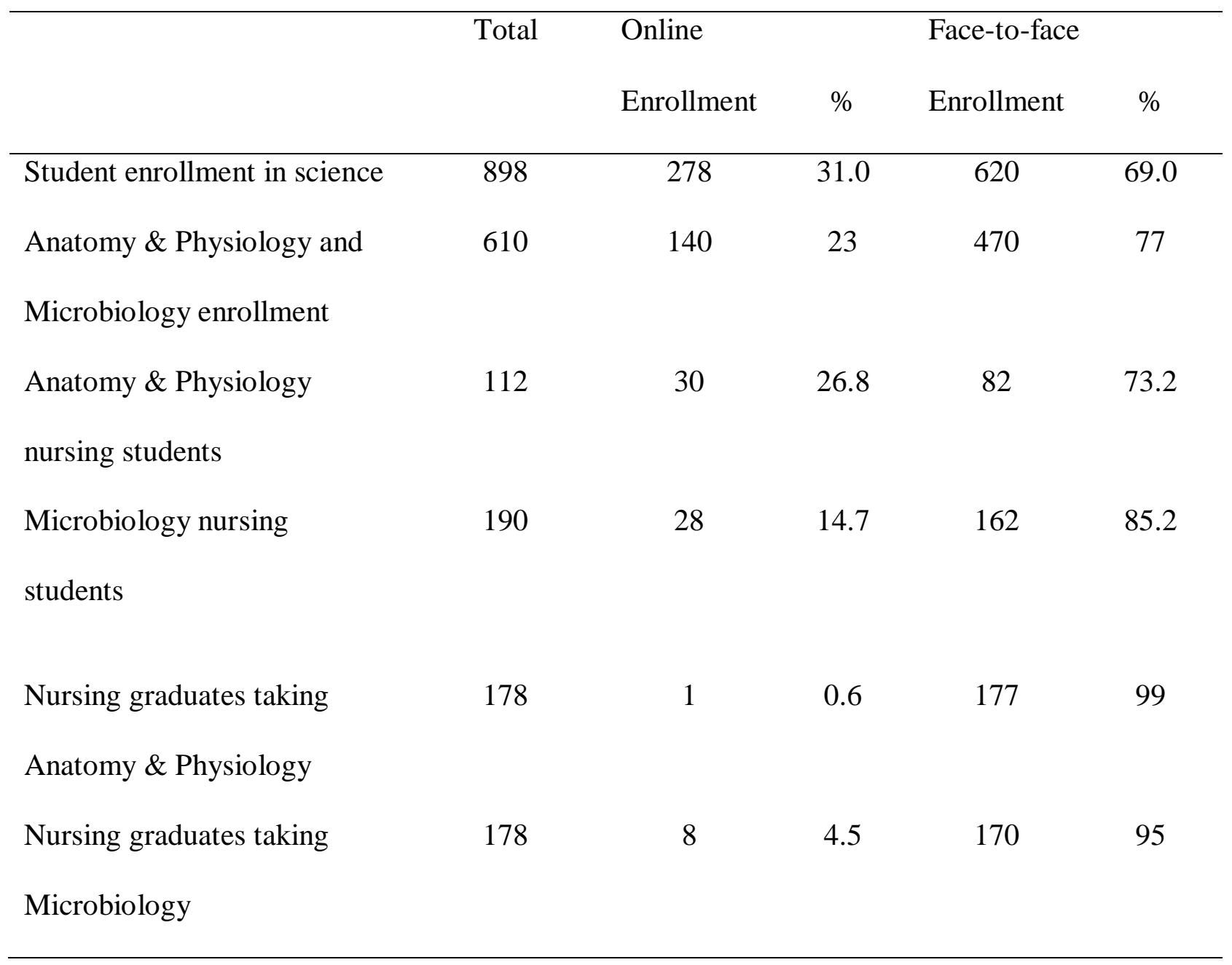

Note. Data supplied by the research institution for the academic years $2007-2009$. 
Approximately $30 \%$ of students who enrolled in science courses, enrolled in online sections at the study institution and approximately $50 \%$ of those students were in the online bioscience laboratory. Of the 112 nursing students who took Anatomy and Physiology during the three designated years, $26.8 \%$ took the online laboratory and $73.2 \%$ scheduled for the face- toface laboratory. Of the 190 nursing students who took Microbiology during the three year period, $14.7 \%$ took the online laboratory and $85.2 \%$ took the face-to-face laboratory. Of the 178 graduate nurses, one student $(0.9 \%)$ took the Anatomy and Physiology laboratory online at the study institution. Eight (4.5\%) of the graduate nurses who took Microbiology had the laboratory online. The data support that fewer graduate nurses chose to enroll in face-to-face bioscience laboratory sections over online sections as compared to other Anatomy and Physiology and Microbiology students and compared to students taking all science courses.

\section{Summary}

Some patterns (Gay et al., chap. 18, 2009) were revealed through analysis of student responses to survey items of the questionnaire and during group discussions. Nursing student responses consistently favored the face-to-face bioscience laboratory over the online laboratory instructional format.

Based on $t$-test analysis, significant differences were noted between the responses of students who had the online course and those who had the face-to-face course, for five survey items related to research question one. Interpersonal interaction, laboratory experience and learning, constructing explanations, course success, and understanding concepts were emergent themes reflecting the value the students seemed to place on content learning and critical thinking. Student responses during conversations regarding research question one encompassed all emergent themes of the study: nursing students favored the face-to-face bioscience laboratory but 
recognized the benefits of a blended methodology and valued the laboratory experience for content learning, critical thinking, and the logistics of the physical learning environment.

Three questionnaire items related to research question 1a (comfort in nursing after laboratory experience and understanding nursing concepts and disease process in nursing) yielded significant differences between responses of students in the two laboratory format groups. Themes relative to content learning, critical thinking, and the value of the physical learning environment are reflective of the three questionnaire statements noted. Emergent themes evident from focus discussions relative to research question 1a were: nursing students favored the face-to-face laboratory delivery, they believed there were benefits of a blended laboratory delivery, and students valued the laboratory experience for content learning, critical thinking, and the physical sensual learning environment.

One survey item determined to be significant related to research question $1 \mathrm{~b}$ (laboratory helped transition into nursing) and reflected the value nursing students seemed to place on the impact of the face-to-face laboratory on content learning, critical thinking, and the physical sensual learning environment. Conversations among students revealed the same themes in addition to their perception that the blended format would provide them the best learning experience.

Students who had a face-to-face bioscience laboratory experience responded more positively to all survey items than students who had the bioscience laboratory via the online format (research question 1c). Based on the typical Likert type scale where strongly agree $=4$ and strongly disagree $=1$, the higher the number, the more positive the student response. The data revealed that nursing students favored the face-to-face bioscience laboratory instructional methodology. The significant survey items noted were consistent with emergent themes 
reflecting the apparent value students placed on content learning, critical thinking and the physical learning environment.

The consistency of the low responses from students having had the online bioscience laboratory experience as compared to the higher survey responses from students with face-toface bioscience laboratory experience suggested that nursing students perceived that not only did the bioscience laboratory impact the transfer of knowledge to nursing education but the instructional format of the bioscience laboratory impacted their nursing education.

Regardless of research variables, students expressed benefits of a blended laboratory methodology. Nursing students perceived their laboratory experience impacted their nursing education with specific regard to the transfer of bioscience content knowledge, the development of critical thinking skills, and their perceived value they placed on the physical, sensual learning environment.

Participants responded relatively positive to all survey items; however students who had their bioscience laboratory online contributed to survey item mean scores that were consistently lower than the item mean scores of respondents who had the face-to-face bioscience laboratory experience for survey items related to all research questions. This indicates that nursing students perceived there was a difference in the impact of the bioscience laboratory experience on the transfer of knowledge to nursing education, nursing courses, and nursing practice, and favored the face-to-face format.

Most of the student responses made during discussions, were overwhelmingly in support of the face-to-face science laboratory experience for nursing education which was specific to research question 1c. Student discussions during focus groups supported the quantitative data that revealed that nursing students perceived that the face-to-face bioscience laboratory 
experience had a positive impact on the transfer of knowledge to nursing education, courses and

practicum experiences. Although the responses from students who had online versus face-to-face laboratory experiences were disproportionate, they were reflective of the disproportionate sample. Regardless of this difference in the number of students in the two groups, there were no negative responses from students in face-to-face bioscience laboratories concerning the teaching methodology as compared to the students in online laboratories who made some negative responses along with the positive ones concerning the teaching format. In addition, many students who verbally identified themselves as having had both online and face-to-face laboratory experiences noted positive aspects of both instructional formats but preferred the faceto-face meeting with the use of some computer based and online experiences supporting a blended delivery format.

Slightly more than $26 \%$ of nursing students took their Anatomy and Physiology online but only $0.6 \%$ of nursing graduates took the course online. Just over $14 \%$ of nursing students took their Microbiology online but only $4.5 \%$ of nursing graduates took the course online. This reflects an $18 \%$ average attrition rate for nursing students in online bioscience laboratories. Since the student numbers and course offerings have been consistent over the study period, I suspect the enrollment and graduation data loosely reflect a trend of less nursing students choosing to schedule for online bioscience laboratory sections compared to other students.

\section{Chapter 5: Discussion and Conclusions}

\section{Introduction}

The biosciences are foundational to nursing education (Clancy et al., 2000; Davis, 2010; Friedel \& Treagust, 2005) and crucial for the nurse to understanding human biological processes and be able to educate their patients about their condition and care. Registered nurses assess, 
plan, implement, and evaluate safe competent nursing care and this requires a thorough education in the biosciences. The purpose of the current study was to analyze nursing student perceptions of the impact of teaching methodology of the requisite bioscience laboratory on nursing education and practice. Research questions guiding the study asked whether the nursing students perceived the bioscience laboratory impacted their transfer of knowledge to nursing education, future nursing courses, and practicum experiences and whether demographic variables had an impact on their perceptions. Triangulation of data was demonstrated via content analysis of questionnaires completed by 107 students, conversational responses of 44 students during focus groups, and institutional enrollment and graduation records.

\section{Discussion and Conclusions}

Research question one. What are nursing student perceptions concerning the impact of Anatomy and Physiology and Microbiology bioscience laboratory experiences on the transfer of knowledge to nursing education? This first research question was the connecting thread to the current research and answering it was the first step in the study. If the laboratory experience itself had no impact, then there would be no reason to proceed further. Results of the current study indicate nursing students perceive their bioscience laboratory experiences have an impact on their nursing education.

Nursing students do perceive their bioscience laboratory is necessary as item analysis of student responses to this questionnaire statement yielded the highest mean scores from both the students who had online laboratory experiences and those who had the face-to-face laboratory experience. Mean scores were lower for the online group in each research question category; however, the greatest distinction in the mean scores was noted with respect to research question one with the four lowest means. Significant $t$-tests of the designated items strengthened the 
findings. Items of particular interest dealt with interpersonal interaction, the benefit of the laboratory experience, and constructing explanations. This reflected previously identified themes revealing the nursing students' perceived value of the bioscience laboratory on content learning, critical thinking, the physical nature of, and their preference for the face-to-face experience.

Focus group data provided further support for the conclusion that the laboratory experience has an impact on the nursing student. Respondents were consistent in their assertions that the bioscience laboratory was important to their nursing education. In accordance with the statistical findings, the discussion points also emphasized nursing students' perceptions consistent with the thematic physical sensual learning environment and their concerns in the areas of instruction and interaction within the laboratory and the nature of specific technical and physical laboratory activities.

Interpersonal interaction and laboratory experiences that were specific to understanding concepts and constructing explanations were concepts of pertinent survey statements relative to research question one that reflected emergent themes of the study: content learning and the logistics of the laboratory instruction. These encompass communication which differs in online versus face-to-face courses in the construction of social meanings (Mantovani, 1996). The findings of Elkan and Robinson (1993) add to the growing evidence of the gap between nursing theory and practice and the importance of biosciences in nursing education. Accountability, team building, and support for one another are important factors in nursing education as the student must prepare for the nursing community service profession. Body language, eye to eye conversations, and emotion are important in forging working relationships and understanding concepts (Hsu and Roth, 2008). All of these can be accomplished through quality face-to-face experiences when aligning these with other course goals and objectives. This socialization into 
the health care environment may be more easily masked in online situations as the online learning experience is often independent and isolated as the student works predominately through the computer.

Situational understanding requires specific personal skills. Participation and cooperation lead to greater cohesion, leadership, and organization (Gardner, 1993). Assessing others mood, temperament, motivations, and intentions are interpersonal skills that have a direct correlation to heath care workers in the field. These skills can be nurtured in education when students participate in apprenticeship type environments (Gardner, 1993) as the teacher facilitates instruction through modeling, demonstrating, and working with students and groups as they learn by practical experience. Learning through experience is not exclusive to facts and discipline content as observation in the classroom has shown us that learning processes include personal relationships which can be built while in the laboratory working shoulder to shoulder (Hsu and Roth, 2008), relationships that depend on and sharpen student interpersonal skills.

Research question 1a. What are nursing student perceptions of the impact of Anatomy and Physiology and Microbiology laboratory experiences on the transfer of knowledge to future nursing courses? The ability to transfer science knowledge to nursing specific content knowledge is necessary for the nursing student. The bioscience laboratory is one component of nursing educational curricula developed to bridge the gap between bioscience and nursing; although, the logistics may vary with the delivery format. Ball et al. (2008) propose that the thinking and reasoning of the student determines how he or she applies the content to program studies. Students were asked what their perceptions were of the impact of their bioscience laboratory on their transfer of knowledge to future nursing courses and the data supports the conclusion that 
students perceive their laboratory experiences have an impact on the transfer of knowledge to future nursing courses.

Mean score comparisons of survey items relevant to research question 1a were the same as item comparisons other research question groupings with face-to-face mean scores that were higher than the online means. The significance of the analysis supports the student perceived impact of the bioscience laboratory on the transfer of knowledge to nursing. The survey item with the highest mean score was related to nursing knowledge from the face-to-face bioscience laboratory experience. Further analysis yielded significant $t$-test scores for survey items related to the laboratory helping students understand nursing concepts and content understanding specific to the disease process. Both items were specific to the Microbiology laboratory. These concepts are specific areas of concern cited by Clancy et al. (2000) and Davis (2010) in their studies concentrating on the gap between theory and practice in nursing education. Results of the current study suggest that the laboratory experience is a possible area of concentration that may lead to narrowing the gap. Consistent themes streaming from data analysis include the nursing students' preference for the face-to-face bioscience laboratory and their perceived impact of the bioscience laboratory on content learning and critical thinking.

Focus group responses contributed to the support of the conclusion drawn concerning research question 1a and were consistent with statistical findings from the questionnaire analysis indicating the bioscience laboratory experience helps nursing students understand concepts and increases their comfort level in nursing. Specific comments made reference to their work with patients and relayed instances where specific laboratories (respiratory to understanding pulmonary pressures, antibiotic resistance, and pharmacology) helped them understand nursing concepts. Once these cognitive schemes are developed they contribute to their later performance 
(Eisner, 1979) in nursing. Themes of focus discussions involved the development of concepts and content knowledge that transfers to nursing and is consistent with those that emerged from the analysis of the survey data.

Research Question 1b. Research question $1 \mathrm{~b}$ asked the nursing students whether they perceived the bioscience laboratory had an impact on their transfer of knowledge to future nursing practicum experiences. Nursing students in face-to-face laboratories are engaged in activities that are similar to what they are expected to face in their future work; bringing them closer to realizing their goal of becoming a health care professional. The findings of the current study support the conclusion that from the students' perspective, the bioscience laboratory impacts them in their nursing practice. This is in alignment with the precept of Dewey's (1900) work that the methodology of instruction should be determined and shaped by the students' perception.

The face-to-face group yielded high means scores in response to both the Anatomy and Physiology and Microbiology survey items that pertained to contamination in nursing care. A significant $t$-test was determined for the questionnaire statement related to the bioscience laboratory aiding student transition into nursing. Conversations during focus groups supported the statistical analysis of survey items. Students stated that the bioscience laboratory helped them develop of critical thinking skills they thought were of primary importance to them in their nursing practice. Several survey items yielded high mean scores from the students who had the face-to-face laboratory and low mean scores from students who had the laboratory online. This may suggest that there is a difference in the students' perceived impact of the laboratory on their nursing practice depending on the instructional format. 
Students voiced their belief in the relevance of specific laboratory experiences to their transition to nursing practice during focus discussions. Experiences they cited were related to patient education, critical thinking, contamination and infection control, and specific content relating to patient care, such as blood, electrolytes, and tissue and wound care. Most of the specific learning experiences cited were face-to-face experiences. The results coincide with the work of Hsu and Roth (2008) who noted the significance of the sensual nature of the science laboratory and the work of Hamza-Lup and Stanescu (2010) who address the challenges this presents to the online format. Both the face-to-face and online experiences were mentioned by students as being valuable to knowledge transfer to the nursing practicum. This is consistent with and reflective of the pattern noted earlier suggesting the benefit of blending the face-to-face and online experiences in requisite bioscience laboratory experiences for nursing students.

In addition to the transfer of specific content knowledge, the nursing student must learn to think critically and function in a crisis situation. These themes coming from the analysis of research question $1 \mathrm{~b}$ are in accordance with those previously stated and translate to the students' function and practice in nursing. Their patients' lives may depend on their ability to quickly and accurately process and assimilate information and respond accordingly. It seems natural to conclude that the earlier students have educational opportunities in which they can begin building this type of action and response skill, the stronger and more practiced they will be when in the field with patients (Eisner, 1979; Granger \& Calleson, 2007; McLachlan et al., 2004). Nurses must interpret what they see, touch, smell, and hear as they assess their patient mentally and physically. Humans are dynamic by nature and just as the scientist engages in normal science as described by Kuhn (1996), the changing patient data must be analyzed and interpreted as nurses problem solve to provide good patient care and instruction and supply accurate 
information to the doctor. Emergent themes evident in the data analysis are consistent with this process foundational to nursing practice.

If science education should reflect real scientific research (National Research Council, 2004; Rudolph, 2002) then along the same line of reasoning, all levels of nursing education with its own scientific foundation should closely reflect nursing practice. Nursing is an applied science. Current results support that nursing students need a thorough and practical educational experience in the bioscience laboratory that will provide them with the foundational knowledge base to aid their transition to nursing practice. Results also provide evidence that the face-to-face laboratory delivery helps students transfer bioscience knowledge to nursing practice. Strengths of both formats were acknowledged by students suggesting that while they perceived the face-toface format was necessary for the bioscience laboratory in nursing education, a blended format was preferred.

Research Question 1c. Does face-to-face versus online laboratory delivery format have an impact on nursing students' perceptions of their transfer of knowledge to a) nursing courses or b) nursing practicum experiences? Results showed that nursing students perceived that their faceto-face bioscience laboratory experience helped them with content learning and learning in their nursing courses and practicum experiences. This indicates that they perceived the face-to-face bioscience laboratory facilitated knowledge transfer to nursing. The conclusion is supported by the analysis of survey data that yielded higher item mean scores from responses of students who had face-to-face bioscience laboratory experiences than item means that were determined from responses of students who had the online laboratory. Data analysis of one survey item yielded equal mean scores for both student groups. That all other survey items had higher mean scores for the face-to-face group than for the online group, is in itself significant in its consistency, if 
not statistically, and reflects that from the nursing students' perspective there is a positive impact of the face-to-face laboratory on nursing education. This is consistent with statements of McLachlan et al. (2004) that cadaver dissections and direct laboratory experiences helped medical students with diagnosis and clinical practice.

Analysis of the data from student surveys also yielded the lowest mean scores for the online group in each of the item groupings relative to the research questions and is further evidence of the impact of the face-to-face bioscience laboratory on the transfer of knowledge to nursing education (research question one), to nursing courses (research question 1a) and nursing practicum experiences (research question 1b). Continued statistical analysis revealed significant $t$-tests of at least one survey item within all research question categories. Results indicate that nursing students perceived there was a distinction between the bioscience laboratory delivery and their transfer of knowledge to nursing; they thought it mattered. Greene (2001) discusses consciousness in connecting knowledge and her theory correlates with the nursing students who attempt to connect their bioscience laboratory experiences with the knowledge they seek.

Conclusions are further supported by focus group discussions, with comments that were overwhelmingly positive concerning the face-to-face experience with no negative responses voiced. Although the group of students who had the online bioscience laboratory experience was small in comparison to those who had the face-to-face laboratory, students were divided in their support of the methodology for the bioscience laboratory specific to their transfer of knowledge to nursing. Most students, whether they had taken the Anatomy and Physiology and/or Microbiology laboratory online or not, had had previous online experience and many had previous online science experience. Regardless of their experience they still preferred not to have the laboratory foundational to their nursing via the online format. Similarly, Science and 
Engineering Indicators (2004) from the National Science Board report revealed that less than $10 \%$ of science students took online courses. Current research subjects expressed much support during discussions for a blended format where they could get the best of both methodologies. This is consistent with the perceptions of students in other science courses as evidenced by Angulo and Bruce (1999) whose participants stated the online was a great supplement but they did not want a fully online course.

Archival data provides relevant insight to research question 1c related to the impact of the instructional format of the bioscience laboratory. Enrollment numbers showed that $23 \%$ of nursing students enrolled in an online bioscience laboratory while less than $5 \%$ of nursing graduates had taken their Microbiology laboratory online and less than $1 \%$ of nursing graduates took their Anatomy and Physiology laboratory online. While there could have been other factors that contributed to the lower percent of nursing graduates who took online laboratory sections, this provides another perspective of student scheduling choices respective of instructional format of the bioscience laboratory. Fewer nursing graduates completing the program chose to schedule for online bioscience laboratory section compared to all nursing students who enrolled in the online sections. Considering the number of general factors that could have contributed to this decrease, the data alone is ambiguous. However, the results are strengthened when combined with the other research components of the study and adds to the body of knowledge concerning the instructional delivery of the bioscience laboratory and nursing education. The National Science Board (“Science and Engineering Indicators,” 2004) addressed the issue of students completing simulated laboratories or at home kitchen laboratories, stating that it will take time to determine if the simulated laboratories will be comparable to conventional laboratories. They also expressed concerns over the assessment of distance education laboratory performance. 
Research question two. How do demographic factors, such as age, gender, and educational and technological experience impact nursing student perceptions of the online and face-to-face bioscience laboratory and the transfer of knowledge and transition to and success in nursing? There were no archival data pertaining to the demographic factors available for the current study; however, statistical analysis showed no significant difference in participant responses due to age or gender. Focus group discussions did reveal some distinctions in how students 25 years or older responded with respect to their concerns about how the online format would impact their learning in preparation for their nursing. Findings are not in line with correlations between online success and age and gender described by Doherty (2006) and Muse (2003), concluding that females and older students are more likely to succeed in online courses.

The statistical findings did not reveal significant differences in participant responses to survey questions and the number of science laboratory courses students had, the number of online courses they had, or the number of online science laboratory courses they had. There were significant $F$ values noted with respect to the number of science laboratory courses a student had and positive item responses; however, the small effect size suggests the variance can not be accounted for by demographic variables and a larger sample size is needed. The Spearman correlation test did reveal positive relationships between the number of semesters a student was in school and the number of online courses he or she had, the number of science courses a student had and the online Microbiology course, and the number of online courses and the number of online sciences courses a student had. This was expected as the longer students are in school, the more opportunities they have to schedule for courses offered with multiple teaching methodologies. It may also be assumed that students who continue to schedule for online courses may eventually take science courses online as well. 
Students learn very differently (Bhargave et al., 2005; Gardner, 2006) and the use of varied modalities in education is sound practice (Cronbach \& Snow, 1977). This may suggest that the course delivery that is best for a student in a particular course is merely a matter of individuality (Harrington \& Laffredo, 2010). Individuals respond differently when looking someone in the eye. Hsu and Roth (2008) discuss the benefits of face-to-face interaction in learning environments and the nuances of body language and responses pertinent to learning. Mantovani (1996) notes the challenges of computer communication and describes distinctive characteristics of the face-to-face interaction and synchronous and asynchronous communication. Focus group responses of the current study support that these concepts may have an impact on guiding nursing education to prepare students for service to the community through their nursing practice. Nursing students stated that they valued the logistics, the physical sensual nature of, and the critical thinking development through the face-to-face laboratory, but that they recognized the benefits of the blended format for the bioscience laboratory. Research results are consistent with the findings of Bliuc, Goodyear and Ellis (2007) in their study of student perceptions of instructional format and blended learning.

Nursing student enrollment records showed that the percentage of nursing students enrolled in the online bioscience laboratory sections and the percentage of nursing students enrolled in face-to-face sections of the bioscience laboratory were much closer than the percentage of nursing graduates who had completed the online laboratory and the percentage of nursing graduates who had completed the face-to-face laboratory course sections. This piece of data supports that successful nursing graduates prefer to schedule for face-to-face bioscience laboratory sections. They perceived that the laboratory delivery would impact their nursing education and success. 
Without specific student tracking, however, archival data can only be interpreted loosely as the totals could include students who did not take their bioscience at the research location and was considered in the limitations of the study. All nursing students are required to take Anatomy and Physiology. There were 66 students who did not take the course at the research institution during the designated three year period. This could easily be explained if the student took their Anatomy and Physiology at another institution or earlier than 2007. Although the archival data may be incomplete with no demographic data reported, it does provide another perspective of the issue. Even with no individual tracking and inconsistent data that does not reflect student emigration and immigration, the comparative numbers lend support for the overall research conclusion that students perceive the instructional methodology of the bioscience laboratory has an impact on nursing student transfer of knowledge to nursing education.

\section{Implications}

Results of the present study revealed that nursing students perceive the bioscience laboratory to be important to their nursing education (research question one). Interdisciplinary dialog among educators may result in a better understanding of each component of the students' educational experiences. This may lead to alterations in instruction or planning to better serve the needs of students while providing them a quality nursing education, relieve student stress, reduce attrition, and mesh the bioscience laboratory experience with nursing.

Several organizations have taken a stance in support of both the use of Internet, webbased, virtual, and simulated online modalities in laboratory instruction and traditional laboratory investigations (National Research Council, 2006; National Science Teachers Association, 2007, 2008). Increased research with pointed emphasis on nursing education may result in clarifying the organizational stance on instructional methodology of bioscience laboratories. 
The National League of Nursing (2006) requires a laboratory component for prerequisite science courses to the program but does not stipulate that the laboratory must be taught in a traditional setting. They have acknowledged online programs of excellence. However, it should be noted that based on a sampling from across the country, programs still require the face-to-face bioscience laboratory experience (Queensborough Community College, 2010; Riverside Community College, 2009; Sacramento State, n.d.; The University of Alabama, n.d.).

From the nursing students' perspective, the bioscience laboratory experience impacts their transfer of knowledge to nursing courses (research question 1a). Curricular changes may be indicated to ensure that the scope of bioscience laboratory course content and experiences reflect the concepts and experiences of students' future nursing courses. The development of a bioscience laboratory course specific for the nursing student may be indicated. Study results indicate that students perceive there is a difference in the type of laboratory experience they have and how they perform in nursing courses; therefore, professionals involved in student counseling should receive thorough information regarding distinctions between the two laboratory methodologies. Based on the findings of this study analyzing student perceptions of instructional format, counseling should include possible implications that student scheduling choices may have on the nursing student in future nursing courses. Bioscience is regarded as a foundational course for nursing and this significance has been the subject of research (Clancy et al., 2000; Davis, 2010; Friedel \& Treagust, 2005). Much of this research however, has not specifically focused on the students' bioscience laboratory experience. The current study suggests the need for further research which may contribute to the body of knowledge and impact nursing education. 
Based on current research findings, nursing students perceive that their bioscience laboratory experience has an impact on their transfer of knowledge to their nursing practice (research question 1b). Therefore, the development of a nursing specific bioscience course may be indicated. Team teaching with nursing faculty may also be indicated in order to provide the student with laboratory activities related to bioscience concepts that are applicable to nursing practice. This type of collaboration was also suggested by Wynne et al, (1997) as a course of action to address the gap between theory and practice in nursing education. Alternatively, institutions may consider staffing a science educator with experience within the allied health community or nursing faculty with concentrated bioscience education.

Specific to research question 1c, results of the current study could potentially impact educators at all levels: national, decision making administrators, those in curriculum development and instructors, as well as the students. Nationally, the trend is to increase all online offerings to include all subject areas within programs. Consequences, particularly in the sciences foundational to nursing at the community college level, should be considered before mandates and political policy and decisions are made. Curriculum specialists and educational leaders need to recognize the significance of pre-nursing and nursing program courses in course offerings, requirements, staffing, and scheduling with specific emphasis on nursing student counseling. Expanding student services specific to pre-nursing and nursing students may help educators address issues pertaining to this unique culture within the community college. The method of instruction and course development should be included as a guiding factor for future course planning and design.

Instructors attempt to see that students get what they need instructionally as well as meet the necessary credit requirements. Schwab (1969a) states that the interaction of teacher, student, 
content and learning environment impacts content capture. Care should be taken while counseling the future and current nursing student with respect to teaching methodology. Individual educational plans should take into account whether the student will have other building opportunities in the sciences or whether they are in a program where time and choices are restricted. Nursing students should be provided with guidelines and/or recommendations made in reference to the bioscience laboratory if choices in instructional methodology are offered.

If the bioscience laboratory is significant to the nursing program but scheduling is strictly personal or even random choice, then the students may be setting themselves up for difficulty or even failure in the nursing program. When viewed through the lens of the nursing student, the face-to-face bioscience laboratory format has a positive impact on the transfer of knowledge to nursing education, nursing courses, and practicum experiences. Study results revealed a consistently higher student preference, though not always significant, for face-to-face laboratories. This indicates the need for close counseling to ensure all nursing and pre-nursing students schedule at least one face-to-face bioscience laboratory section.

There are implications of research findings of the current study relative to nursing education. There is and has been an increase in the number and type of programs that offer fully online degree programs (Allen \& Seaman, 2007, 2008, 2010). Most online degree programs are aimed at continuing education rather than degree programs for the pre-licensed applicant, individuals who do not hold a license to practice nursing. Programs accepting pre-licensed applicants are rare but available and typically with the biosciences listed as prerequisites for application. Disregarding these restrictions, online nursing degrees are increasingly available. This may have an impact on the employment of graduate nurses. Adams, Defleur, and Heald 
(2007) concluded from a national survey of health care administrators that $95 \%$ of employers would prefer applicants with traditional degrees over those with online or partly online degrees for healthcare positions. There is also evidence that nurses do not hold the same respect for other nurses who have online degrees as noted via questionnaire and interview data from the work of Atack (2003). Simpson (2006) goes so far as to question the inferiority of the online degree. Surveys of over $60 \%$ of human resource professionals conclude that “online degrees weren't as credible" when compared to traditional university degrees. These results do not conclude that an online degree is inferior to a traditional degree but rather that the online degree is still perceived as inferior by those making the hiring decisions and even those in the field of nursing.

Student scheduling issues are the predominant implications of the current study resulting from findings specific to demographic factors impacting student perceptions (research question 2). Students are required to take many courses as they pursue a degree in nursing. Their choice of whether to take a basic bioscience laboratory course online or face-to-face, may not seem that important at the time of scheduling, during the course, or even just after completion of the course, but may seem to have significance once students are in their nursing courses. Research findings indicate that the longer students are enrolled in classes and the more online experiences they have had, the more likely they are to take online sciences as well. This is evident in today's technological society as students are being socialized with electronics and computers. Students also evaluate online and face-to-face courses differently (Arbaugh, Bangert \& Cleveland-Innes, 2010) as reflected by their scheduling choices based on their perceptions of the impact of the bioscience laboratory on their nursing education. Concerns about the bioscience online laboratory format expressed by students over the age of 25 may suggest a need to address technology issues specific to the adult learner. The institution, counselors, instructors, and other 
educational leaders should consider curricular adjustments that address the changing and varied needs of the student population.

\section{Future Research}

Future research exploring the perceptions of the practicing registered nurse and nursing educators could contribute to the understanding of the bioscience laboratory for nursing education. Modifications of the study to incorporate quantitative measures of nursing function in respect to methodology comparisons may deepen the understanding of the characteristics and nuances of each bioscience laboratory format. More specifically, the study should incorporate quantitative content and skill assessment measures concerning the face-to-face and online laboratories in biosciences specific to nursing education, similar to Granger and Calleson's (2007) work with the impact of dissections on the performance of medical students.

Additionally, inter-institutional community college comparison studies would broaden the research for more meaningful and generalizable results.

The disproportionate sample sizes between the students who had their laboratory in the face-to-face setting and those students who had the online laboratory may have skewed the findings. Future studies should incorporate methods resulting in a larger proportionate sample. With the continued increase in the utilization of numerous and varied technologies in education, studies should be done that will clarify and distinguish the effectiveness of each methodology. Downing and Holt (2008) summarize existing online designs for a science laboratory and researchers such as Hamza-Lup and Stanescu (2010) have investigated the merits of specific technologies. As technology advances, future research is warranted in the area of assessing student learning of diverse content as new educational technologies evolve. Studies should assess student learning styles and explore other variables that may impact education specific to the 
technical learning environment. Technology has broken the geographic boundaries of the learning environment and enabled the student to access education anywhere, anytime. This suggests future research aimed at multitasking and learning in different learning environments to determine if all environments are conducive to learning.

Demographic data was not available related to student enrollment and nursing graduation records for the current study. Continued research should include individual student tracking throughout the progression in the nursing program to provide a more accurate representation of this data source. A case study should be considered as a viable option to add to the body of knowledge available with respect to the impact of the biosciences on the nursing student. Based on themes emerging from the current study, more research should assess the development of critical thinking, content learning and the physical sensual learning via varied modes of instruction for nursing education with specific emphasis on blended environments. Research should also continue with specific regard to teaching methodology to ensure equity and efficacy.

\section{Summary}

The current research was guided by educational theorists resulting in a process that has personally strengthened my educational foundations and facilitated vast personal and professional growth. The progression through the planning, implementation, and reflection of the research has increased and broadened my level of consciousness (Greene, 2001). New understandings within nursing education and the development of richer meanings arising from examining student perspectives and the process of seeking knowledge have helped me evolve, developing a deeper level of consciousness.

The present study encompasses Schwab's (1969a) commonplaces in education of the teacher, the learner, course and program content, and the learning environment. Findings of the 
study of nursing student perceptions of the impact of the laboratory experience have added to the body of knowledge pertaining to the instructional methodology of the bioscience laboratory in specific conjunction with nursing education. Data support the assertion that nursing students perceive the teaching methodology in the bioscience laboratory has an impact on the transfer of knowledge to nursing education from the teaching institution into health care practice. Results demonstrate the importance of instructional formatting from the nursing students' perspective. The students seek the expertise of the educational institution for guidance. Educators must be responsible in determining what is best for the student rather than responding to innate driving forces such as; ease, comfort or financial consideration.

The findings of Elkan and Robinson (1993) and Friedel and Treagust (2005) supply evidence of the gap between the biosciences and nursing. The current study supports the importance of the bioscience laboratory in bridging that gap as perceived by the students. Freire (1993) focused on the power of the students' involvement in their own learning. Nursing students seemed to understand the importance of the bioscience content and were serious in their intent to gain that knowledge. As presented in this body of work, there exists a diverse range of implementation of the bioscience laboratory (Granger \& Calleson, 2006; Hsu \& Roth, 2008; Kelly et al., 2009; McLachlan et al., 2004). However, results support that the face-to-face instructional format met the educational needs of the nursing students of this study. The data suggest a definite nursing student preference for face-to-face bioscience laboratories as evidenced by enrollment numbers and the positive impact of the face-to-face bioscience laboratory on the transfer of knowledge that lead to student success and graduation.

Physical dissections provided the student the opportunity to see and touch different tissues via cutting experiences and direct tissue and textural comparisons. Laboratories such as 
urine analysis, blood testing and practicing sterile technique while handling microbes are experiences directly related to their health programs. Nursing students may be more prepared to deal with patients if they have been exposed to these and other physical laboratory experiences. In nursing practice the student must have a practical understanding of the biosciences to know what data to collect, what is more important to patient function, what may be happening to the patient (Clancy et al., 2000) and what can wait until the next visit by the doctor and what cannot. Nurses are vital as they assist the doctor in providing total patient care. It stands to reason that the more the nursing student is exposed to physical educational situations incorporated into the nursing curriculum (including the biosciences) the more similar it is to the science of nursing and nursing practice and the more beneficial it is for the nursing student. Students appear to recognize the dynamics of the profession as reflected by the themes that encompass content learning, critical thinking, and the physical learning environment that were presented by the research findings.

Results indicate the need for the face-to-face bioscience laboratory encounter for the nursing student population while suggesting the benefits of a blended learning environment incorporating quality face-to-face and online experiences (Kim, 2006). If science education should reflect the work of science (Kuhn, 1996; Rudolph, 2002) then quality nursing education, including foundational biosciences, should reflect nursing practice which supports a blended methodology. Cognitive schemes (Eisner, 1979) imperative to the profession of nursing are established within the nursing students educational experience. A quality education for the nursing student must provide them with opportunities within the pre-nursing and nursing program, to develop the intellectual and professional schemes as well as the physical tools that will shape their future and ensure the best possible care for their patients. 
Research has provided significant findings touting the benefits of both online and face-toface laboratory methodologies (Bhargava et al., 2005; Hamza-Lup \& Stanescu, 2010; Hsu \& Roth, 2008; Stuckey-Mickell \& Stuckey-Danner, 2007). The best case scenario would incorporate both face-to-face and online methodology (Ginns \& Ellis, 2007) in bioscience laboratory instruction for nursing students. This is supported by the current data with focus group consensus that regardless of student choice of learning format, all participants agreed that a combination of both methodologies would be best for nursing education. Bliuc, Goodyear and Ellis (2007) found similar results in their work concerning blended learning and student perceptions of instructional methodology. There is not just one teaching method that is best for all students (Cronbach \& Snow, 1977).

Evidenced by the student perspectives of their nursing education presented in this work, the bioscience laboratory instructional methodology should foster the development of critical thinking skills and content learning while providing physical sensual experiences directly linking to their nursing courses and practice. Particularly because this issue is strewn with mixed messages, the consequences of the choices made by both consumers and producers of nursing education concerning the format of course delivery must continue to be investigated. 


\section{References}

Adams, J., DeFleur, M. \& Heald, G. (2007). The acceptability of credentials earned online for obtaining employment in the health care professions. Communication Education, 56(3), 292-307. doi:10.1080/03634520701344959

Allen, I., \& Seaman, J. (2007). Online Nation: Five years of growth in online learning. Needham, MA: The Sloan Consortium. Retrieved from http://www.sloanconsortium.org/sites/default/files/online_nation.pdf

Allen, I., \& Seaman, J. (2008). Staying the course: Online education in the United States, 2008. Needham, MA: The Sloan Consortium. Retrieved from http://www.sloanc.org/publications/survey/staying_course

Allen, I., \& Seaman, J. (2010). Learning on Demand: Online Education in the United States, 2009. Needham, MA: The Sloan Consortium. Retrieved from http://www.sloanconsortium.org/publications/survey/pdf/learningondemand.pdf

Angulo, A., \& Bruce, M. (1999). Student Perceptions of Supplemental Web-Based Instruction. Innovative Higher Education. 24(2). 105-125.

Arbaugh, J., Bangert, A. \& Cleveland-Innes, M. (2010). Subject matter effects and the Community of Inquiry (CoI) framework: An exploratory study. Internet and Higher Education. 13(1-2), 37-44. doi:10.1016/j.iheduc.2009.10.006

Atack, L (2003). Becoming a web-based learner: registered nurses' experiences. Journal of Advanced Nursing, 44(3), 289-297.

Ball, D., Thames, M., \& Phelps, G. (2008). Content knowledge for teaching: What makes it special? Journal of Teacher Education. 69(5). 389-407. doi: 10.1177/0022487108324554 
Ballon, B., Silver, I. (2004). Context is key: an interactive experiential and content frame game. Medical Teacher, 26(6), 525-528. doi: 10.1080/01421590412331282282

Barab, S., Scott, B., Siyahhan, S., Goldstone, R., Ingram-Goble, A., Zuiker, S. et al. (2009). Transformational Play as a Curricular Scaffold: Using Videogames to Support Science Education. Journal of Science Education Technology, 18(4), 305-320. doi: $10.1007 / \mathrm{s} 10956-009-9171-5$

Bell, J. (1999). The Biology Labs On-Line Project: Producing Educational Simulations That Promote Active Learning. Interactive Multimedia Electronic Journal of Computer Enhanced Learning. 1(2). Retrieved from http://imej.wfu.edu/Articles/1999/2/01/index.asp

Bhargava, P., Antonakakis, J., Cunningham, C., \& Zehnder, A (2005). Web-based Virtual Torsion Laboratory. Computer Applications I Engineering Education. 14(1), 1-8.

Bliuc, A., Goodyear, P., \& Ellis, R. (2007). Research focus and methodological choices in studies into students' experiences of blended learning in higher education. Internet and Higher Education, 10(4), 231-244. doi: 10.1016/j.iheduc.2007.08.001

Bright, N. (2009, October 12). The Evolution of Distance Learning. Retrieved from http://ezinearticles.com/?The-Evolution-of-Distance-Learning\&id=3074063

Brown, K. (2009, July 26). The Incredible Shrinking Steel Industry. West Virginia Public Broadcasting. Retrieved from http://www.wvpubcast.org/newsarticle.aspx?id=10537

Clancy, J., McVicar, A., \& Bird, D. (2000). Getting it right? An exploration of issues relating to the biological sciences in nurse education and nursing practice. Journal of Advanced Nursing, 32(6), 1522-1532. 
Cote', J., \& Levine, C. (2000). Attitude Versus Aptitude: Is Intelligence or Motivation More Important for Positive Higher-Educational Outcomes?. Journal of Adolescent Research. 15(1). 58-80. doi: 10.1177/0743558400151004

Cronbach, L., Snow, R. (1977). Aptitudes and instructional methods: A handbook for research on interaction. New York, NY: Irvington

Davis, G. (2010). What is provided and what the registered nurse needs - Bioscience learning through the pre-registration curriculum. Nurse Education Today, 30(8), 707-712. doi: 10.1016/j.nedt.2010.01.008

Dewey, J. (1900). The School and Society. Chicago, IL: The University of Chicago Press.

Dewey, J. (1897). "My pedagogic creed”. The School Journal, 54(3), 77-80. Retrieved from http://dewey.pragmatism.org/creed.htm

Diaz, S., Swan, K., Ice, P., \& Kupczynski, L., (2010). Student ratings of the importance of survey items, multiplicative factor analysis, and the validity of the community of inquiry survey. Internet and Higher Education, 13(1-2), 22-30. doi: 10.1016/j.iheduc.2009.11.004

Dillon, S. (2006, October 20). No Test Tubes? Debate on Virtual Science Classes. The New York Times. Retrieved from http://www.nytimes.com/2006/10/20/education/20online.html?_r=1\&oref=slogin

Doherty, W. (2006). An analysis of multiple factors affecting retention in Web-based community college courses. Internet and Higher Education, 9(4). 245-255. doi: 10.1016/j.iheduc.2006.08.004

Downing, K., \& Holtz, J. (2008). Online Science Learning: Best Practices and Technologies. Hershey, PA: Information Science 
Eisner, E. (1979). The educational imagination: on the design and evaluation of school programs $\left(3^{\text {rd }}\right.$ ed.). Upper Saddle River, NJ: Pearson Education

Elkan, R. \& Robinson, J. (1993). Project 2000: The gap between theory and practice. Nurse Education Today, 13 (4), 295-298.

Field, A. (2005). Discovering Statistics Using SPSS (2 ${ }^{\text {nd }}$ edition). Thousand Oaks, CA: SAGE Freire, P. (1993). Pedagogy of the oppressed. In D.J. Flinders, S. J. Thornton (Ed.), The Curriculum Studies Reader, (3 ${ }^{\text {rd }}$ ed.). (pp.147-154). New York, NY: Routledge.

Friedel, J., \& Treagust, D. (2005). Learning bioscience in nursing education: Perceptions of the intended and the prescribed curriculum. Learning in Health and Social Care, 4(4), 203216. doi: 10.1111/j.1473-6861.2005.00104.x

Gardner, H. (1993). Multiple Intelligences: The Theory in Practice. New York, NY: Basic Books.

Gardner, H. (2006). Multiple Intelligences: New Horizons. New York, NY: Basic Books.

Gay, L., Mills, G., \& Airasian, P. (2009). Educational Research: Competencies for Analysis and Applications ( $9^{\text {th }}$ edition). Upper Saddle River, NJ: Prentice-Hall

Ginns, P., Ellis, R. (2007). Quality in blended learning: Exploring the relationships between online and face-to-face teaching and learning. 10(1), 53-64. doi: 10.1016j.iheduc.2006.10.003

Giroux, Henry. (1988). Teachers as Transformative Intellectuals: Toward a Critical Pedagogy of Learning. Westport, CT: Bergin \& Garvey Publishers

Granger, N. \& Calleson, D. (2007). The Impact of Alternating Dissection on Student Performance in a Medical Anatomy Course: Are Dissection Videos an Effective 
Substitute for Actual Dissection?. Clinical Anatomy, 20(3), 315-321. doi:

10.1002/ca.20359

Greene, M. (2001). Variations On a Blue Guitar: The Lincoln Center Institute Lectures on Aesthetic Education. New York, NY: Teachers College Press.

Gresty, K., \& Cotton, D. (2003). Supporting biosciences in the nursing curriculum: development and evaluation of an online resource. Journal of Advanced Nursing, 44(4), 339-349. doi: 10.1046/j.0309-2402.2003.02813x

Haavind, S., Rose, R., Galvis, A. \& Tinker, R. (2002). Online Courses That Work...and some That Don't. The Concord Consortium Newsletter, 6(1), 1-3. Retrieved from http://www.concord.org/publications/newsletter/2002winter/online_courses.html

Hamza-Lup, F. \& Stanescu, I. (2010). The haptic paradigm in education: Challenges and case studies. Internet and Higher Education, 13(1-2), 78-81. doi:

10.1016/j.iheduc.2009.12.004

Harasim, L. (2000). Shift happens: Online Education as a New Paradigm for Learning. Internet and Higher Education, 3(1-2), 41-61. doi: 10.1016/S1096-7516(00)00032-4

Harrington, R. \& Loffredo, D. (2010). MBTI personality type and other factors that relate to preference for online versus face-to-face instruction. Internet and Higher Education. 13(1-2), 89-95. doi: 10.1016/j.iheduc.2009.11.006

Hirumi, A., \& Bermudez, A. (1996). Interactivity, distance education, and instructional systems design converge on the information superhighway. Journal of Research on Computing in Education. 29(1), 1-16.

Hopper, K., \& Hendricks, R. (2008). Technology Integration in the College Classroom: A Baker's Dozen Frugal but Promising Strategies. Educational Technology, 48(5), 10-17. 
Retrieved from http://www.spsu.edu/htc/hopper/KBH_home/KBHHendricks_Bdozen.pdf

Hsu, P-L., \& Roth, W-M. (2008). Lab technicians and high school student interns - Who is scaffolding whom?: On forms of emergent expertise. Science Education, 93(1), 109-130. doi: $10.1002 /$ sce.20289

Illich, I. (1972). Deschooling Society. Retrieved from http://www.preservenet.com/theory/Illich/Deschooling/chap6.html

Jairath, N., \& Mills, M. (2006). Online health science education: Development \& implementation. Philadelphia, PA: Lippincott, Williams \& Wilkins.

Jette, S., Tribble, D., Gagnon, J., \& Mathieu, L. (2010). Nursing students' perceptions of their resources toward the development competencies in nursing informatics. Nurse Education, 30(8), 742-746. doi: 10.1016/j.nedt.2010.01.016

Johnson, M. (2002). Introductory Biology Online. Journal of College Science Teaching. 31(5), 312-317.

Jordan, S. \& Reid, K. (1997). The biological sciences in nursing: an empirical paper reporting on the applications of physiology to nursing care. Journal of Advanced Nursing, 26(1), 169179. doi: 10.1046/j.1365-2648.1997.1997026169.x

Kariya, S. (2003). Online Education Expands and Evolves. IEEE Spectrum, 4(5), 49-51.

Kearsley, G. (2008). Preparing Engineering Faculty to Teach Online. Educational Technology, 48(5), 28-33.

Keller, H. (2008, May 5). Science Labs: Virtual Versus Simulated. T.H.E. Journal. Retrieved from http://www.thejournal.com/articles/22548 
Kelly, M., Lyng, C., McGrath, M., \& Cannon, G., (2009). A multi-method study to determine the effectiveness of, and student attitudes to, online instructional videos for teaching clinical nursing skills. Nurse Education Today, 29(3), 292-300. doi:10.1016/jnedt.2008.09.004

Kerr, M.S., Rynearson, K., \& Kerr, M.C., (2006). Student characteristics for online learning success. Internet and Higher Education, 9(1), 91-105. doi: 10.1016/j.iheduc.2006.03.002

Kim, K., Curtis, B. (2006). The Future of Online Teaching and Learning in Higher Education: The Survey Says . ... Educause Quarterly Magazine, 29(4), 22-30. Retrieved from http://net.educause.edu/ir/library/pdf/eqm0644.pdf

Kuhn, T. (1996). The Structure of Scientific Revolutions ( $3^{\text {rd }}$ ed.). Chicago, IL: The University of Chicago Press.

Lords, E. (1999). 2 Years or 4? The question splits nursing education. Chronicle of Higher Education, 46(5), A55. Retrieved from http://chronicle.com.www.libproxy.wvu.edu/article/2-Years-or-4-The-Question-/12982/

Mantovani, G. (1996). Social Context in HCI: A new framework for mental models, cooperation and communication. Cognitive Science: A multidisciplinary Journal, 20(2), 237-296. doi:10.12007s15516709 $\operatorname{cog} 2002 \_3$

McConville, S., \& Lane, A. (2006). Using on-line video clips to enhance self-efficacy toward dealing with difficult situations among nursing students. Nurse Education Today, 26(3), 200-208. doi:10.1016/j.nedt.2005.09.024

McLachlan, J., Bligh, J., Bradley, P., \& Searly, J. (2004). Teaching anatomy without cadavers. Medical Education, 38(4), 418-424.

Meyer, K. (2007). Student Perceptions of Face-to-Face and Online Discussions. Journal of Distance Learning Administration, 11(4), 43-48. 
Mickle, J. \& Aune, P. (2008). Development of a Laboratory Course in Nonmajors General Biology for Distance Education. Journal of College Science Teaching, 37(5), 35-39.

Monko, A. (n.d.) Online Adult Education: A Look Back to the Future. Retrieved from http://www.allonlineschools.com/online-education-resource-center/history-onlineeducation/

Morris, L. \& Wu, S. (2005). Predicting Retention in Online General Education Courses. American Journal of Distance Education, 19(1), 23-36. Retrieved from http://web.ebscohost.com.www.libproxy.wvu.edu/ehost/pdfviewer/pdfviewer?hid=113\&s id=1a810848-ebf4-4d8f-ac45-e0518a92f1bf\%40sessionmgr111\&vid=48

Mullen, G., Tallent-Runnels, M. (2006). Student outcomes and perceptions of instructors' demands and support in online and traditional classrooms. Internet and Higher Education, 9(4), 257-266. doi: 10.1016/j.iheduc.2006.08.005

Muse, H. (2003). The Web-based community college student: An examination of factors that lead to success and risk. The Internet and Higher Education, 6(3), 241-261. doi:10.1016/S1096-7516(03)00044-7

National League of Nursing (2006). A guide to state-approved schools of nursing RN. (58 ${ }^{\text {th }}$ ed.) New York, NY: NLN Publications

National Research Council (NRC). (2004). Inquiry and the National Science Education Standards: A Guide for Teaching and Learning. Washington, DC: National Academy Press

National Research Council (NRC). (2006). America's Lab Report: Investigation in High School Science. Washington, DC: National Academy Press 
National Science Teachers Association (NSTA). 2007. NSTA Position Statement: The Integral Role of Laboratory Investigations in Science Instruction. Retrieved from www.nsta.org/about/positions/laboratory.aspx

National Science Teachers Association (NSTA).2008. NSTA Position Statement: The Role of ELearning in Science Education. Retrieved from www.nsta.org/about/positions/elearning.aspx

O’Neil, C., \& Fisher, C. (2008). Should I take this course online? Journal of Nursing Education, 47(2), 53-58.

Oosting, J. (2009, July 14). Full text of President Barack Obama’s “American Graduation Initiative" speech in Warren. Metrotimes. Retrieved from http://www.mlive.com/news/detroit/index.ssf/2009/07/full_text_of_president_barack.htm 1

Palmer, P. (1993). To know as we are known: education as a spiritual journey. New York, NY: HarperCollins

Parker, A. (1999). A Study of Variables That Predict Dropout from Distance Education, Internaltion Journal of Educational Technology 1(2), 1-10. Retrieved from http://www.ed.uiuc.edu.www.libproxy.wvu.edu/ijet/v1n2/parker/index.html

Parsad, B. \& Lewis, L. (2008, December 30). Distance Education at Degree-Granting Postsecondary Institutions: 2006-07. National Center for Educational Statistics. Retrieved from http://nces.ed.gov/fastfacts/display.asp?id=80

Patton, M. (2002). Qualitative Research \& Evaluation Methods. Thousand Oaks, CA: Sage Publications 
Queensborough Community College (2010). Queensborough Community College Catalog.

Retrieved from http://www.qcc.cuny.edu

Ramage, T. (2002). The "No Significant Difference" Phenomenon: A Literature Review. Dr.

Thomas R. Ramage Publications, Paper 1. Retrieved from

http://spark.parkland.edu/cgi/viewcontent.cgi?article=1000\&context=ramage_pubs

Riverside Community College (2009). Riverside Community College Catalog. Retrieved from http://www.rcc.edu

Roblyer, M. \& Ekhaml, L. (2000). How Interactive Are Your Distance Courses? A Rubric for Assessing Interaction in Distance Learning. Journal of Distance Learning Administration, 3(2). Retrieved from http://www.westga.edu/ distance/ojdla/summer32/roblyer32.pdf

Rodriguez, J., Ortiz, I. \& Dvorsky, E. (2006). Introducing Evolution Using Online Activities in a Nonmajor Biology Course. Journal of College Science Teaching, 35(6), 31-35.

Rudolph, J. (2002). Scientists in the Classroom: The Cold War Reconstruction of American Science Education. New York, NY: Palgrave

Sacramento State (n.d.). Division of Nursing Bachelor of Science in Nursing Prerequisite and Corequisite Courses. Retrieved from http://www.csus.edu/HHS/NRS/undergraduate/traditional/docs/req_prereq_coreq.pdf

Sadler, T., \& Fowler, S. (2006). A Threshold Model of Content Knowledge Transfer for Socioscientific Argumentation. Science Education, 90(6), 986-1004. doi: $10.1002 /$ sce. 20165

Saint Louis Community College (2010). Saint Louis Community College Catalog. Retrieved from http://www.stlcc.edu 
Schwab, J. (1969a). The Practical: A language for curriculum. School Review, 78(1), 1-23. Retrieved from http://www.eric.ed.gov/PDFS/ED038332.pdf

Science and Engineering Indicators 2004. (2004, May 4). National Science Board. Retrieved from http://www.nsf.gov/statistics/seind04/c2/c2s1.htm

Simpson, R. (2006). See the Future of Distance Education. [Electronic Version], Nursing Management, 37(2), 42-51.

Smith, G., Heindel, A. \& Torrez-Ayala, A. (2008). E-Learning commodity or community: Disciplinary differences between online courses. Internet and Higher Education, 11(3-4), 152-159. doi: 10.1016/j.iheduc.2008.06.008

Stuckey-Mickell, T. \& Stuckey-Danner, B. (2007). Virtual Labs in the Online Biology Courses: Student Perceptions of Effectiveness and Usability. MERLOT Journal of Online Learning and Teaching. 3(2), 105-111.

The University of Alabama (n.d.). RN Options - Capstone College of Nursing. Retrieved from http://academicoutreach.ua.edu/page.cfm?page=degrees\&sub_page=3\&degree_no=2 Tyler, R. (1949). Basic Principles of Curriculum and Instruction. Chicago, IL: University of Chicago Press.

U.S. Department of Education. Institute of Education Sciences, National Center for Education Statistics. (2002). Nontraditional Undergraduates (NCES 2002-012). Washington, DC: Choy. Retrieved from http://nces.ed.gov/programs/coe/2002/analyses/nontraditional/index.asp University of Maryland Baltimore County (2006). Undergraduate FAQS. Retrieved from http://www.umbc.edu/biosci/undergrad/faqs.php 
Wynne, N., Brand, S., \& Smith, R. (1997). Incomplete holism in pre-registration nurse education: the position of the biological sciences. Journal of Advanced Nursing, 26(3), $470-474$.

Young, A., Norgard, C. (2006). Assessing the quality of online courses from the students' perspective. Internet of Higher Education, 9(2), 107-115.

doi:10.1016/j.iheduc.2006.03.001

Zakon, R. (n.d.). Hobbes Internet Timeline. Retrieved from http://www.zakon.org/robert/internet/timeline/ 
Appendix A

Online Microbiology Syllabus Sample

Course objectives beyond scientific content:

- 1 . introduce the student to electronic communication and information storage/retrieval (EMail, WebCT, Internet).

- 2. encourage the students to develop skills applicable to technology, electronic communication, and information storage/retrieval.

- 3. emphasize the development of student critical thinking and writing skills in the study of microbiology (applicable to all other disciplines and life too).

- 4. explore some of the moral and ethical questions facing students in the health sciences in the context of our global community.

\section{COURSE REQUIREMENTS:}

1) Blackboard Vista Bulletin Board: Students will participate in a Blackboard Bulletin Board on __ This conference will include 4 topics posted by the instructor. Students will be responsible for posting an initial response on each topic, will participate in debate and discussion using the Blackboard Bulletin Board, and will post a final response or conclusion on each topic. Specific directions may be added as the conference develops.

2) Written Assignments: Various written assignments will be made throughout the semester. Some of these assignments will require doing an experiment (Winogradsky Columns, See What Grows); all will require research and study.

3) Group Project: Students will be divided into groups (size will depend upon enrollment). Each group will select a topic from the list provided by the instructor for research. All members of the group must participate. At the conclusion of the project, both a statement of findings and a summary of conclusions will be presented to the class. Presentation format is open: presentation by recorded electronic means, presentation in real time by electronic means, or presentation via video. All projects will be used by all students to learn about the topics assigned.

4) Exams: Self-explanatory - these are tests! Specific information to be covered and expectations of student performance on exams will be communicated to students at least 2 weeks prior to the examination period.

5) Final Course Evaluation: Each student will be responsible for turning in a written course evaluation, including an assessment of the learning environment, the technological tools used, the content and pace of the course, and the student's suggestions for revisions and improvements. 


\section{Tentative Schedule}

\begin{tabular}{|l|l|l|l|}
\hline Week & Topics & Lab Outline & Chapter \\
\hline 1 & Introduction and Overview & 1 & Intro,1,2 \\
\hline \hline & Enabling Computer Skills & handouts/URLs & \\
\hline 3 & Snabling Computer Skills & handouts/URLs & \\
\hline 3 & Structure/Function Prokaryotes & 2 & 3 \\
\hline 4 & $\begin{array}{l}\text { Structure/Function Prokaryotes } \\
\text { Chakaryotic Growth Requirements and }\end{array}$ & 2 & \\
\hline 5 & Growth and Reproduction & 3 & 3 \\
\hline 6 & Bacterial Metabolism and Genetics & 3 & 4 \\
\hline
\end{tabular}

Note: Lecture Outlines are available on the WWW. They are accessible from my homepage by following the links labeled Microbiology 117 Resources, or by direct access at On the Micro 117 Resource page there are other links to information on technology and course content. Recent lecture Smartboard presentations are also available at . Additional lecture information can be found at 


\section{Appendix B}

\section{Face-to-face Microbiology Syllabus Sample}

\section{METHODOLOGY:}

The lab portion uses a hands-on approach. This includes the use of microscopes, learning and using aseptic technique, transferring bacteria and noting test results, etc. Lab tests may use projected images of material, microscopes and test results, as well as short answer and objective questions about content learned in the lab. There will be a minimum of one unknown during the semester. A group lab project is required. Participation points are earned in most labs.

Some lab points are based on participation and performance (lab weeks excluded: first, unknowns, and tests), therefore lab attendance is mandatory. If a student is absent from the lab, he/she cannot earn participation points for that lab.

The following list of course outcomes will be achieved at the successful completion of the course. Only the outcomes specific to the face-to-face laboratory are listed.

5. Investigate the growth and control of microbes in the laboratory.

6. Perform common lab tests.

\section{Partial LAB SCHEDULE MICROBIOLOGY}

\begin{tabular}{|l|l|l|l|l|}
\hline WEEK & TOPIC & CHAP & LAB TOPIC & EXERCISE \\
\hline 1 & Intro to Micro & 1 & Intro to Microscopes & 1,2 \\
\hline 2 & $\begin{array}{l}\text { Structure/Function } \\
\text { Prokaryotes, Eukar. }\end{array}$ & 3 & $\begin{array}{l}\text { Sci Meth, Asep Tech, } \\
\text { Transfer, Simple Staining }\end{array}$ & $3,4,5,7$ \\
\hline 3 & Prokaryotic Growth & 4 & Neg, Acid Stain & 6,8 \\
\hline 4 & Control of Microbial Growth & 5 & Endospore, Capsule Stains & 9 \\
\hline 5 & $\begin{array}{l}\text { TEST 1 } \\
\text { Metabolism }\end{array}$ & 6 & Dilution, Sp. Media & 11,12 \\
\hline 6 & $\begin{array}{l}\text { Metab., Blueprint, DNA to } \\
\text { Protein }\end{array}$ & 6,7 & Morphologic Unknown & 10 \\
\hline
\end{tabular}




\section{PROJECT DEADLINES}

WEEK

$3 \quad$ Solidify groups

$6 \quad$ Paragraph summary of design

8 Turn in finalized design procedure

12 Last day to conduct experiments in lab

15 Presentation / report submission 


\section{Appendix C}

Online Anatomy and Physiology (2 $2^{\text {nd }}$ semester $)$ Syllabus Sample

The online lab requires computer access for required physiology modules and links to interactive sites and materials. You will be required to access Blackboard often for notes and worksheets, as well as general communication. Both lab and lecture use visual material from various sources, including publisher managed internet sites.

\begin{tabular}{|l|l|l|l|}
\hline WEEK & TOPIC & Text & Online lab * \\
\hline 1 & Intro., Endocrine & 16 & $27,28,28 \mathrm{~B}$, ADAM \\
\hline 2 & Blood & 17 & $29,29 \mathrm{~B}$ \\
\hline 3 & $\begin{array}{l}\text { Test 1 Ch 16, 17 } \\
\text { Cardiovasc. Heart }\end{array}$ & 18 & 30,31, ADAM, IP \\
\hline 4 & Heart, Cardio. Vessels & 18,19 & Test 1 \\
\hline 5 & $\begin{array}{l}\text { TEST 2 Ch 18-19 } \\
\text { Lymphatic }\end{array}$ & 20 & $32,33,33 \mathrm{~B}, 34 \mathrm{~B}$ \\
\hline 6 & Immune Sys & 21 & 35, ADAM \\
\hline 7 & Respiratory Sys & 22 & $\begin{array}{l}36,37,37 \mathrm{~B}, \\
\text { ADAM, IP }\end{array}$ \\
\hline
\end{tabular}

*Online lab will use lab manual, PhysioEx (B) simulated labs, ADAM program and manual \& Interactive Physiology CD (IP)

Note: Learning outcomes and student learning performance objectives are not specific to either the online or face-to-face sections. 


\section{Appendix D}

Face-to-face Anatomy and Physiology (2 $2^{\text {nd }}$ semester) Syllabus Sample

You will be required to access Blackboard often for notes and worksheets, as well as general communication. The traditional (face-to-face) lab portion of this course uses a hands-on approach with some dissection and other wet lab investigations in addition to some computer usage.

\begin{tabular}{|l|l|l|l|l|l|}
\hline WEEK & DATE & TOPIC & Text & Lab & Tech lab * \\
\hline 1 & $1 / 24$ & Intro., Endocrine & 16 & $27,28,28 \mathrm{~B}$ & $27,28,28 \mathrm{~B}$, ADAM \\
\hline 2 & $1 / 31$ & Blood & 17 & 29, bl typing & $29,29 \mathrm{~B}$ \\
\hline 3 & $2 / 7$ & $\begin{array}{l}\text { Test 1 Ch 16, 17 } \\
\text { Cardiovasc. Heart }\end{array}$ & 18 & $\begin{array}{l}30,31, \text { Heart } \\
\text { Dissection }\end{array}$ & 30,31, ADAM, IP \\
\hline 4 & $2 / 14$ & Heart, Cardio. Vessels & 18,19 & Test 1 & Test 1 \\
\hline 5 & $2 / 21$ & $\begin{array}{l}\text { TEST 2 Ch 18-19 } \\
\text { Lymphatic }\end{array}$ & 20 & $32,33,33 \mathrm{~B}$ & $32,33,33 \mathrm{~B}, 34 \mathrm{~B}$ \\
\hline 6 & $2 / 28$ & Immune Sys & 21 & 35 & 35, ADAM \\
\hline 7 & $3 / 7$ & Respiratory Sys & 22 & 36,37 & $\begin{array}{l}36,37,37 \mathrm{~B}, \\
\text { ADAM, IP }\end{array}$ \\
\hline
\end{tabular}

Note: Learning outcomes and student learning performance objectives are not specific to either the online or face-to-face sections. 


\section{Appendix E}

\section{Survey Questionnaire}

Thank you for your time and effort in completing this survey. I am currently a doctoral student at West Virginia University in the field of Curriculum and Instruction. I am gathering information that may be relevant to future curriculum decisions. Your completion of this form signifies your consent for the anonymous use of this data for a research study on the impact of online and faceto-face bioscience laboratory courses in health care programs.

Debbie Folger

Demographic Information

1. Semester in nursing at WVNCC:

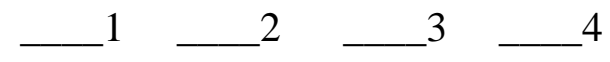

2. Age: $18-21$ $22-25$ 26-35 $36-45$ over 45

3. Gender: Female Male

4. Number of college science courses (with a lab) you have completed: ${ }^{0}-1+2 \_3-4$ - other

5. Number of online science courses you have completed ${ }^{0}-1-2 \_3-4$ - other

6. Number of any online courses you have completed in any subject ${ }^{0}{ }^{1}{ }^{1}{ }^{2}-3-4$ - other

7. I completed my college Anatomy and Physiology bioscience lab courses:

Online and/or fully computer based face-to-face

8. I completed my college Microbiology bioscience lab course:

Online and/or fully computer based face-to-face 
Please mark an $\mathbf{X}$ in the number box that best describes your perceptions toward your learning and Anatomy and Physiology (A\&P) or Microbiology (Micro) laboratory experience.
1- Strongly disagree
2- Disagree
3- Agree
4- Strongly agree

\begin{tabular}{|c|c|c|c|c|c|}
\hline & Question & 1 & 2 & 3 & 4 \\
\hline 1 & The assignments in my A\&P lab helped me master the course content. & & & & \\
\hline 2 & The interpersonal interaction in my A\&P lab was beneficial to my success in the course. & & & & \\
\hline 3 & My A\&P lab experiences were as beneficial to my learning as my A\&P lecture. & & & & \\
\hline 4 & Learning activities in my A\&P lab helped me construct explanations and/or solutions. & & & & \\
\hline 5 & The A\&P lab experience helped me understand the concepts of A\&P. & & & & \\
\hline 6 & The A\&P lab should be required for nursing students taking an A\&P lecture course. & & & & \\
\hline 7 & I use the knowledge from my A\&P lab experiences in my nursing courses. & & & & \\
\hline 8 & My A\&P lab experience helped me understand nursing concepts. & & & & \\
\hline 9 & I am more comfortable in my nursing courses after having my A\&P lab experience. & & & & \\
\hline 10 & My A\&P lab experiences relate well with my nursing courses. & & & & \\
\hline 11 & Some nursing knowledge builds on knowledge from my A\&P lab experience. & & & & \\
\hline 12 & There were times in my nursing course when I recalled an experience from my A\&P lab. & & & & \\
\hline 13 & My A\&P lab helped me understand the disease processes studied in my nursing courses. & & & & \\
\hline 14 & My A\&P lab helped me transition easily into the nursing program. & & & & \\
\hline 15 & The A\&P lab activities were practical to my nursing practice. & & & & \\
\hline 16 & I use the skills gained from my A\&P lab experiences in my nursing practice. & & & & \\
\hline 17 & My A\&P lab experiences accurately represent reality. & & & & \\
\hline 18 & My A\&P lab experience has helped me become more proficient in my nursing practice. & & & & \\
\hline 19 & My A\&P experience has helped me reduce contamination in my nursing care practice. & & & & \\
\hline 20 & My A\&P lab helped me explain the disease process to my patients. & & & & \\
\hline 21 & The assignments in my Micro lab helped me master the course content. & & & & \\
\hline 22 & The interpersonal interaction in my Micro lab was beneficial to my success in the course. & & & & \\
\hline 23 & My Micro lab experiences were as beneficial to my learning as my Micro lecture. & & & & \\
\hline 24 & Learning activities in my Micro lab helped me construct explanations and/or solutions. & & & & \\
\hline 25 & The Micro lab experience helped me understand the concepts of Micro. & & & & \\
\hline 26 & The Micro lab should be required for nursing students taking a Micro lecture course. & & & & \\
\hline 27 & I use the knowledge from my Micro lab experiences in my nursing courses. & & & & \\
\hline 28 & My Micro lab experience helped me understand nursing concepts. & & & & \\
\hline 29 & I am more comfortable in my nursing courses after having my Micro lab experience. & & & & \\
\hline 30 & My Micro lab experiences relate well with my nursing courses. & & & & \\
\hline 31 & Some nursing knowledge builds on knowledge from my Micro lab experience. & & & & \\
\hline 32 & There were times in my nursing course when I recalled an experience from my Micro lab. & & & & \\
\hline 33 & My Micro lab helped me understand the disease processes studied in my nursing courses. & & & & \\
\hline 34 & My Micro lab helped me transition easily into the nursing program. & & & & \\
\hline 35 & The Micro lab activities were practical to my nursing practice. & & & & \\
\hline 36 & I use the skills gained from my Micro lab experiences in my nursing practice. & & & & \\
\hline 37 & My Micro lab experiences accurately represent reality. & & & & \\
\hline 38 & My Micro lab experience has helped me become more proficient in my nursing practice. & & & & \\
\hline 39 & My Micro experience has helped me reduce contamination in my nursing care practice. & & & & \\
\hline 40 & My Micro lab helped me explain the disease process to my patients. & & & & \\
\hline
\end{tabular}




\section{Appendix F \\ Corrected Survey Questionnaire with Eliminations}

Please mark an $\mathbf{X}$ in the number box that best describes your perceptions toward your learning and Anatomy and Physiology (A\&P) or Microbiology (Micro) laboratory experience.
1- Strongly disagree
2- Disagree
3- Agree
4- Strongly agree

\begin{tabular}{|c|c|c|c|c|c|}
\hline & Question & 1 & 2 & 3 & 4 \\
\hline 2 & The interpersonal interaction in my A\&P lab was beneficial to my success in the course. & & & & \\
\hline 3 & My A\&P lab experiences were as beneficial to my learning as my A\&P lecture. & & & & \\
\hline 4 & Learning activities in my A\&P lab helped me construct explanations and/or solutions. & & & & \\
\hline 5 & The A\&P lab experience helped me understand the concepts of A\&P. & & & & \\
\hline 6 & The A\&P lab should be required for nursing students taking an A\&P lecture course. & & & & \\
\hline 7 & I use the knowledge from my A\&P lab experiences in my nursing courses. & & & & \\
\hline 8 & My A\&P lab experience helped me understand nursing concepts. & & & & \\
\hline 9 & I am more comfortable in my nursing courses after having my A\&P lab experience. & & & & \\
\hline 10 & My A\&P lab experiences relate well with my nursing courses. & & & & \\
\hline 11 & Some nursing knowledge builds on knowledge from my A\&P lab experience. & & & & \\
\hline 12 & There were times in my nursing course when I recalled an experience from my A\&P lab. & & & & \\
\hline 14 & My A\&P lab helped me transition easily into the nursing program. & & & & \\
\hline 15 & The A\&P lab activities were practical to my nursing practice. & & & & \\
\hline 16 & I use the skills gained from my A\&P lab experiences in my nursing practice. & & & & \\
\hline 17 & My A\&P lab experiences accurately represent reality. & & & & \\
\hline 18 & My A\&P lab experience has helped me become more proficient in my nursing practice. & & & & \\
\hline 19 & My A\&P experience has helped me reduce contamination in my nursing care practice. & & & & \\
\hline 20 & My A\&P lab helped me explain the disease process to my patients. & & & & \\
\hline 21 & The assignments in my Micro lab helped me master the course content. & & & & \\
\hline 22 & The interpersonal interaction in my Micro lab was beneficial to my success in the course. & & & & \\
\hline 23 & My Micro lab experiences were as beneficial to my learning as my Micro lecture. & & & & \\
\hline 24 & Learning activities in my Micro lab helped me construct explanations and/or solutions. & & & & \\
\hline 25 & The Micro lab experience helped me understand the concepts of Micro. & & & & \\
\hline 27 & I use the knowledge from my Micro lab experiences in my nursing courses. & & & & \\
\hline 28 & My Micro lab experience helped me understand nursing concepts. & & & & \\
\hline 31 & Some nursing knowledge builds on knowledge from my Micro lab experience. & & & & \\
\hline 32 & There were times in my nursing course when I recalled an experience from my Micro lab. & & & & \\
\hline 33 & My Micro lab helped me understand the disease processes studied in my nursing courses. & & & & \\
\hline 34 & My Micro lab helped me transition easily into the nursing program. & & & & \\
\hline 35 & The Micro lab activities were practical to my nursing practice. & & & & \\
\hline 36 & I use the skills gained from my Micro lab experiences in my nursing practice. & & & & \\
\hline 37 & My Micro lab experiences accurately represent reality. & & & & \\
\hline 38 & My Micro lab experience has helped me become more proficient in my nursing practice. & & & & \\
\hline 39 & My Micro experience has helped me reduce contamination in my nursing care practice. & & & & \\
\hline 40 & My Micro lab helped me explain the disease process to my patients. & & & & \\
\hline
\end{tabular}




\section{Appendix G}

\section{Focus Questions}

1. What do you think is the purpose of the A\&P and Microbiology bioscience lab course?

2. How do you think learning is the same for all subjects and how do you think learning should be different for different subjects?

3. What factors were important to as you scheduled for online or face-to-face A\&P and Microbiology labs? What are advantages and disadvantages of each?

4. How do you feel you're A\&P and Microbiology bioscience laboratory course prepared you for your current courses and program?

5. In what ways have you ever been reminded of $\mathrm{A} \& \mathrm{P}$ or Microbiology bioscience lab while in your current courses? When? How so?

6. How do you connect information from bioscience courses to nursing?

7. What A\&P or Microbiology bioscience lab skills have been most relevant to you in your nursing courses?

8. What Anatomy \& Physiology or Microbiology lab activity has helped you understand your patient's medical condition? With patient education?

9. In what situations have you ever worked with patients when you were reminded of your A\&P or Microbiology bioscience lab? 


\section{Appendix $\mathrm{H}$}

\section{Permission to Conduct Study}

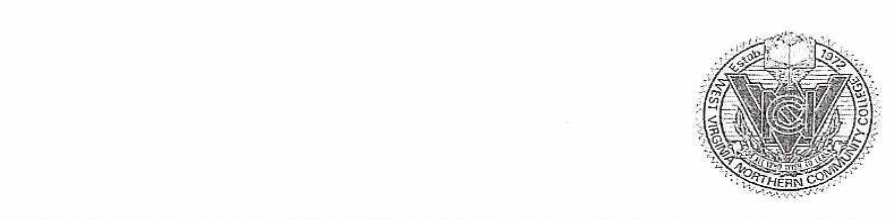

From the Office of the President

July 27, 2009

To Whom It May Concern:

As President of West Virginia Northern Community College, (WVNCC) I am writing to give permission for Debbie Folger to conduct her research study at WVNCC. I understand this study will investigate whether students in online biological labs are any more or less prepared for success as they progress into future courses and programs than their counterparts in traditional face-to face labs. This study will include pretests, posttests and survey questionnaires to be completed by Anatomy and Physiology students. All FERPA regulations will be adhered to during the study.

Sincerely,

w w w -

Martin Olshinsky, Ed.D.

President 
Appendix I

IRB Protocol-Exemption

\title{
WestVirginiaUniversity. \\ Office of Research Compliance
}

\section{IRB Protocol-Exemption}

\author{
To: $\quad$ Obenauf, Patricia \\ From: $\quad$ WVU Office of Research Compliance \\ Date: Wednesday, December 22, 2010 \\ Subject: Exemption Acknowledgement \\ Tracking \#: $\mathrm{H}-22769$ \\ Title: $\quad$ Biological Laboratory: A comparison of online and face-to-face lab \\ delivery
}

The above-referenced study was reviewed by the West Virginia University Institutional Review Board (IRB) and was granted exemption in accordance with 45 CFR 46.101(2).

This protocol was reviewed using the following:

This research study was granted an exemption because the Research involves educational tests, survey procedures, interview procedures or observation of public behavior and (i) information obtained is recorded in such a manner that human subjects cannot be identified, directly or through identifiers linked to the subjects; and (ii) any disclosure of the human subjects' responses outside the research could not reasonably place the subjects at risk of criminal or civil liability or be damaging to the subjects' financial standing, employability, or reputation [45 CFR 46.101(2)].

Exempt Research Checklist (210r)

The following documents have been acknowledged for use in this study and are available in the BRAAN system:

Locations of Research

Offsite Location Details

Attachments - Public School

WNNCC Res permiss.bmp Permission letter from Dr. Olshinsky for conducting educational research at the institution. 


\author{
Attachments \\ Survey - focus ques .doc \\ Miscellaneous Attachments \\ Attachments \\ Research cover letter.rff Research cover letter
}

Thank you.

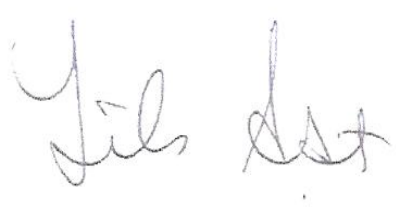

Board Designee: Ast, Lilo

Letter Sent By: Ast, Lilo, 12/22/2010 3:43 PM

Once you begin your human subject research, the following regulations apply:

1. Any modifications to the study protocol must be reviewed and acknowledged by the IRB prior to implementation.

2. You may not use a modified form until it has been acknowledged by the IRB. 


\title{
Appendix J
}

\author{
Cover Letter
}

\begin{abstract}
(N)
Department of Curriculum \& Instruction/Literacy Studies WestVirginiaUniversity.

College of Human Resources and Education

Dear Participant,

This letter is a request for you and other nursing students to take part in a research project to determine nursing student perceptions of their online and face-to-face bioscience laboratory experiences as they pertain to their nursing courses and practice. The research is being conducted by Deborah Folger, MAT in the Department of Curriculum \& Instruction at WVU with supervision of Dr. Patricia Obenauf, a professor in the College of Curriculum \& Instruction, for a Doctoral Degree in Curriculum \& Instruction. Your participation in this project is greatly appreciated and will take approximately 10 minutes to fill out the attached questionnaire and approximately 40 minutes if you volunteer to participate in the focus group discussion.

Your involvement in this project will be kept as anonymous as possible. Focus groups of 15 to 20 nursing students will be closed to anyone other than research participants and the researcher. Although the researcher will maintain confidentiality, due to the nature of a focus group, the researcher can not guarantee that other participants will keep the discussion confidential. All survey and archival data will be reported in the aggregate. You must be 18 years of age or older to participate. I will not ask any information that should lead back to your identity as a participant. Your participation is completely voluntary. You may skip any question that you do not wish to answer and you may discontinue at any time. Your class standing will not be affected if you decide either not to participate or to withdraw. West Virginia University's Institutional Review Board acknowledgement of this project is on file.
\end{abstract}

I hope that you will participate in this research project, as it could be beneficial in contributing to the understanding of the impact of online and face-to-face bioscience laboratories in nursing education. Thank you very much for your time. Should you have any questions about this letter or the research project, please feel free to contact Deborah Folger at (304) 723-7526; e-mail at dfolger@wvncc.edu or Patricia Obenauf at patricia.obenauf@mail.wvu.edu .

Thank you for your time and help with this project.

Sincerely,

Deborah Folger John H. ou=Acquisitions Department, 